\title{
Phospho-tuning immunity through Denisovan, modern human and mouse TNFAIP3 gene variants
}

Authors: Nathan W. Zammit ${ }^{1}$, Owen M. Siggs ${ }^{1,2 *}$, Paul Gray ${ }^{3,4}$, Keisuke Horikawa ${ }^{5}$, Stephen R. Daley ${ }^{5 \wedge}$, David B. Langley ${ }^{1}$, Daniele Cultrone ${ }^{1}$, Elisabeth K. Malle ${ }^{1}$, Stacey N. Walters ${ }^{1}$, Jeanette E. Villanueva ${ }^{1}$, Joanna Warren ${ }^{1}$, Amanda Russell ${ }^{1}$, Mark J. Cowley ${ }^{1,16}$, Velimir Gayevskiy ${ }^{1}$, Marcel E. Dinger ${ }^{1,16}$, Claudia Loetsch ${ }^{1}$, Cecile King ${ }^{1}$, Robert Brink ${ }^{1}$, David Zahra ${ }^{1}$, Geeta Chaudhri ${ }^{5^{\wedge}}$, Gunasegaran Karupiah ${ }^{5^{\wedge}}$, Belinda Whittle ${ }^{5}$, Carla Roots ${ }^{5}$, Edward Bertram ${ }^{5}$, Michiko Yamada ${ }^{5}$, Yogesh Jeelall ${ }^{5}$, Anselm Enders ${ }^{5}$, Benjamin E. Clifton ${ }^{6}$, Peter D. Mabbitt ${ }^{6}$, Colin J. Jackson ${ }^{6}$, Susan R. Watson ${ }^{7}$, Craig N. Jenne ${ }^{\wedge}$, Lewis L. Lanier ${ }^{7}$, Tim Wiltshire ${ }^{8}$, Matthew H. Spitzer ${ }^{\wedge}$, Garry P. Nolan ${ }^{9}$, Frank Schmitz ${ }^{10}$, Alan Aderem ${ }^{10}$, Benjamin T. Porebski ${ }^{11}$, Ashley M. Buckle ${ }^{11}$, , Derek W. Abbott ${ }^{12}$, John B. Ziegler ${ }^{3,4}$, Maria E. Craig ${ }^{13,4}$, Paul Benitez-Aguirre ${ }^{13}$, Juliana Teo ${ }^{13}$, Melanie Wong ${ }^{13}$, Murray P. Cox ${ }^{14}$, Wilson Phung ${ }^{15}$, Ingrid E. Wertz ${ }^{15}$, Daniel Christ ${ }^{1,16}$, Christopher C. Goodnow ${ }^{1,16 * \dagger}{ }^{1}$, Shane T. Grey ${ }^{1,16 * \dagger}$

\section{Affiliations:}

${ }^{1}$ Garvan Institute of Medical Research, 384 Victoria St, Darlinghurst, New South Wales, 2010 Australia

${ }^{2}$ Flinders University, Bedford Park, South Australia, 5042 Australia.

${ }^{3}$ Sydney Children's Hospital, Randwick NSW, Australia.

${ }^{4}$ School of Women's and Children's Health, University of New South Wales, Sydney, Australia

${ }^{5}$ John Curtin School of Medical Research, The Australian National University, Canberra, Australian Capital Territory, 2601 Australia.

${ }^{6}$ Research School of Chemistry, The Australian National University, Acton, Canberra, Australian Capital Territory, 2601 Australia.

${ }^{7}$ Department of Microbiology and Immunology and the Parker Institute for Cancer Immunotherapy, University of California San Francisco, Parnassus Ave, San Francisco, California, 94143 USA.

${ }^{8}$ Eshelman School of Pharmacy, University of North Carolina, Chapel Hill, NC 27599;

${ }^{9}$ Department of Microbiology \& Immunology, Stanford University, California, 94350, USA.

${ }^{10}$ Seattle Biomedical Research Institute, Seattle, Washington, 98109-5219 USA.

${ }^{11}$ Department of Biochemistry and Molecular Biology, Monash University, Clayton, Victoria 3800 Australia.

${ }^{12}$ Department of Pathology, Case Western Reserve University School of Medicine, Cleveland, Ohio 44106

${ }^{13}$ The Children's Hospital at Westmead, and Discipline of Child and Adolescent Health, University of Sydney, Australia.

${ }^{14}$ Institute of Fundamental Sciences, Massey University, Palmerston North, New Zealand.

${ }^{15}$ Genentech Inc., 1 DNA Way, M/S 40 South San Francisco, California, 94080, USA. 
$41{ }^{16}$ St Vincent's Clinical School, The University of New South Wales Sydney, New South 42 Wales, 2010 Australia.

43 Apresent address: SD, Department of Biochemistry and Molecular Biology, Monash 44 University, Clayton, Victoria 3800 Australia; GC, Research School of Population Health, The 45 Australian National University, Canberra, Australian Capital Territory, 2601 Australia; \& 46 GK, School of Medicine, The University of Tasmania, Hobart, TAS 7000, Australia; CJ, 47 Snyder Institute for Chronic Diseases, University of Calgary, AB T2N 4N1; MHS, 48 Departments of Otolaryngology and Microbiology \& Immunology and the Parker Institute 49 for Cancer Immunotherapy, University of California San Francisco, Parnassus Ave, San 50 Francisco, California, 94143 USA; FS, Celgene, 1616 Eastlake Ave E, Seattle, USA.

$51 †$ Corresponding authors: Email c.goodnow@garvan.org.au (C.C.G.) or s.grey@garvan.org.au 52 (S.T.G.)

$53 *$ These authors contributed equally to this work. 


\section{Abstract:}

55 Resisting or tolerating microbes are alternative strategies to survive infection, but little is

56 known about the evolutionary mechanisms controlling this balance. Here, genomic analyses

57 of anatomically modern humans, extinct Denisovan hominins, and mice revealed a series of

58 missense variants in the immune response inhibitor A20 (encoded by TNFAIP3), substituting

59 non-catalytic residues of the ubiquitin protease domain to diminish IKB-dependent

60 phosphorylation and activation of A20. Two A20 variants with partial phosphorylation

61 deficits appeared beneficial: one originating in Denisovans and introgressed in modern

62 humans throughout Oceania, and another in a mouse strain resistant to Coxsackievirus. By

63 contrast, a variant with 95\% loss of phosphorylation caused spontaneous inflammatory

64 disease in humans and mice. Analysis of the partial phosphorylation variant in mice revealed

65 diminished tolerance of bacterial lipopolysaccharide or to poxvirus inoculation as trade-offs

66 for enhanced immunity.

68 One Sentence Summary:

69 Modern and ancient variants reveal a genetically tunable element for balancing immunity and 70 microbial tolerance. 


\section{Main Text:}

Microbial resistance involves innate and adaptive immune responses that prevent, diminish, or clear infection, often causing collateral damage to host tissues and increased energy demands. Studies in plants ${ }^{1}$, and more recently in animals ${ }^{2,3}$, have shown that in some circumstances it can be more efficient for a host to tolerate microbes rather than resist them. Microbial tolerance involves homeostatic mechanisms to raise thresholds for initiating immune responses, to physically separate microbes from host immune receptors, and to repair damage caused directly by microbes or by collateral inflammation ${ }^{3-6}$. The genetic means by which microbial resistance and tolerance are balanced remains incompletely understood. Population genetic modelling predicts that resistance traits favor host polymorphism and microbial evasion, whereas microbial tolerance traits tend towards fixation in hosts and microbial mutualism ${ }^{7}$. High mortality in indigenous human populations of Oceania and the Americas exposed to smallpox demonstrate how a tolerated pathogen in its adapted host can cause devastating disease when introduced into non-adapted populations ${ }^{8,9}$. An example in animals can be seen for European rabbits exposed to myxoma poxvirus originating from South American rabbits ${ }^{8}$. These cases illustrate the importance of fine-tuning microbial immunity and tolerance during co-evolution of host and microbe, although little is known about the molecular pathways which underpin it.

A binary perspective of the importance of balancing microbial immunity and tolerance comes from Mendelian gene variants in mice and humans that completely inactivate the function of one or both alleles of genes such as CTLA4, IL10, FOXP3, or TNFAIP $3^{10-12}$. These cause severe pediatric autoimmune or inflammatory disease, particularly at mucosal barriers where large microbial populations are normally tolerated, such as the microbial burden that drives inflammatory pathology in mouse Tnfaip3 deficiency ${ }^{6}$. Genome-wide and candidate association studies in humans implicate variants at or near the TNFAIP3 locus with susceptibility to autoimmune disease ${ }^{13}$. In contrast to these disease-associated traits, few examples of beneficial genetic adjustments that decrease microbial tolerance in favor for heightened immunity exist.

A20, encoded by the TNFAIP3 gene, promotes microbial tolerance as a negative regulator of NF- $\kappa B$ signaling: an evolutionarily ancient and central pathway for activating innate and adaptive immune responses ${ }^{13}$. A20 has multiple domains with inhibitory activity against NF$\kappa \mathrm{B}$, primarily preventing activation of the central I $\kappa \mathrm{B}$ kinase (IKK) by upstream proteins RIPK1, TRAF6 and NEMO. The A20 ovarian tumor (OTU) domain is a deubiquitin (DUB) protease that cleaves activating K63-linked ubiquitin chains from RIPKI, TRAF6 or $\mathrm{NEMO}^{14-16}$. The A20 zinc finger 7 domain $(\mathrm{ZnF} 7)$ binds linear polyubiquitin to suppress IKK activation, whereas $\mathrm{ZnF} 4$ promotes ligation of K48-linked ubiquitin chains to RIPK1, triggering RIPK1 proteolysis ${ }^{14,17}$. A20 feedback inhibition is induced at two levels: NF- $\mathrm{KB}$ proteins directly induce TNFAIP3 mRNA, and the inhibitory activities of A20 protein are enhanced by IאK $\beta$-induced serine phosphorylation near the ZnF domains, notably S381 ${ }^{18,19}$.

The role of the A20 OTU domain nevertheless remains enigmatic. The $\mathrm{ZnF}$ domains alone are sufficient for NF- $\kappa B$ inhibitory function in cell-based studies ${ }^{20,21}$, and mice homozygous for TNFAIP3 missense variants creating a catalytically inactive OTU domain have little $\mathrm{e}^{15,18}$ or no evidence ${ }^{20}$ of excessive NF- $\mathrm{KB}$ signaling. Here we demonstrate that anatomically modern human, archaic Denisovan, and mouse missense variants in the OTU domain modulate A20 phosphorylation by IKK, serving as a genetically tunable element with profound effects on the balance between microbial tolerance and immunity, and evidence of introgression to high frequencies during human history. 


\section{Modern human A20 OTU variants acquired from Denisovans}

120 Three convergent sequencing studies led us to a unique functional class of A20 missense 121 variants affecting the OTU domain, separate from the ubiquitin protease catalytic site (Fig. 122 1A, B; Extended Data Fig. 1). The most subtle allele, comprising T108A (rs376205580 g.138196008A $>$ G) and I207L (rs141807543 g.138196957A $>$ C) missense variants in cis, was identified by whole genome sequencing in four of 85 families in Sydney. The majority of individuals in our cohort carrying the T108A;I207L allele were healthy family members of Māori or Pacific Islander ancestry. These variants were rare in a public variant collection (gnomAD r2.0.2) but most frequent among individuals with an unassigned ancestry (Extended Data Fig. 2A).

We traced the global distribution of the T108A;I207L allele in 279 individuals from the Simons Genome Diversity Project dataset ${ }^{22}$, revealing high frequencies ranging from $25-75 \%$ among people of Island Southeast Asia and Oceania, but an absence of the allele elsewhere in the world (Extended Data Fig. 2B, Extended Data Table 1).

Unlike Africans or Eurasians, people in Island Southeast Asia and Oceania acquired up to 5\% of their genome from Denisovans: archaic hominins that interbred with modern humans $\sim 50,000$ years ago migrating through Asia to settle the continent of Sahul (now Papua New Guinea and Australia) $)^{23-26}$. Analysis of the high-coverage genome of a Denisovan finger phalanx from a cave in the Altai Mountains of Siberia ${ }^{27}$ revealed homozygous T108A;I207L variants (Fig. 1C). Both variants were absent from the genome of a Neanderthal who had inhabited the same cave ${ }^{28}$ (Extended Data Table 2), suggesting that T108A and I207L arose after the divergence of Denisovan and Neanderthal lineages 170,000-700,000 years ago ${ }^{27}$.

Multiple Denisovan-derived genomic regions, including one encompassing TNFAIP3, bear strong signatures of introgression in Papuans ${ }^{25,26,29}$. By imputing haplotypes (Extended Data Table 2) using genotype array data from 514 individuals from indigenous populations across Island Southeast Asia and Oceania ${ }^{30}$, we found evidence that the Denisovan TNFAIP3 haplotype has reached high frequencies in populations east of the Wallace Line, a 50 million year-old faunal boundary separating organisms of Asiatic and Australian origin via deep water channels between the two continental shelves (Fig. 1D, E and Extended Data Fig. 3) 31 . Frequencies ranged from $0 \%$ in almost all populations west of the Wallace Line, but reached $100 \%$ in 8 Baining individuals from eastern Papua New Guinea. We observed the same haplotype in 31/144 (22\%) of exome-sequenced alleles in Martu Indigenous Australians from the Pilbara region of Western Australia ${ }^{32}$, implying the haplotype enrichment occurred before the isolation of Indigenous Australian and Papuan populations. The high frequency in Polynesia indicates the Denisovan TNFAIP3 haplotype was retained after admixture with Austronesian farming populations expanding from mainland Asia starting $\sim 4,000$ years ago ${ }^{33}$ in Eastern Indonesia and 3,000 years ago in the Southwest Pacific ${ }^{34}$.

Aside from the two missense variants in the introgressed Denisovan TNFAIP3 haplotype, many other non-coding variants could conceivably modulate transcription. Deep sequencing of cDNA nevertheless revealed equal amounts of TNFAIP3 mRNA from Denisovan and modern human alleles in heterozygous leukocytes, with or without $\mathrm{TNF} \alpha$ stimulation (Extended Data Fig. 4). Of the two coding variants, T108A was not predicted computationally to alter A20 function (Phred-scaled CADD score of 0.002) and occurs in other vertebrate species (Extended Data Fig. 1). By contrast, I207 is invariant across most jawed vertebrates, and $1207 \mathrm{~L}$ was predicted to be the most deleterious variant across the Denisovan TNFAIP3 haplotype (Phred-scaled CADD score: 23.2; Extended Data Fig. 3E). 


\section{A mouse A20 OTU variant confers heightened resistance to Coxsackievirus}

The results above identify an ancient substitution in the A20 OTU domain as apparently beneficial in human history. Further evidence that A20 OTU domain variants could be beneficial came from another OTU substitution, I325N, identified in a genome-wide mouse mutagenesis screen segregating with increased frequencies of circulating CD44 ${ }^{\text {hi }}$ activated/memory $\mathrm{T}$ cells and regulatory $\mathrm{T}$ cells (Fig. 2A) in otherwise healthy adult mice. Detailed analysis revealed the $\mathrm{I} 325 \mathrm{~N}$ mutation also increased numbers of $\mathrm{B}$ cells in the spleen and peritoneal cavity, and diminished $\mathrm{I} \kappa \mathrm{B} \alpha$ within $\mathrm{B}$ cells, CD8 $\mathrm{T}$ cells, NK cells and dendritic cells (Fig. 2B and Extended Data Fig. 5). Macrophages immortalized from bone marrow of $\mathrm{I} 325 \mathrm{~N}$ mutant mice produced more inflammatory cytokines in response to lipopolysaccharide (LPS) than controls from wild-type mice (Extended Data Fig. 6). In thymocytes, I325N increased $\mathrm{TNF} \alpha$-induced NF- $\kappa \mathrm{B}$ signaling in ways consistent with diminished A20-mediated inhibition (Extended Data Fig. 7) ${ }^{18}$.

In wild-type mice transplanted with mixtures of mutant and wild-type A20 bone marrow, the I325N mutation acted cell autonomously to increase B cell activation and proliferation by LPS or antigen receptors, and to increase TCR and CD28-dependent formation of FOXP3 ${ }^{+}$ $\mathrm{CD}^{+}{ }^{+}$regulatory $\mathrm{T}$ cells and their Helios ${ }^{+} \mathrm{FOXP}^{-}$precursors within the thymus (Fig. $2 \mathrm{C}, \mathrm{D}$, Extended Data Fig. 8). Surprisingly, I325N had a greater effect than the C103A OTU domain mutation analyzed in parallel bone marrow transplant recipients, despite C103A completely inactivating the polyubiquitin protease activity of $\mathrm{A} 20^{15,20}$, indicating $\mathrm{I} 325 \mathrm{~N}$ must diminish additional inhibitory mechanisms.

Consistent with heightened cellular markers of immunity, I325N mutant mice had greater resistance to Coxsackievirus B4 strain E2, a virus isolated from a human neonate with a disseminated fatal infection causing extensive pancreatic necrosis ${ }^{35,36}$. A virus dose that was lethal for $90 \%$ of wild-type C57BL/6 mice was not lethal for Tnfaip $3^{1325 \mathrm{~N} / 1325 \mathrm{~N}}$ littermates, and caused less mortality in Tnfaip3 $3^{\mathrm{I} 25 \mathrm{~N} / 4}$ mice (Fig. 2E; Extended Data Fig. 9A). Mutant mice had less infectious virus and viral RNA in the pancreas, less mRNA encoding immune response cytokines IL-1 $\beta$ and IFN $\beta$, less pancreatic necrosis, higher serum IL-6, and preserved body-weight and euglycemia (Fig. 2F, G; Extended Data Fig. 9B-G).

The homogeneous genetic background of I325N mutant mice allowed testing if heightened immunity imposed a subclinical cost or altered the insulin anabolic axis ${ }^{37}$. Tnfaip3 $3^{1325 \mathrm{~N} / 4}$ mice were healthy, of normal weight, and fertile, producing homozygous mutant offspring at the expected ratio. Homozygotes also appeared healthy, although their body weight was 5-20\% less than heterozygous or wild-type littermates (Fig. 3A), with histological analysis revealing low-grade inflammation of the pancreatic islets, colon, kidney, and liver (Fig. 3B-C, Extended Data Fig. 10). Pancreatic insulitis in I325N homozygotes was associated with a $50 \%$ reduction in beta cell mass (Fig. 3D), although random blood glucose levels and glucose tolerance tests were normal (Extended Data Fig. 11A-E). Isolated Tnfaip $3^{1325 \mathrm{~N} / 1325 \mathrm{~N}}$ islets exhibited normal basal insulin output but reduced insulin secretion when stimulated in vitro (Extended Data Fig. 11F). Islet transplant and culture experiments showed the A20 mutation acted within islet cells, exaggerating canonical and non-canonical NF- $\kappa \mathrm{B}$ signaling, lowering insulin secretion, and increasing inflammatory cytokine production (Fig. 3E-H and Extended Data Fig. 11G-I \& 12) ${ }^{38}$. 


\section{An allelic series of OTU domain variants with graded reductions of A20 213 phosphorylation}

214 The apparent beneficial effects of the T108A;I207L and I325N OTU domain substitutions 215 above contrasted with a third OTU domain substitution, C243Y, found as a family-specific 216 variant causing dominant Mendelian inflammation resembling Behçet's disease, with childhood-onset oral and genital ulceration and skin inflammation ${ }^{39}$. The biochemical basis for the clinically penetrant effects of $\mathrm{C} 243 \mathrm{Y}$ was obscure, because other similarly affected cases of haploinsufficiency of A20 (HA20) result from nonsense or frameshift variants that truncate or eliminate A20 protein ${ }^{12}$.

Despite different clinical consequences, the three OTU domain variants formed a graded biochemical allelic series when full-length A20 and IKK $\beta$ were co-expressed in mouse insulinoma cells and S381-phosphorylated A20 was compared with total A20 protein by Western blotting. None of the variants affected A20 protein accumulation but each affected IKK $\beta$-mediated S381 phosphorylation (Fig. 4A-C; Extended Data Fig. 13A). The pathogenic $\mathrm{C} 243 \mathrm{Y}$ variant caused the most severe loss of function, diminishing IKK $\beta$-mediated S381 phosphorylation to 5\% of wild-type, whereas the Denisovan T108A;I207L variant diminished phosphorylation the least ( $80 \%$ of wild-type) and the non-pathogenic $\mathrm{I} 325 \mathrm{~N}$ variant had an intermediate effect ( $50 \%$ of wild-type). By contrast, the C103A catalytic site substitution did not cause a significant decrease in A20 phosphorylation. Loss of S381 phosphorylation was also observed by mass spectrometry of A20 purified from unstimulated human cells transfected with $\mathrm{A} 20^{\mathrm{I} 25 \mathrm{~N}}$ compared to $\mathrm{A} 20^{\mathrm{WT}}$, whereas $\mathrm{A} 20^{\mathrm{C} 103 \mathrm{~A}}$ exhibited normal phosphorylation (Extended Data Fig. 13B).

S381-phosphorylated A20 predominantly migrated more slowly in SDS-PAGE than unphosphorylated A20, either when tested by co-transfection with IKK $\beta$ (Fig. 4A, B) or in TNF $\alpha$-stimulated peripheral blood leukocytes with endogenous A20 and IKK $\beta$ (Fig. 4D, S14). The ratio of this slowly migrating A20 species to the more rapidly migrating form was markedly decreased in blood leukocytes from healthy donors heterozygous for the Denisovan T108A;I207L variants, and further decreased in a healthy T108A;I207L homozygous donor, compared to healthy controls without these variants (Fig. 4E). The ratio of phosphorylatedS381 to fast-migrating A20 was also decreased (Extended Data Fig. 14F). TNF- $\alpha$ stimulated leukocytes from variant carriers also had heightened expression of NF- $\kappa \mathrm{B}$-induced transcripts of ICAM1, CXCL2, TNF, and TNFAIP3 itself (Extended Data Fig. 15), and a trend towards reduced IкB $\alpha$ protein levels (Extended Data Fig. 14H).

When A20 was measured for inhibition of an NF-kB luciferase reporter in unstimulated or $\mathrm{TNF} \alpha$-stimulated mouse insulinoma cells, inhibition was diminished in a graded fashion by each OTU domain variant in the same order that these diminished S381 phosphorylation (Fig. 4F; Extended Data Fig. 13C). The deleterious C243Y variant was the most compromised inhibitor of the series, almost as compromised as A20 with S381 substituted to nonphosphorylatable alanine (S381A). Combining the intermediate I325N mutation with a S381A mutation in cis did not cause a further decrease in A20 inhibition, consistent with I325N having its effect upon phosphorylation. That conclusion was reinforced by combining I325N in cis with a substitution of S381 to the phosphoserine mimetic glutamate (S381E), which rescued the lost activity caused by I325N (Extended Data Fig. 13D, E). Testing the two Denisovan variants individually, T108A had no measurable effect whereas I207L diminished A20 inhibitory activity comparably to the two variants combined (Extended Data Fig. 13F), supporting $\mathrm{I} 207 \mathrm{~L}$ as the functional variant within the introgressed Denisovan haplotype. 
259 To explore the structural and biochemical consequences of variants on the posterior surface

260 of the OTU domain, we focused on the intermediate I325N allele. Crystallographic structures

261 of A20 OTU domains with wild-type I325 or mutant N325 revealed no differences in features

262 with known functions, including the catalytic triad and ubiquitin-binding surface (Fig. 1B;

263 Extended Data Fig. 16A-C). I325N also did not alter the conserved posterior surface of the

264 OTU domain ${ }^{40}$, including the $\beta 3-\beta 4$ loop containing C243 (Extended Data Fig. 16G),

265 although there were subtle shifts in the stem of the $\beta 7-\beta 8$ loop, which contains conserved

266 surface residues T321, T322 and L324 (Extended Data Fig. 16D-G). The $\beta 7-\beta 8$ loop itself is

267 disordered in all available OTU structures but, like the disordered loops in the unliganded S1

268 ubiquitin-binding site, it may undergo conformational changes upon binding a cognate

269 partner that are hindered by the $\mathrm{I} 325 \mathrm{~N}$ variant. Wild-type and variant OTU domains exhibited

270 similar thermal denaturation profiles (Extended Data Fig. 17A-C), and the corresponding

271 full-length proteins were comparably stable in cycloheximide-treated mammalian cells

272 (Extended Data Fig. 17D). I325N did not decrease DUB activity of bacterially expressed

273 OTU domain against K48-polyubiquitin in vitro (Extended Data Fig. 17E-G), but I325N

274 diminished K63-polyubiquitin DUB activity and K48-ubiquitin ligase activity when full

275 length A20 was expressed in human cells (Extended Data Fig. 17H, I) consistent with these

276 activities requiring $\mathrm{S} 381$ phosphorylation ${ }^{18,19}$.

277

278

279

280

281

282

283

284

285

286

287

288

289

290

291

292

293

294

295

296

297

298

299

300

301

302

\section{Shift from beneficial to detrimental loss of microbial tolerance}

We next explored the possibility that partial loss of A20 phosphorylation and subclinical loss of microbial tolerance might become detrimental in particular environmental or genetic settings. In an experimental model for septic shock, I325N homozygous mice had increased IL-6 production and high mortality following injection of a dose of bacterial LPS that was not lethal in wild-type controls (Fig. 5A, B). In the rodent counterpart of smallpox, infection with the orthopoxvirus ectromelia virus was tolerated and controlled by wild-type mice, yet resulted in high mortality and higher viral titres in I325N homozygotes (Fig. 5C, D and Extended Data Fig. 18). In bone marrow chimeric mice with a higher frequency of pancreatic islet-reactive $\mathrm{CD}^{+} \mathrm{T}$ cells , autoreactive $\mathrm{T}$ cells escaped deletion and precipitated diabetes when half the hematopoietic cells were homozygous for I325N (Extended Data Fig. 19A-C). The rogue islet-reactive $\mathrm{T}$ cells were nevertheless derived equally from A20 wild-type or I325N precursors, whereas I325N acted cell autonomously to increase MHC II and the T cell costimulator CD86 on B cells and dendritic cells and to increase frequencies of germinal centre B cells (Extended Data Fig. 19D-F).

While specific stressors were required to reveal detrimental effects of the intermediate $\mathrm{I} 325 \mathrm{~N}$ variant, wasting disease occurred spontaneously in young C57BL/6 mice homozygous for the severe C243Y variant. C243Y homozygotes were born at the expected Mendelian ratio but compared to wild-type littermates failed to thrive, exhibiting a large reduction in body weight and early lethality (Fig. 5E, F; Extended Data Fig. 20). Surviving C243Y homozygotes showed intestinal pathology including loss of goblet cells responsible for sustaining the mucin barrier between epithelium and microbes of the intestinal lumen, along with an increased frequency of circulating CD44 ${ }^{\text {hi }}$ activated/memory T cells (Extended Data Fig. 20). C243Y homozygous mice thus resemble A20-null mice ${ }^{5,11}$, paralleling the clinical similarity between C243Y missense and A20 loss-of-function variants in heterozygous humans ${ }^{12}$. 


\section{Discussion}

304 Our findings reveal genetic and biochemical mechanisms for adaptively increasing immunity, 305 with trade-offs against microbial tolerance and anabolic metabolism that either remain 306 clinically silent or become detrimental in specific contexts. Three different missense alleles in 307 the N-terminal A20 OTU domain act, to different degrees, by diminishing A20 308 phosphorylation and tuning down A20's immune inhibitory activity. A rare human variant, 309 C243Y, diminishes phosphorylation almost entirely and shifts the balance away from microbial tolerance to the extremes of immunity, resulting in severe inflammatory disease in both mice and humans. This outcome is comparable with other human variants that eliminate or truncate A20 protein from one TNFAIP3 allele or engineered mouse variants that eliminate A20 from both alleles ${ }^{11,12}$. By contrast, I325N and I207L variants decrease A20 phosphorylation more modestly, without precipitating spontaneous inflammatory disease in the mice or humans who harbor them. $\mathrm{I} 325 \mathrm{~N}$ in the mouse confers dramatically increased resistance to an otherwise lethal dose of a Coxsackievirus. A similar resistance to microbial pathogens may explain the beneficial effect of Denisovan I207L, as evidenced by its high frequency in modern human populations east of the Wallace Line, who likely encountered new infectious agents as they moved into environments with unique fauna and flora.

Previous studies in mice have conditionally deleted A20 in specific tissues, causing severe inflammatory disease, or directly disabled individual enzymatic functions of A20 in all tissues resulting in surprisingly little inflammation ${ }^{5,6,11,15,18,20}$. By contrast, OTU domain variants tuning phosphorylation regulate multiple ubiquitin-editing functions of $\mathrm{A} 20^{18,19}$, and as shown here have greater effects on microbial tolerance and resistance in vivo than variants affecting individual ubiquitin-editing activities. The $\mathrm{C} 243 \mathrm{Y}$ and $\mathrm{I} 325 \mathrm{~N}$ variants involve buried residues in two separate surface loops, $\beta 3-\beta 4$ and $\beta 7-\beta 8$ respectively (Extended Data Fig. 16), on the highly conserved posterior surface of the OTU domain ${ }^{40}$. Structural studies of full-length A20 protein may illuminate how this surface relates to the C-terminal domain carrying S381. Because the conserved surface bounded by C243Y and I325N is large, it potentially offers many opportunities for substitution of buried or surface residues to tune immunity and tolerance.

Our study of the intermediate loss-of-function A20 variant, I325N, provides two examples of genetic trade-offs. The first was with glucose metabolism, where Tnfaip ${ }^{1325 \mathrm{~N}}$ had the surprising effect within pancreatic islet beta cells of decreasing insulin secretion while increasing inflammation. This is reminiscent of findings in Drosophila that insulin production or action decreases during infection, diminishing body glycogen supplies through increased FOXO activity, a transcriptional inducer of starvation responses ${ }^{37}$. Resting insulin levels are a good prognostic marker in human sepsis, and exogenous insulin treatment improves outcome $^{41}$. Subtly decreased A20 activity may enhance immune demands for energy and, separately, help meet these energy demands by lowering insulin-induced anabolic growth, both contributing to cachexia associated with chronic infection and inflammation.

The second example of a trade-off is the experimental demonstration that a beneficial trait in one context can be deleterious in another. Tnfaip $3^{I 325 N}$ conferred increased resistance to Coxsackievirus, an important human enterovirus, but increased mortality to ectromelia virus, a relative of variola and myxoma viruses. Higher ectromelia virus mortality in Tnfaip $3^{I 325 N}$ mice is reminiscent of the high mortality in indigenous populations of the Americas and Oceania exposed to variola virus relative to Europeans ${ }^{8}$. The findings here suggest that the devastation wrought by these and other microbes reflects selection during earlier environmental conditions for lower microbial tolerance and a stronger immune response, with 350 A20 representing one critical determinant of this outcome. 


\section{References and Notes:}

\section{Main text references 1-42}

1 Caldwell, R. M., Schafer, J. F., Compton, L. E. \& Patterson, F. L. Tolerance to Cereal Leaf Rusts. Science 128, 714-715, doi:10.1126/science.128.3326.714 (1958).

2 Ayres, J. S. \& Schneider, D. S. Tolerance of infections. Annu Rev Immunol 30, 271-294, doi:10.1146/annurev-immunol-020711-075030 (2012).

3 Soares, M. P., Teixeira, L. \& Moita, L. F. Disease tolerance and immunity in host protection against infection. Nat Rev Immunol 17, 83-96, doi:10.1038/nri.2016.136 (2017).

4 Hooper, L. V., Littman, D. R. \& Macpherson, A. J. Interactions between the microbiota and the immune system. Science 336, 1268-1273, doi:10.1126/science.1223490 (2012).

$5 \quad$ Vereecke, L. et al. A20 controls intestinal homeostasis through cell-specific activities. Nature communications 5, 5103, doi:10.1038/ncomms6103 (2014).

6 Turer, E. E. et al. Homeostatic MyD88-dependent signals cause lethal inflammation in the absence of A20. J Exp Med 205, 451-464, doi:10.1084/jem.20071108 (2008).

7 Roy, B. A. \& Kirchner, J. W. Evolutionary dynamics of pathogen resistance and tolerance. Evolution 54, 51-63 (2000).

8 Fenner, F. The Florey lecture, 1983. Biological control, as exemplified by smallpox eradication and myxomatosis. Proc R Soc Lond B Biol Sci 218, 259-285 (1983).

$9 \quad$ Boughton, C. R. Smallpox and Australia. Intern Med J 32, 59-61 (2002).

10 Bousfiha, A. et al. The 2017 IUIS Phenotypic Classification for Primary Immunodeficiencies. J Clin Immunol 38, 129-143, doi:10.1007/s10875-017-0465-8 (2018).

11 Lee, E. G. et al. Failure to regulate TNF-induced NF-kappaB and cell death responses in A20-deficient mice. Science 289, 2350-2354 (2000).

12 Zhou, Q. et al. Loss-of-function mutations in TNFAIP3 leading to A20 haploinsufficiency cause an early-onset autoinflammatory disease. Nat Genet 48, 67-73, doi:10.1038/ng.3459 (2016).

13 Ma, A. \& Malynn, B. A. A20: linking a complex regulator of ubiquitylation to immunity and human disease. Nat Rev Immunol 12, 774-785, doi:nri3313 [pii]10.1038/nri3313 (2012).

14 Wertz, I. E. et al. De-ubiquitination and ubiquitin ligase domains of A20 downregulate NF-kappaB signalling. Nature 430, 694-699, doi:10.1038/nature02794nature02794 [pii] (2004).

15 Lu, T. T. et al. Dimerization and ubiquitin mediated recruitment of a20, a complex deubiquitinating enzyme. Immunity 38, 896-905, doi:S1074-7613(13)00146-5 [pii]10.1016/j.immuni.2013.03.008 (2013).

16 Evans, P. C. et al. Zinc-finger protein A20, a regulator of inflammation and cell survival, has deubiquitinating activity. Biochem J 378, 727-734, doi:10.1042/BJ20031377BJ20031377 [pii] (2004).

17 Bosanac, I. et al. Ubiquitin binding to A20 ZnF4 is required for modulation of NF-kappaB signaling. Mol Cell 40, 548-557, doi:S1097-2765(10)00785-9 [pii]10.1016/j.molcel.2010.10.009 (2010).

18 Wertz, I. E. et al. Phosphorylation and linear ubiquitin direct A20 inhibition of inflammation. Nature 528, 370-375, doi:10.1038/nature16165 (2015).

19 Hutti, J. E. et al. IkappaB kinase beta phosphorylates the K63 deubiquitinase A20 to cause feedback inhibition of the NF-kappaB pathway. Mol Cell Biol 27, 7451-7461 (2007).

20 De, A., Dainichi, T., Rathinam, C. V. \& Ghosh, S. The deubiquitinase activity of A20 is dispensable for NF-kappaB signaling. EMBO Rep 15, 775-783, doi:10.15252/embr.201338305 (2014).

21 Verhelst, K. et al. A20 inhibits LUBAC-mediated NF-kappaB activation by binding linear polyubiquitin chains via its zinc finger 7. EMBO J 31, 3845-3855, doi:emboj2012240 [pii]10.1038/emboj.2012.240 (2012).

22 Mallick, S. et al. The Simons Genome Diversity Project: 300 genomes from 142 diverse populations. Nature 538, 201-206, doi:10.1038/nature18964 (2016).

23 Reich, D. et al. Genetic history of an archaic hominin group from Denisova Cave in Siberia. Nature 468, 1053-1060, doi:10.1038/nature09710 (2010).

24 Reich, D. et al. Denisova admixture and the first modern human dispersals into Southeast Asia and Oceania. American journal of human genetics 89, 516-528, doi:10.1016/j.ajhg.2011.09.005 (2011).

25 Sankararaman, S., Mallick, S., Patterson, N. \& Reich, D. The Combined Landscape of Denisovan and Neanderthal Ancestry in Present-Day Humans. Curr Biol 26, 1241-1247, doi:10.1016/j.cub.2016.03.037 (2016).

26 Vernot, B. et al. Excavating Neandertal and Denisovan DNA from the genomes of Melanesian individuals. Science 352, 235-239, doi:10.1126/science.aad9416 (2016).

27 Meyer, M. et al. A high-coverage genome sequence from an archaic Denisovan individual. Science 338, 222-226, doi:10.1126/science. 1224344 (2012). 


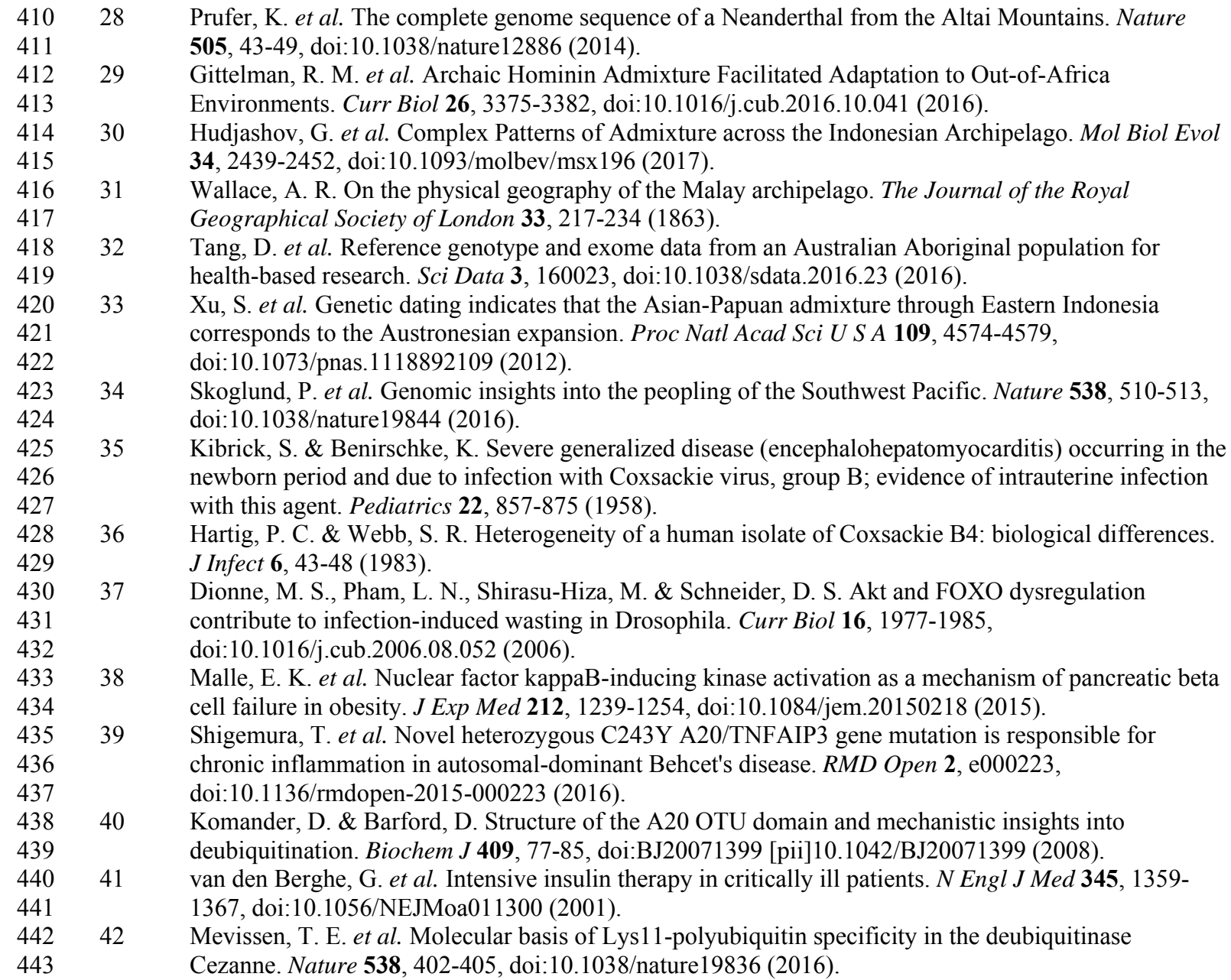

\section{References cited in Materials and Methods and Extended Data:}

43 McKenna, A. et al. The Genome Analysis Toolkit: a MapReduce framework for analyzing next016-0974-4 (2016).

45 MacArthur, D. G. et al. A systematic survey of loss-of-function variants in human protein-coding genes. Science 335, 823-828, doi:10.1126/science.1215040 (2012).

46 Paila, U., Chapman, B. A., Kirchner, R. \& Quinlan, A. R. GEMINI: integrative exploration of genetic variation and genome annotations. PLoS Comput Biol 9, e1003153, doi:10.1371/journal.pcbi.1003153 (2013).

47 Gayevskiy, V., Roscioli, T., Dinger, M. E. \& Cowley, M. J. Seave: a comprehensive web platform for storing and interrogating human genomic variation. bioRxiv, doi:10.1101/258061 (2018).

48 Thorvaldsdottir, H., Robinson, J. T. \& Mesirov, J. P. Integrative Genomics Viewer (IGV): highperformance genomics data visualization and exploration. Brief Bioinform 14, 178-192, doi:10.1093/bib/bbs017 (2013).

49 Kircher, M. et al. A general framework for estimating the relative pathogenicity of human genetic variants. Nat Genet 46, 310-315, doi:10.1038/ng.2892 (2014).

50 Ho, W. Y., Cooke, M. P., Goodnow, C. C. \& Davis, M. M. Resting and anergic B cells are defective in CD28-dependent costimulation of naive CD4+ T cells. J Exp Med 179, 1539-1549 (1994).

51 Akkaraju, S. et al. A range of CD4 T cell tolerance: partial inactivation to organ-specific antigen allows nondestructive thyroiditis or insulitis. Immunity 7, 255-271 (1997).

52 Tahiliani, V., Chaudhri, G., Eldi, P. \& Karupiah, G. The orchestrated functions of innate leukocytes and $\mathrm{T}$ cell subsets contribute to humoral immunity, virus control, and recovery from secondary poxvirus challenge. $J$ Virol 87, 3852-3861, doi:10.1128/JVI.03038-12 (2013). 
Acknowledgments: This manuscript is dedicated to the memory of Susan Watson, who led the isolation of the $\mathrm{I} 325 \mathrm{~N}$ mouse. We wish to thank the National Computational Infrastructure, Xenon systems, Nvidia, and the Multi-modal Australian ScienceS Imaging and Visualisation Environment (MASSIVE) (www.massive.org.au) for compute resources. We thank Oliver Venn, Iain Mathieson, Bastien Llamas, Yassine Souilmi, Raymond Tobler and Alan Cooper for stimulating discussions. CNJ thanks Jason Cyster for mentorship. We thank Wendy Sandoval for assistance with A20 phosphorylation site mass spectrometry, and Kim Newton and Vishva Dixit for reagents. This study makes use of data generated by the Telethon Kids Institute. A full list of the investigators who contributed to the generation of the data is available from http://bioinformatics.childhealthresearch.org.au/AGHS.

Funding: N.W.Z was supported by an Australian Postgraduate Award and is supported by the International Pancreas and Islet Transplant Association (IPITA) Derek Gray Scholarship. A.M.B. is a National Health and Medical Research (NHMRC) Senior Research Fellow (1022688). C.C.G. is supported by the Bill and Patricia Ritchie Chair and by an NHMRC Senior Principal Research Fellowship. S.T.G. is supported by an NHMRC Senior Research Fellowship. The research was supported by grants to C.C.G. from the NIH (AI52127, AI054523, AI100627) and NHMRC $(1016953,585490,1081858)$, to S.T.G. from the NIH (DK076169) and NHMRC (1130222, 1140691).

Author contributions: Human family recruitment and genome sequence analysis: PG, JBZ, MEC, PB-A, JT, MW, OMS, AR, MJC, VG, MED, CCG. Tracing Denisovan haplotype in human populations by OMS, PG, AR, MPC, CCG; peripheral blood analyses by NWZ, AR, CCG, STG. I325N mutation: identification by SRW, CNJ, LLL, TW, CR, BW, CCG; immune cell analysis by KH, SRD, YJ, NWZ, MY, EB, AE, MHS, GPN, FS, DEZ, AA, IEW, STG, CCG; Coxsackievirus studies by NWZ, CL, JW, CK, STG; Ectromelia studies by GC, GK; body weight, islet, LPS and inflammation studies by NWZ, SNW, EKM, JEV, STG; protease activity and structural studies by KH, NWZ, DBL, DC, WP, IEW, BEC, PDM, CJJ, BTP, AMB, STG, CCG. C243Y mouse strain production and analysis by NWZ, RB, DZ, SNW, DC, JW, STG. A20 phosphorylation and NF- $\kappa B$ luciferase analysis by NWZ, DC, DWA, WP, IEW, CCG, STG.

Competing interests: Authors declare no competing interests.

Data and materials availability: All data is available in the main text or the supplementary materials.

\section{Extended Data:}

Materials and Methods

Extended Data Figures 1-20

Extended Data Tables 1-5

References (43-78) 
A
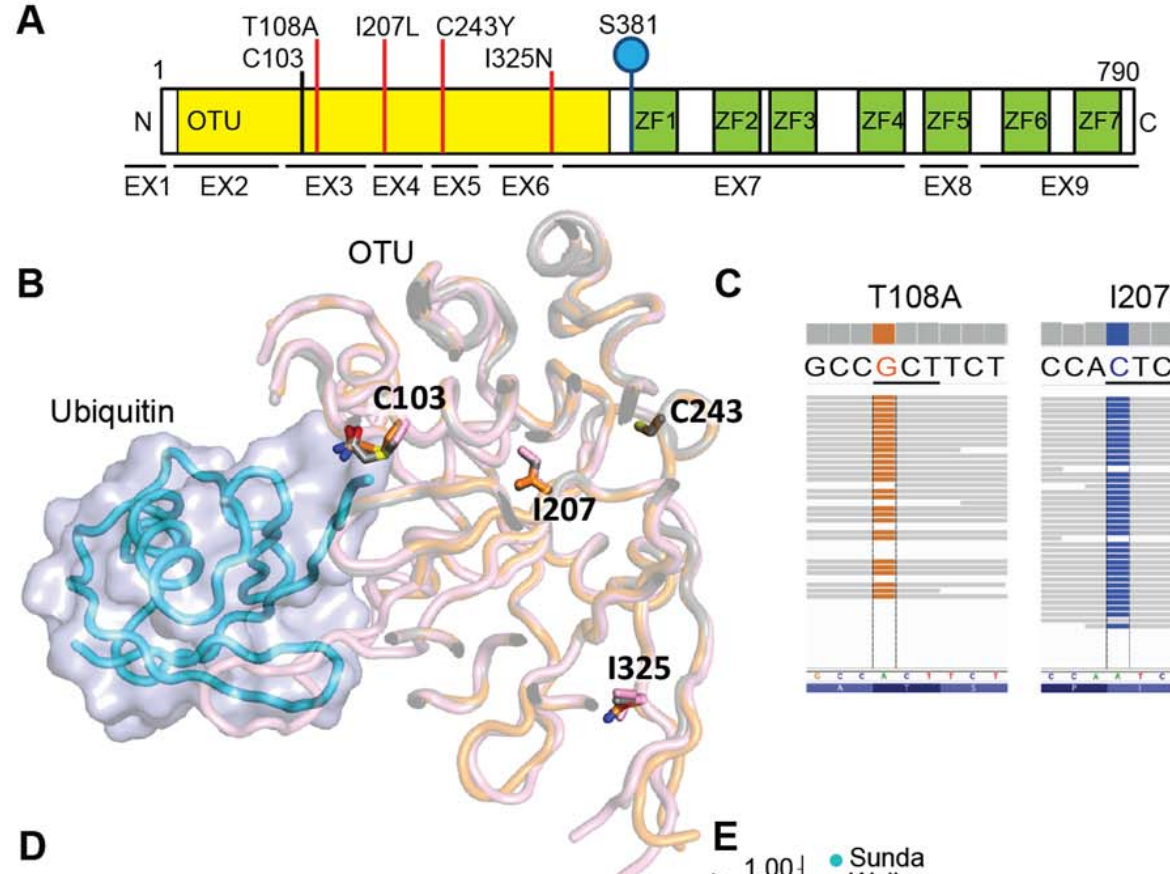

D

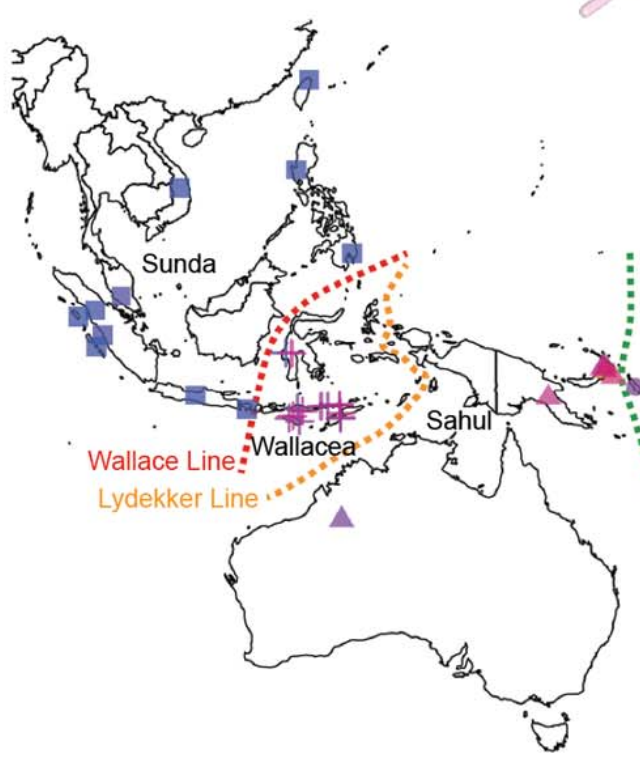

C
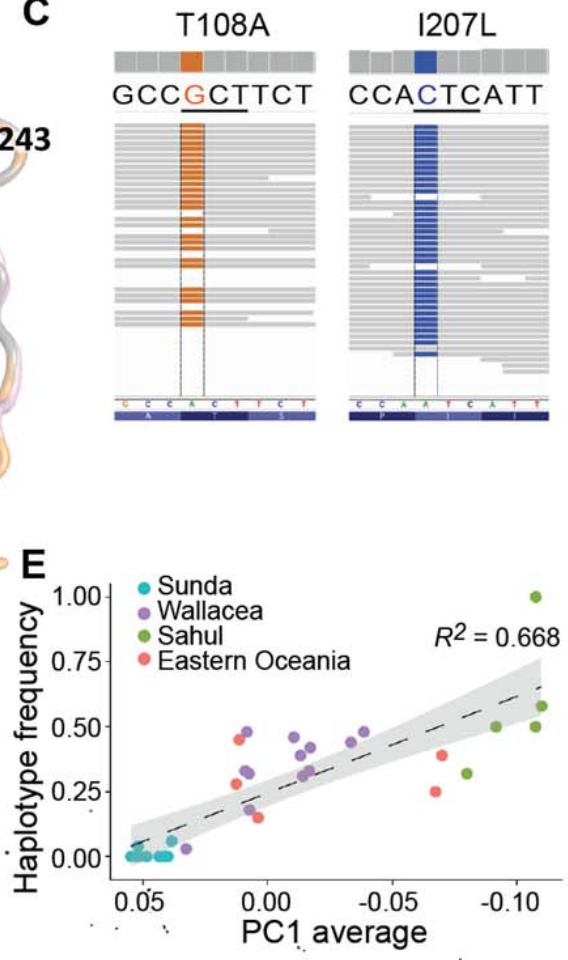

Fig. 1. Denisovan, modern human, and mouse variants substituting noncatalytic residues of the A20 OTU domain. (A) Schematic of A20 protein encoded by the TNFAIP3 gene (CCDS5187), showing exons (EX1-9), ovarian tumor domain (OTU), zinc fingers (ZF17), OTU catalytic residue (C103), S381 phosphorylation site, and missense variants studied here (red lines). (B) Location of variant residues in sliced structure $5 \mathrm{LRX}^{42}$ of A20 OTU domain (pink) complexed with ubiquitin (blue). Structures for WT and I325N OTU domains are superposed in grey and orange, respectively. (C) Read data of a high-coverage Denisovan genome $^{27}$ across TNFAIP3 codons 108 and 207. (D) Imputed frequency of the Denisovan TNFAIP3 haplotype in genotype array data from 514 individuals from indigenous populations across Island Southeast Asia and Oceania ${ }^{30}$, and directly observed in exome data from 72 Martu indigenous Australians ${ }^{32}$. Different shape symbols group populations from 
584 Sunda, Wallacea, Sahul and Eastern Oceania. (E) Imputed Denisovan TNFAIP3 haplotype

585 frequency from populations described in (D) (filled circles) versus a surrogate estimate of 586 Papuan ancestry (principal component 1, Extended Data Fig. 3). Gray shading indicates 95\% 587 confidence interval of linear regression line. 
A

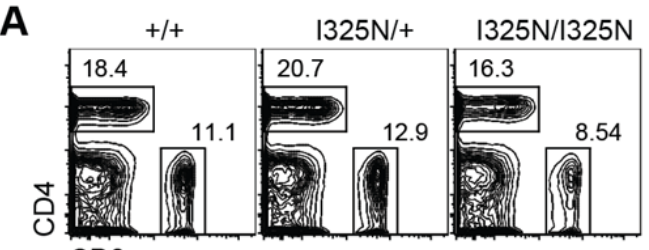

CD8
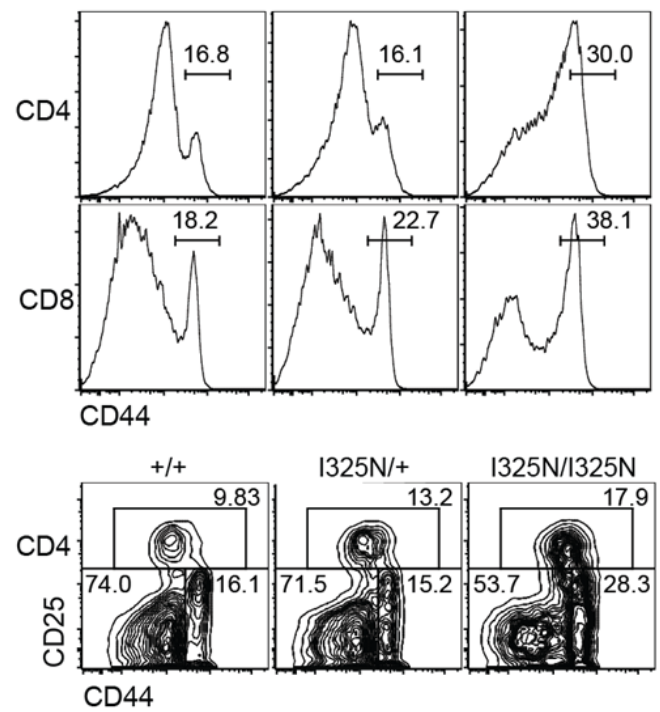

B

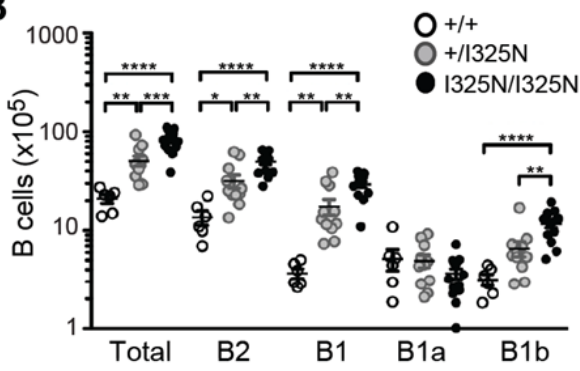

C

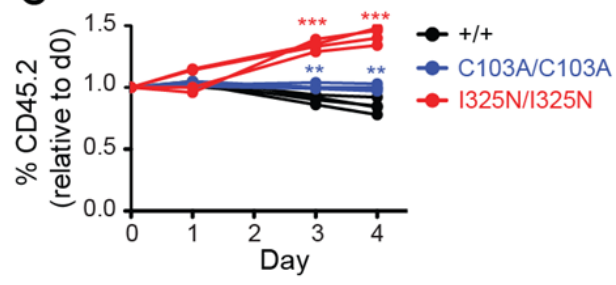

D

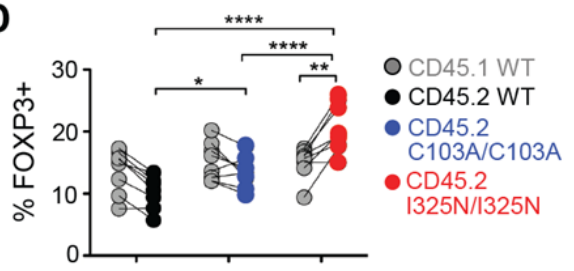

E

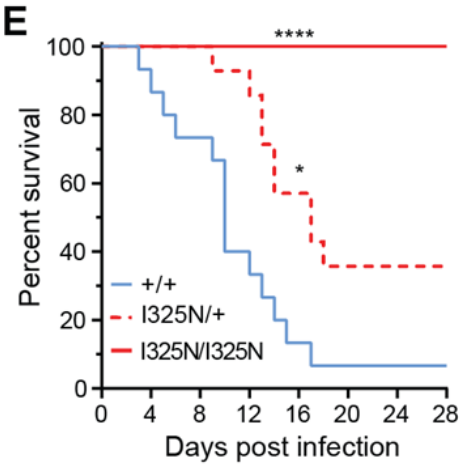

589

590

591

592

593

594

595

596

597

598

599

600

601

602

603

604
F

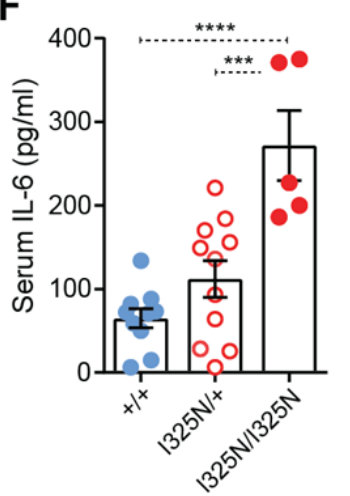

G

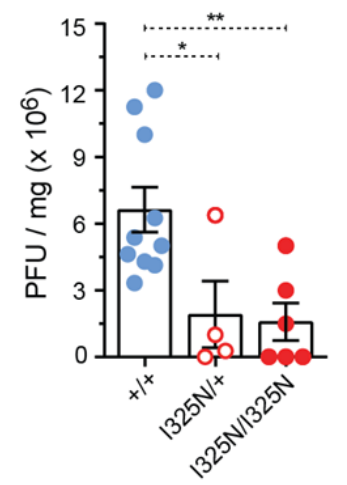

Fig. 2. I325N OTU variant confers heightened immunity in mice. (A) Representative flow cytometric analysis of splenocytes, showing percentage of $\mathrm{CD}^{+}$or $\mathrm{CD} 8^{+} \mathrm{T}$ cells, and percentage $\mathrm{CD} 44^{\mathrm{hi}}$ activated/memory cells within these subsets or percentage CD25 ${ }^{+} \mathrm{CD} 44^{\text {int }}$ regulatory $\mathrm{T}$ - cells or $\mathrm{CD} 25^{-} \mathrm{CD} 44^{\text {high }}$ effector/memory $\mathrm{T}$ cells among $\mathrm{CD} 4^{+}$cells. (B) Numbers of indicated B cells in peritoneum of individual Tnfaip3 mice (circles). (C, D) Wild-type $\mathrm{CD} 45.1^{+}$mice transplanted with equal mixtures of congenic bone marrow from Tnfaip $^{+/+} \mathrm{CD}^{+} 5.1^{+}$donors and CD $45.2^{+}$donors of Tnfaip3 $3^{1325 \mathrm{~N} / 1325 \mathrm{~N}}$, Tnfaip3 ${ }^{\mathrm{C} 103 \mathrm{~A} / \mathrm{C} 103 \mathrm{~A}}$ or Tnfaip3 $^{+/+}$genotypes. (C) Splenocytes from chimeras cultured with $0.1 \mu \mathrm{g} / \mathrm{ml}$ LPS for $0-4$ days, and the frequency of CD $45.2^{+}$cells of the indicated Tnfaip3 genotypes was measured among B cells from individual chimeras (lines), expressed relative to their frequency on day 0 . (D) Pairwise comparison of frequency of FOXP3 ${ }^{+}$cells amongst CD45.2 ${ }^{+}$and CD $45.1^{+}$ $\mathrm{CD}^{+}$splenocytes from the same chimera. (E-G) Female Tnfaip3 ${ }^{+/+}(n=15)$, Tnfaip $3^{1325 \mathrm{~N} /+}$ $(n=14)$ or Tnfaip ${ }^{31325 \mathrm{~N} / 1325 \mathrm{~N}}(n=10)$ C57BL/6 mice were injected with Coxsackie B4 virus strain E2 on day 0. (E) Kaplan-Meier survival data (Log-rank test). (F) Plasma IL-6 and (G) virus titers (plaque forming units, PFU) per mg of pancreas on day 3. Error bars represent 
bioRxiv preprint doi: https://doi.org/10.1101/589507; this version posted March 27, 2019. The copyright holder for this preprint (which was not certified by peer review) is the author/funder, who has granted bioRxiv a license to display the preprint in perpetuity. It is made available under aCC-BY 4.0 International license.

605 SEM and one-way ANOVA used for significance analysis unless otherwise stated, $* P<0.05$;

$606 * * P<0.01 ; * * * P<0.001 ; * * * * P<0.0001$. 

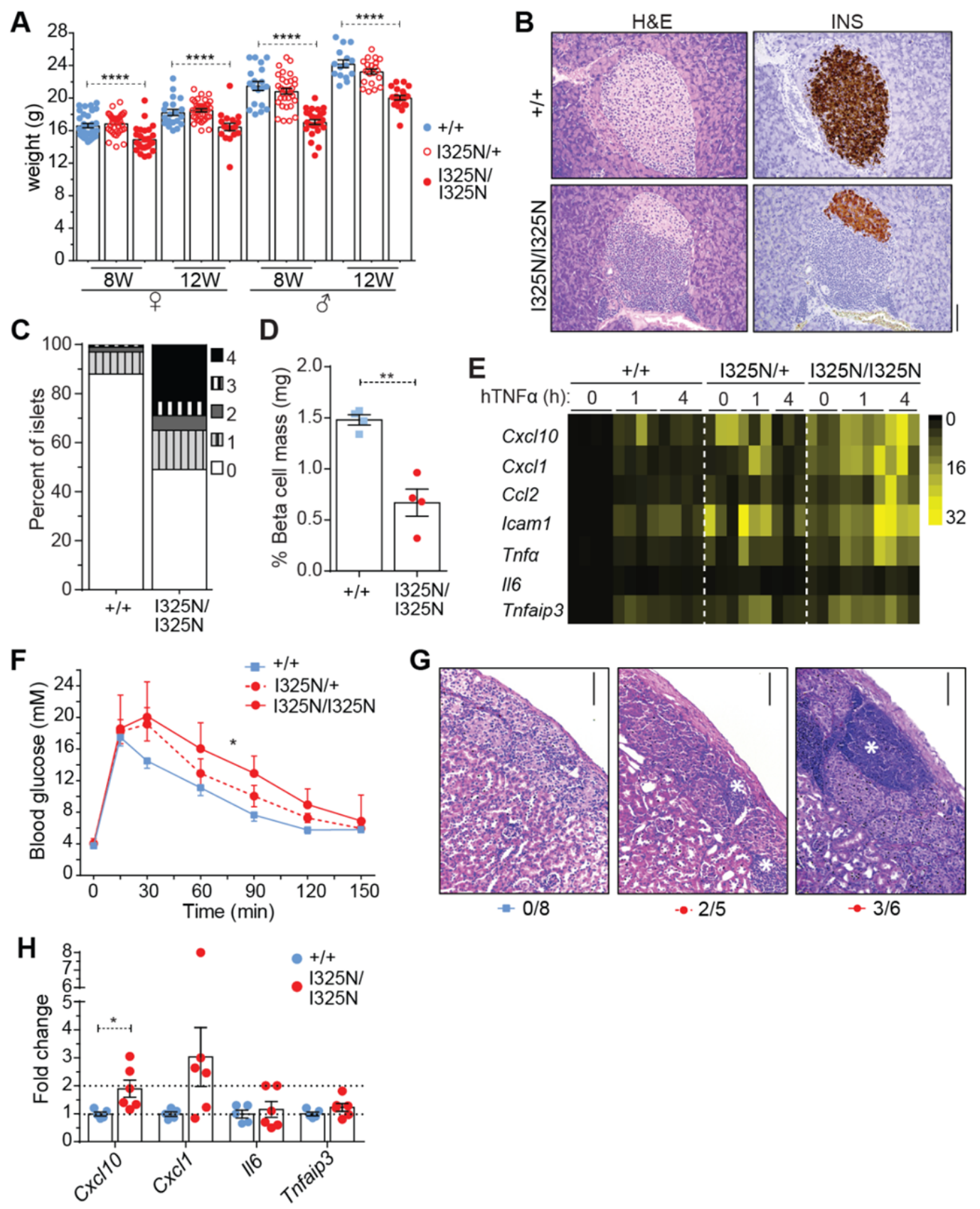

Fig. 3. Subclinical inflammatory and metabolic consequences of the I325N variant. (A) Body weights of Tnfaip3 ${ }^{+/+}$, Tnfaip ${ }^{1325 \mathrm{~N} /+}$, Tnfaip $3^{1325 \mathrm{~N} / 1325 \mathrm{~N}}$ mice of the indicated age and sex. Statistical analysis by unpaired one-way ANOVA: ****P<0.0001. (B) Hematoxylin and eosin (H\&E) and insulin (INS) stained pancreas sections (scale $=100 \mu \mathrm{m})$ with (C) cumulative insulitis scores (4 represents $>75 \%$ islet mononuclear cell infiltration, and 0 an absence of infiltrating cells) and (D) calculated beta cell mass for Tnfaip3 ${ }^{+/+}$and Tnfaip $3^{\mathrm{I} 325 \mathrm{~N} / 1325 \mathrm{~N}}$ mice. (E) Expression of TNF $\alpha$-induced genes in islets from Tnfaip3 $3^{+/+}$, Tnfaip3 ${ }^{\mathrm{I} 25 \mathrm{~N} / /}$, Tnfaip $3^{\mathrm{I} 325 \mathrm{~N} / 1325 \mathrm{~N}}$ mice. Data represents 3 independent islet preparations with 34 biological replicates. (F) Glucose tolerance test in diabetic wild-type mice transplanted with Tnfaip3 $^{+/+}$, Tnfaip $3^{\mathrm{I} 325 \mathrm{~N} /+}$ or Tnfaip $3^{\mathrm{I} 325 \mathrm{~N} / 1325 \mathrm{~N}}$ islets, $\mathrm{N}>8$ mice per group. (G) H\&E sections of islet grafts at post-operative day $30($ scale $=50 \mu \mathrm{m})$ with the fraction of grafts exhibiting immune infiltrate shown below. (H) Islet grafts isolated on post-operative day 10 were 
bioRxiv preprint doi: https://doi org/10.1101/589507; this version posted March 27, 2019. The copyright holder for this preprint (which was not certified by peer review) is the author/funder, who has granted bioRxiv a license to display the preprint in perpetuity. It is made available under aCC-BY 4.0 International license.

620 analysed for indicated mRNAs by RT-qPCR. $P$ values represent Student's $t$-test unless

621 otherwise stated, $* P<0.05 ; * * P<0.01 ; * * * * P<0.0001$. 
A

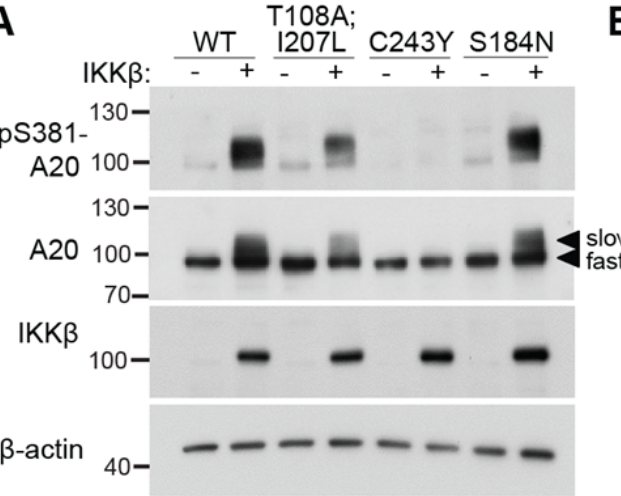

C

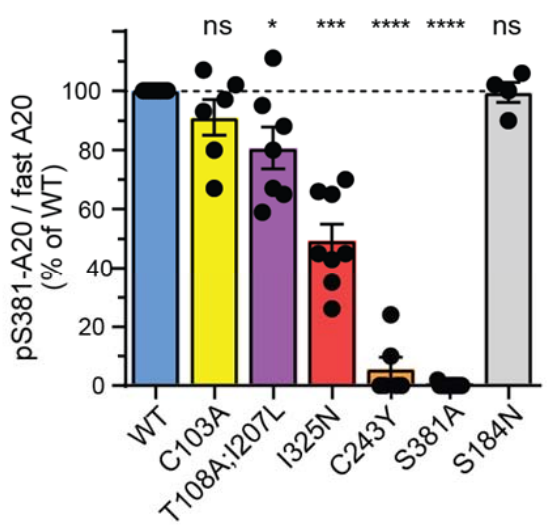

E

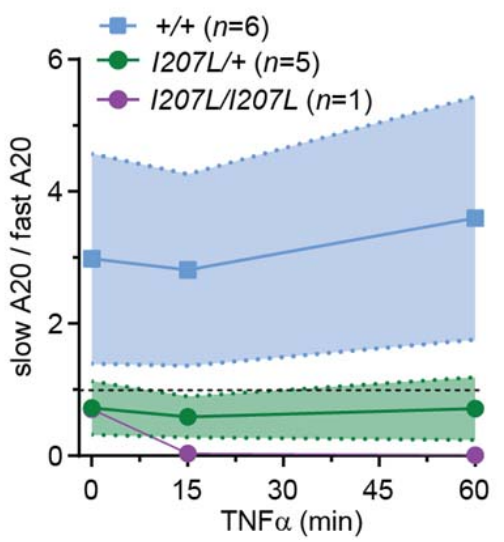

B

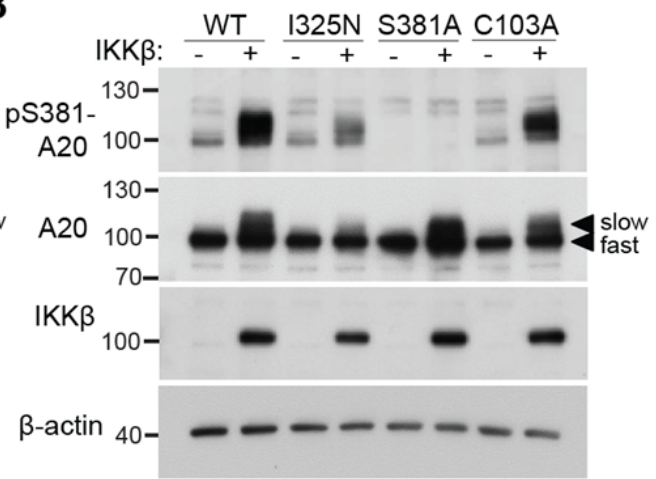

D
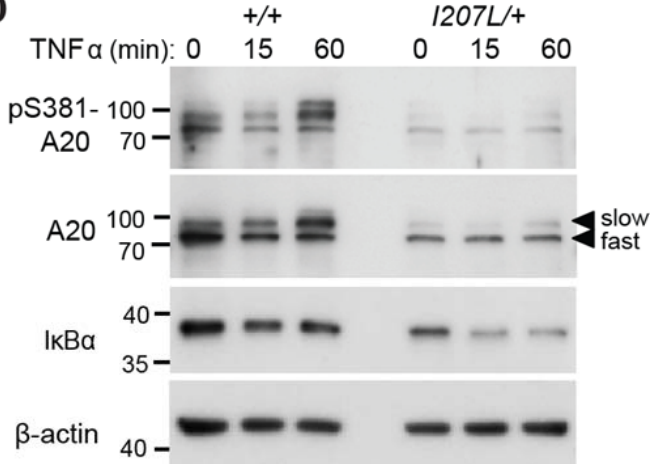

F

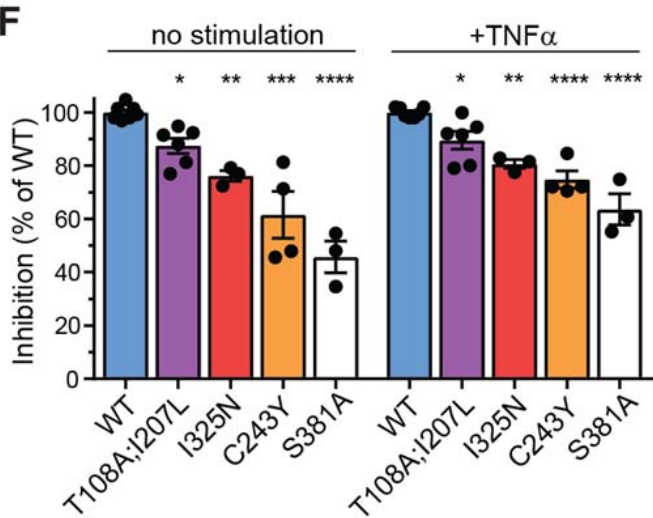

Fig. 4. OTU domain variants decrease A20 phosphorylation and NF-kB inhibition. (AC) Representative western blot of lysates from $\beta T C 3$ mouse insulinoma cells transfected with vectors encoding wild-type (WT) A20 or the indicated A20 mutants, with or without cotransfected IKK $\beta$, and probed with antibodies to phospho-Ser381 A20, total A20, IKK $\beta$ and $\beta$-actin. Molecular weight markers $(\mathrm{kD})$ and slow- or fast-migrating A20 species are indicated. (C) Densitometric analysis from multiple independent experiments (dots) showing the ratio of pSer381-A20 to total fast migrating A20 in IKK $\beta$-cotransfected cells, expressed relative to the ratio in cells with WT A20. (D) Representative western blot, probed with antibodies to the indicated proteins, of lysates from peripheral blood mononuclear cells from healthy donors with wild-type A20 or heterozygous for the Denisovan T108A;I207L haplotype, stimulated with TNF $\alpha$ for the indicated times. (E) Densitometric ratio of slow- to fast-migrating A20 species, showing mean and standard deviation from six normal donors, five T108A;I207L heterozygotes, and one T108A;I207L homozygote (Extended Data Fig. 
636

637

638

639
14). (F) Inhibition of an NF- $\kappa \mathrm{B}$ luciferase reporter in $\beta \mathrm{TC} 3$ cells by co-transfection of WT A20 or the indicated A20 mutants, expressed relative to wild-type A20 (Extended Data Fig. 13). Statistical analysis in $\mathrm{C}$ and $\mathrm{F}$ by one-way ANOVA: ns, $P>0.05 ;{ }^{*} P<0.05 ;{ }^{* *} P<0.01$; $* * * P<0.001 ; * * * * P<0.0001$. 
A

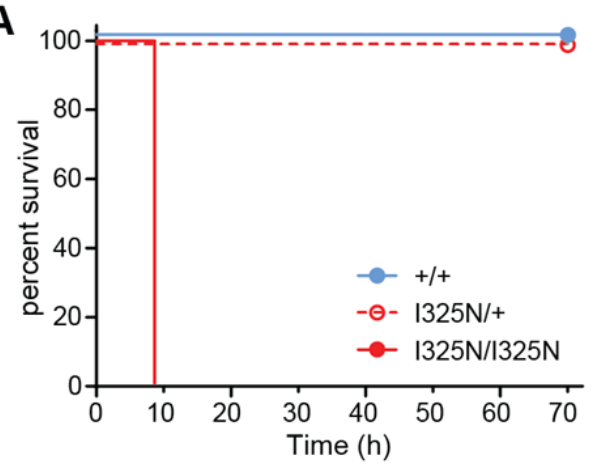

C

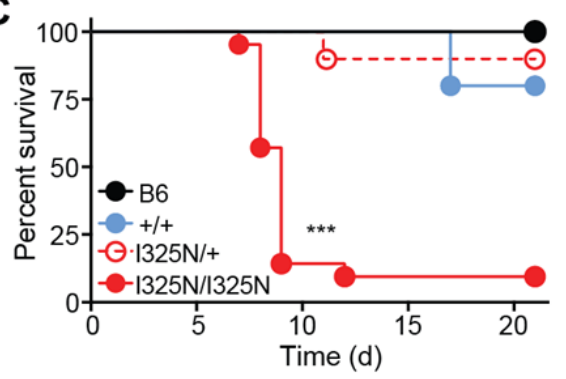

E

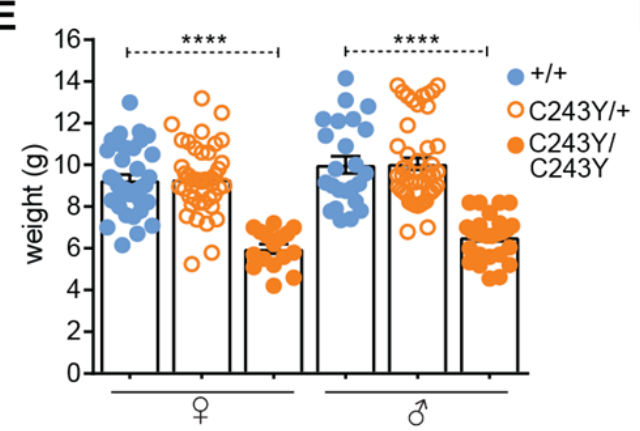

B
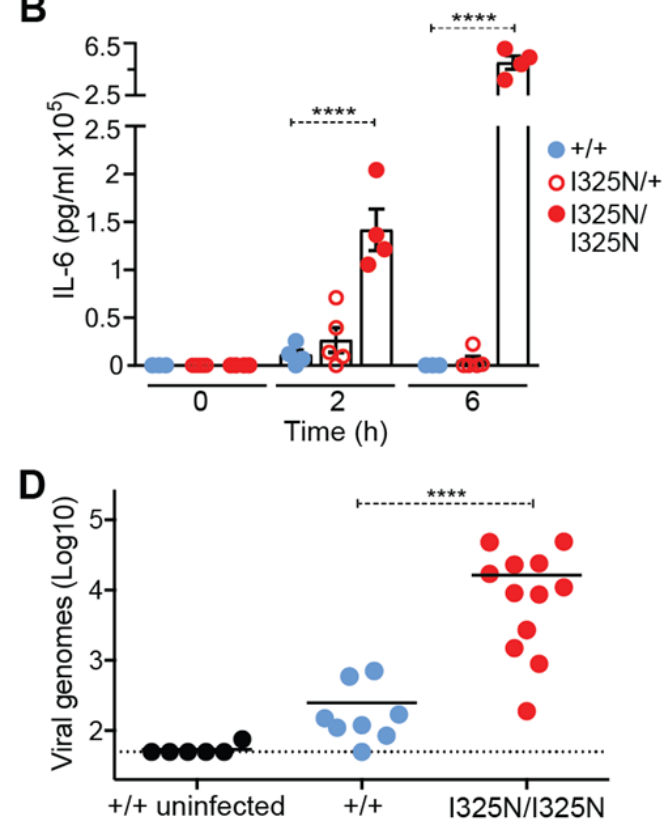

$\mathbf{F}$

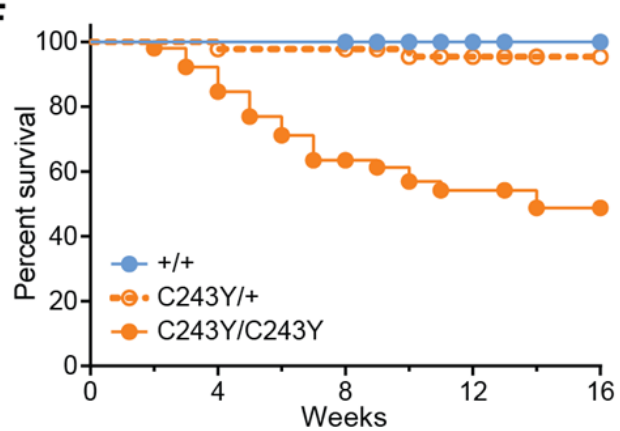

Fig. 5. Shift from beneficial to detrimental effects in response to environmental or genetic stressors. Kaplan-Meier survival curves (A) and serum IL-6 concentration (B) in mice of the indicated genotypes given $50 \mu \mathrm{g}$ LPS by intraperitoneal injection at time $=0$. $N=16-18$ for each curve in (A). (C) Kaplan-Meier survival curves for sex-matched littermates of the indicated Tnfaip3 genotypes and wild-type controls (B6) infected with Ectromelia virus. (D) Day 8 serum viral load assessed from mice in (C). (E) Weight of 3-week-old Tnfaip $3^{\mathrm{C} 243 \mathrm{Y} / \mathrm{C} 243 \mathrm{Y}}$ mice and heterozygous or wild-type littermates. (F) Survival of C243Y homozygous mice $(n=52)$ compared to heterozygous $(n=43)$ or wild-type littermates $(n=41)$. Statistical analysis by Students $t$-test and one-way ANOVA: ${ }^{* * *} P<0.001, * * * * P<0.0001$. 
652

653

654

655

656

657

658

659

660

661

662

663

664

665

666

667

668

669

670

671

672

673

674

675

676

677

678

679

680

681

682

683

684

685

686

687

688

689

690

691

692

693

694

695

696

697

698

699

700

\section{Materials and Methods}

Human subjects

Patients and healthy family members were recruited via the Clinical Immunogenomics Research Consortium Australia and The Children's Hospital at Westmead, providing written informed consent under protocols approved by relevant human research ethics boards.

\section{Genome sequencing}

Parent-proband trio genomes were sequenced on the Illumina HiSeq X platform using DNA isolated from whole blood. Libraries were generated using either Illumina TruSeq PCR-free or TrueSeq Nano.

Raw reads were aligned to the hs37d5 reference using BWA-MEM v0.7.10-r789 (arXiv:1303.3997 [q-bio.GN]), and sorted and duplicate-marked with Novosort v1.03.01 (Novocraft Technologies). The GATK suite v3.3-0-g37228 af ${ }^{43}$ was used for local indel realignment and base quality score recalibration. gVCFs were generated with GATK HaplotypeCaller, joint-called as trios using GATK GenotypeGVCFs, and variants recalibrated using GATK Variant Quality Score Recalibrator (VQSR). Finally, VCF files were annotated with Variant Effect Predictor (VEP) v7 $6^{44}$ using the LoFTEE ${ }^{45}$ and dbNSFP plugins.

Variants were packaged into databases using GEMINI (v0.18.3) ${ }^{46}$ and imported into Seave $^{47}$. All reported variants were manually inspected using $\mathrm{IGV}^{48}$ to verify their authenticity and validated by Sanger Sequencing.

\section{Population genetic analysis}

TNFAIP3 genotypes were extracted from 279 publicly-available genomes from the Simons Genome Diversity Project samples ${ }^{22}$, or exome data from 72 Martu indigenous Australians ${ }^{32}$. In addition, a collection of 514 individuals from across mainland and Island Southeast Asia, Papua New Guinea and Oceania was genotyped at 567,096 variants using the Affymetrix Axiom Genome-Wide Human Array, with 538,139 autosomal variants with $<5 \%$ missing data kept for further analyses ${ }^{30}$. Weir and Cockerham's estimated $\mathrm{F}_{\mathrm{ST}}$ values were calculated using VCFtools v0.1.14, and principal component analysis was performed using PLINK v1.9. Genotypes were phased and imputed using the Michigan Imputation Server v1.0.3 (http://imputationserver.sph.umich.edu), and compared to high-coverage Denisovan ${ }^{27}$ and Altai Neanderthal ${ }^{28}$ TNFAIP3 haplotypes. Phred-scaled CADD scores ${ }^{49}$ were calculated for all PASS variants across the extended Denisovan haplotype with gnomAD allele frequency $<0.01$.

\section{PBMC isolation and manipulation}

Human PBMCs were prepared using a Ficoll- Hypaque gradient and live count taken using $0.1 \%$ trypan blue. Cells were resuspended at $10^{6}$ cells $/ \mathrm{ml}$ in sterile freezing medium (RPMI-1640, 10\% DMSO, 50\% FCS) in $1.5 \mathrm{ml}$ Sarstedt cyrovials and stored in liquid nitrogen. Human PBMCs were thawed in a $37^{\circ} \mathrm{C}$ water bath and added drop wise to prewarmed medium (RPMI-1640, 10\% FCS, $100 \mathrm{U} / \mathrm{ml}$ P/S, 1\% HEPES, 2 mM L-Glutamine, $2 \mathrm{mM}$ EDTA) and resuspended for culture at $37^{\circ} \mathrm{C}+5 \% \mathrm{CO}_{2}$ for $1 \mathrm{~h}$ prior to stimulation with recombinant human TNF $\alpha$ (R\&D Systems). Following stimulation, cells were pelleted and processed for immunoblotting or RT-qPCR, as described below.

Mice

The Tnfaip3 Lasvegas strain (Tnfaip3 ${ }^{\mathrm{I} 25 \mathrm{~N}}$ ) were generated by $N$-ethyl- $N$-nitrosourea (ENU) mutagenesis of C57BL/6 mice, and propagated by backcrossing to C57BL/6. The 
strain was maintained as heterozygous breeding pairs so that WT littermates could be used for controls. To generate Tnfaip3 ${ }^{C 243 Y}$ mice, a guide RNA with the sequence 5'GGGATATCTGTAACACTCC-3' was microinjected into C57BL/6 zygotes in combination with Cas9 mRNA. Founder mice carrying the $\mathrm{C} 243 \mathrm{Y}$ substitution were then crossed to C57BL/6, and heterozygous offspring intercrossed to generate homozygous, heterozygous and wild-type littermates for experimentation. Mouse lines were housed at the Australian Phenomics Facility (Australian National University, Canberra, Australia), or at the Australian BioResources Centre (ABR) (Moss Vale, NSW, Australia). Tnfaip3 ${ }^{\mathrm{C} 103 \mathrm{~A}}{ }^{18}, 3 \mathrm{~A} 9 \mathrm{TCR}$ transgenic ${ }^{50}$ and insHEL transgenic ${ }^{51}$ mice have been described. Mice were genotyped for transgenes and mutations by PCR and used 7-28 (typically 10-16) weeks after birth. For $\mathrm{TCR}^{3 \mathrm{~A} 9}$ transgenic mouse experiments, mice were hemizygous for the $3 \mathrm{~A} 9$ or insHEL transgenes on the B10.BR and the B10.BR.SJL-Ptprc ${ }^{a}$ (CD45.1) backgrounds, and the Tnfaip3 ${ }^{\mathrm{I} 25 \mathrm{~N}}$ mutation was backcrossed to B10.BR. To make chimeras, congenic B6.SJLPtprc $^{a}$ or B10.BR.SJL-Ptprc ${ }^{a}$ (CD45.1) mice were irradiated with two doses of 4.5 Gy 4 hrs apart, and injected IV with mixtures of $1.8 \times 10^{6}$ bone marrow cells from B6 or B10.BR SJLPtprc $^{a}$ mice and $1.8 \times 10^{6}$ bone marrow cells from B6 (CD45.2) mutant or control mice, and analyzed 8-14 weeks later. Animal studies were approved by the Garvan/St Vincent's or the Australian National University Animal Ethics Committees. All procedures performed complied with the Australian code of Practice for Care and Use of Animals for Scientific Purposes.

\section{Coxsackievirus infection model and virus quantification}

Mice were intraperitoneally injected with normal saline (control) or 20 plaque forming units (PFU) in $200 \mu 1$ saline of the CVB4 E2 lab strain kindly provided by Prof. Malin Flodström Tullberg (Karolinska Institutet, Solna, Sweden) grown in HeLa cells. Mice were monitored daily and euthanized if they displayed gross signs of illness (e.g., ruffling, hunching). The pancreas was harvested at indicated times for RT-qPCR and histopathology analysis and viral titre determination. Serum was also collected by cardiac puncture for measurement of IL-6 by ELISA (BD; OptEIA ${ }^{\mathrm{TM}}$ Set Mouse IL-6), as per manufacturer's instructions. Non-fasting blood glucose levels were measured at least twice-weekly using Freestyle Lite Blood Glucose Test Strips (Abbott, Australia). Plaque assays were performed to determine viral titres within the pancreas following infection. HeLa cells $\left(0.6 \times 10^{6} /\right.$ well $)$ were seeded in $2 \mathrm{ml}$ complete medium (RPMI with 10\% FCS, $2 \mathrm{mM}$ L-Glutamine, $100 \mathrm{U} / \mathrm{ml}$ Penicillin, $100 \mu \mathrm{g} / \mathrm{ml}$ Streptomycin and $100 \mu \mathrm{g} / \mathrm{ml}$ Normocon) in 6 well plates and incubated over night at $37^{\circ} \mathrm{C}$. Infections samples were collected in RPMI, homogenized in a Dounce tissue grinder and passed through a $22 \mu \mathrm{m}$ filter, before preparing tenfold serial dilutions. HeLa cells, at $90 \%$ confluency, were washed with $1 \mathrm{X}$ PBS and $400 \mu \mathrm{l}$ of infectious homogenate added to each well and incubated for $60 \mathrm{~min}$ at $37^{\circ} \mathrm{C}$ under gentle rocking. Infectious media was removed and $3 \mathrm{ml}$ of agar mix (2x 1.8\% agar, 2x MEM containing 10\% FCS) was added to each well before incubating at $37^{\circ} \mathrm{C}$ for 3 days. Cells were then fixed with Carnoys reagent for $60 \mathrm{~min}$ and subsequently stained with $0.5 \%$ Crystal violet for $60 \mathrm{~s}$. Wells were extensively washed with $\mathrm{H}_{2} \mathrm{O}$ and plaques counted.

\section{Ectromelia virus model}

Mice were inoculated subcutaneously with $10^{3}$ PFU Ectromelia virus (Moscow strain; ATCC \#VR-1374) in the flank of the left hind limb between the regio tarsi and regio pedis under avertin anesthesia. Clinical scores were recorded daily, and animals weighed on days 0 , 5 and every 2 days thereafter until day 21 , and bled on days -1 and 8 to measure viral load. Animals with a significant clinical score or $25 \%$ decrease of starting weight were euthanized and considered dead the following day. Viral load was measured in blood by qPCR for 
ECTV-Mos-156 viral genomes and in organs by viral plaque assay as $\log _{10} \mathrm{PFU} / \mathrm{gram}$ tissue $^{52}$.

\section{Macrophage cultures}

Bone marrow from femurs and tibiae was cultured 7 days in complete RPMI1640 medium with $10 \%$ fetal bovine serum, $100 \mathrm{U} / \mathrm{ml}$ penicillin, $100 \mu \mathrm{g} / \mathrm{ml}$ streptomycin, $2 \mathrm{mM} \mathrm{L-}$ glutamine (Life Technologies) and 50ng/ml recombinant human Macrophage colonystimulating factor (Peprotech). Cells were placed into 6-well plates for stimulation with 10ng/ml Salmonella Minnesota R595 (Re) ultra-pure LPS (List Biological) for different timepoints. RNA was extracted by TRIzol (Life Technologies), reverse transcribed to cDNA with SuperScriptII (Life Technologies), Cxcl1and Cxcl11 levels were measured using the Taqman assay (Applied Biosystems). RNA levels relative to Ef1a were calculated with the delta Ct values. Conditionally Hoxb8-immortalized bone-marrow progenitor cells were generated as described $^{53}$.

\section{LPS sepsis model}

A low dose of $50 \mu \mathrm{g}$ LPS was administered by intraperitoneal injection. Mice were monitored every $1 \mathrm{~h}$ for $10 \mathrm{~h}$ and sacrificed if ethical end-point reached. Monitoring was conducted using body conditioning score and Grimace Scale (NC3Rs [National Centre for the Replacement Refinement \& Reduction of Animals in Research) approved by the Garvan/St Vincent's Animal Ethics Committee. Monitoring continued twice daily for 7 days in surviving mice, were weights and blood glucose levels were also measured. Serum was collected by tail-tipping before LPS injection and 2 and 4 hours following injection for IL6 determination by ELISA (BD; OptEIA ${ }^{\mathrm{TM}}$ Set Mouse IL-6), as per manufactures instructions.

Immunohistochemistry and beta cell area determination

Tissues were fixed in $10 \%$ neutral buffered formalin (Sigma-Aldrich), paraffin embedded and parallel sections $(5 \mu \mathrm{m})$ prepared. Sections were stained with hematoxylin and eosin (H\&E; Sigma-Aldrich) and for pancreatic tissue parallel sections stained for insulin (purified rabbit anti-mouse insulin polyclonal antibody; 4590; Cell Signaling Technology). Visualization of bound anti-insulin antibody was achieved using HRP-labelled polymerconjugated goat anti-rabbit IgG (Dako EnVision+ System), followed by counterstain with hematoxylin. For pancreatic beta cell mass determination consecutive pancreatic serial sections at $200 \mu \mathrm{m}$ intervals were stained for insulin and beta cell area quantified from total area taken by insulin positive cells compared to non-positive tissue (ImageJ). Beta cell mass (mg) was calculated by multiplying relative insulin-positive area by the mass of the isolated pancreas before fixation. Images were captured using a Leica DM 4000 or Leica DM 6000 Power Mosaic microscope (Leica Microsystems).

\section{Metabolic studies}

Blood glucose levels (BGL) were determined using a FreeStyle Lite ${ }^{\circledR}$ glucometer and blood glucose test strips (Abbott Diabetes Care) via tail tipping. Measurements were taken from 8 and 12 week old male or female non-fasted mice. Intraperitoneal glucose tolerance tests (IP-GTT) were conducted following an overnight fast $(16 \mathrm{~h})$ with access to water. The following day mice were weighed and fasting blood glucose measurements taken. Subsequently, mice were injected (IP) with 20\% dextrose w/v (Sigma Aldrich) to a final concentration of $2 \mathrm{~g}$ glucose per $\mathrm{kg}$ body weight $(2 \mathrm{~g} / \mathrm{kg})$. Blood glucose levels were measured from the tail vein at 15, 30,60 and 120 min post-glucose administration. Intravenous (IV) GTT was conducted in a similar manner; however, glucose $(1 \mathrm{~g} / \mathrm{kg})$ was administered intravenously into the tail vein and blood glucose measurements taken at 0,5 , 
$80110,15,20,30$, and 60 min post-injection. During the IV-GTT blood samples were also taken

802

803

804

805

806

807

808

809

810

811

812

813

814

815

816

817

818

819

820

821

822

823

824

825

826

827

828

829

830

831

832

833

834

835

836

837

838

839

840

841

842

843

844

845

846

847

848

849

850 for the determination of insulin content via ELISA, conducted as per manufactures

instructions (Cayman Chemical). Glucose-stimulated insulin secretion assay (GSIS) was

performed for islets ex vivo as descried ${ }^{54}$.

Islet isolation, transplantation, and in vitro studies

Islets were isolated as previously described ${ }^{55}$, and counted for islet transplantation or in vitro experiments using a Leica MZ9.5 stereomicroscope. Islets were transplanted under the kidney capsule of diabetic B6 littermates as described ${ }^{56}$. Diabetes was induced by IP injection of $180 \mathrm{mg} / \mathrm{kg}$ streptozotocin (Sigma-Aldrich) dissolved in $0.1 \mathrm{M}$ citrate buffer ( $\mathrm{pH}$ 4.2 ) at a concentration of $20 \mathrm{mg} / \mathrm{ml}$. Diabetes was determined as [blood glucose] $\geq 16 \mathrm{mM}$ on two consecutive days measured by FreeStyle Lite ${ }^{\circledR}$ glucometer and Abbott Diabetes Care test strips following tail tipping. Islet grafts were retrieved from recipients at indicated time points post-transplantation for analysis of islet morphology, function, or degree of lymphocytic infiltration by histology or gene expression by RT-qPCR. Gene expression in islet grafts was calculated using the average WT $\Delta \mathrm{Ct}$ value. Islets to be used for in vitro studies were cultured overnight in islet overnight culture media (RPMI-1640, 20\% FCS, $100 \mathrm{U} / \mathrm{ml} \mathrm{P/S,} 2 \mathrm{mM} \mathrm{L}-$ Glutamine) at $37^{\circ} \mathrm{C}+5 \% \mathrm{CO}_{2}$.

\section{Flow cytometry}

Flow cytometric staining was performed as described in ${ }^{57,58}$. Antibodies against the following surface antigens were: CD4 (RM4-5), CD8 (53-6.7), CD21 (7G6), CD23 (B3B4), CD25 (PC61.5), CD44 (IM7), CD69 (H1.2F3), CD93 (AA4.1), CD45.2 (104), B220 (RA36B2), IgM (II/41), IgD (11-26). Splenocytes were labeled with CFSE (Invitrogen) and cultured in RPMI1640 supplemented with 10\% FCS, 2 mM L-glutamine, $55 \mu \mathrm{M} 2-$

mercaptoethanol, and penicillin/streptomycin. B cells were stimulated with: F(ab') ${ }_{2}$ goat antimouse IgM (10 $\mu \mathrm{g} / \mathrm{ml}$, Jackson Immunoresearch Laboratories), LPS from E. coli 055:B5 $(10,1,0.1 \mu \mathrm{g} / \mathrm{ml}$, SIGMA), anti-CD40 (10 $\mu \mathrm{g} / \mathrm{ml} \mathrm{FGK4.5,} \mathrm{BioXCell).} \mathrm{When} \mathrm{analysing} \mathrm{3A9}$ TCR transgenic cells single cell suspensions from thymus, spleen or pancreatic lymph node were incubated for $30 \mathrm{~min}$ at $4^{\circ} \mathrm{C}$ in culture supernatant from the $1 \mathrm{G} 12$ hybridoma (specific for $\mathrm{TCR}^{3 \mathrm{~A} 9}$ ). Then, cells were pelleted by centrifugation and incubated for $30 \mathrm{~min}$ at $4^{\circ} \mathrm{C}$ in FACS buffer containing assortments of fluorochrome- or biotin-conjugated monoclonal antibodies against cell surface proteins. After washing in FACS buffer, cells were fixed and permeabilised using the eBioscience Foxp3 staining buffers, then incubated with antibodies specific for intracellular proteins and Brilliant Violet 605-streptavidin conjugate (BioLegend) to detect biotin-conjugated antibodies. Antibodies were purchased from BD, eBioscience or BioLegend. Data were acquired with LSR II flow cytometers (BD) and analyzed using FlowJo software (Tree Star).

\section{CyTOF:}

Unstimulated spleen cells from four wild-type and four I325N-homozygous mutant mice were individually labeled with mass-barcodes, mixed, permeabilized and stained with masslabeled antibodies to a panel of cell surface markers and intracellular proteins including $\mathrm{I} \kappa \mathrm{B} \alpha$, and analyzed by CYTOF mass spectrometry ${ }^{59,60}$. Spanning-tree Progression Analysis of Density-normalized Events (SPADE) ${ }^{61}$ analysis was used to resolve leukocyte lineages and subsets, and the relative intensity of $\mathrm{I} \kappa \mathrm{B} \alpha$ in each subset compared between mutant and wildtype cell counterparts. 


\section{Real Time quantitative PCR (RT-qPCR)}

Mouse islets were isolated and placed into 12-well non-tissue culture-treated plates (150200 islets/well; Fisher Scientific). Following an overnight culture islets were treated with $200 \mathrm{U} / \mathrm{ml}$ recombinant human (h) TNF $\alpha$ (R\&D Systems) for 1, 4, or $24 \mathrm{~h}$. Total RNA was extracted using the RNeasy Plus Mini Kit (Qiagen) and reverse transcribed using Quantitect Reverse Transcription Kit (Qiagen). Primers were designed using Primer3 software ${ }^{62}$ with sequences obtained from GenBank and synthesized by Sigma Aldrich (Table 3, 4). PCR reactions were performed on the LightCycler ${ }^{\circledR} 480$ Real Time PCR System (Roche) using the FastStart SYBR Green Master Mix (Roche). Cyclophilin ( $\mathrm{CPH}$ ) was used as the housekeeping gene and data analyzed using the $2^{\Delta \Delta \mathrm{CT}}$ method. Initial denaturation was performed at $95^{\circ} \mathrm{C}$ for $10 \mathrm{sec}$, followed by a three-step cycle consisting of $95^{\circ} \mathrm{C}$ for $15 \mathrm{sec}$ $\left(4.8^{\circ} \mathrm{C} / \mathrm{s}\right.$, denaturation), $63^{\circ} \mathrm{C}$ for $30 \mathrm{sec}\left(2.5^{\circ} \mathrm{C} / \mathrm{sec}\right.$, annealing), and $72^{\circ} \mathrm{C}$ for $30 \mathrm{sec}\left(4.8^{\circ}\right.$ $\mathrm{C} / \mathrm{s}$, elongation). A melt-curve was performed after finalization of 45 cycles at $95^{\circ} \mathrm{C}$ for 2 min, $40^{\circ} \mathrm{C}$ for $3 \mathrm{~min}$ and gradual increase to $95^{\circ} \mathrm{C}$ with 25 acquisitions $/{ }^{\circ} \mathrm{C}$. Expression differences were visualized using GraphPad or BAR Heatmapper plus tool.

Immunoblot analysis and immunoprecipitation

Primary islets were lysed in islet lysis buffer $(50 \mathrm{mM}$ Tris-HCL pH7.5, $1 \%$ Triton X, $0.27 \mathrm{M}$ sucrose, $1 \mathrm{mM}$ EDTA, $0.1 \mathrm{mM}$ EGTA, $1 \mathrm{mM} \mathrm{Na}_{3} \mathrm{VO}_{4}, 50 \mathrm{mM} \mathrm{NaF}, 5 \mathrm{mM}$ $\mathrm{Na} 4 \mathrm{P} 2 \mathrm{O} 7,0.1 \%$-mercaptoethanol; supplemented with EDTA-free protease inhibitor [Roche]), $\beta \mathrm{TC}_{3}$ cells were lysed with radioimmunoprecipitation (RIPA) buffer with SDS, following relevant treatment with or without $200 \mathrm{U} / \mathrm{ml}$ of recombinant human (h) or mouse (m) TNF $\alpha$ (R\&D Systems). Protein concentration was measured using the Bradford assay (Bio-Rad) and total protein (20-25 $\mu \mathrm{g}$ ) resolved on a 7 - 10\% SDS PAGE gel and then transferred to a nitrocellulose membrane, Immobilon- $\mathrm{P} \circledast$ (Merck Millipore). Membranes were incubated with anti-IкB $\alpha$ (9242), anti-phospho-IкB $\alpha$ (9256), anti-JNK (9252), anti-

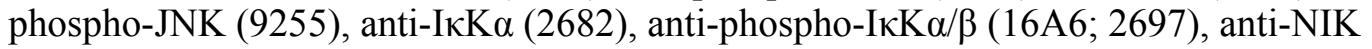
(4994), anti-NF-kB2 p100/p52 (4882), anti-RelB (C1E4, 4922) (Cell Signaling Technology); anti-beta-actin (AC15) (Sigma-Aldrich); or anti-S381-A20 (a kind gift by Professor Derek W. Abbott ${ }^{19}$ ) followed by horseradish peroxidase (HRP)-labeled secondary antibody goat-antimouse IgG Fc (Pierce Antibodies) or donkey-anti-rabbit IgG (GE Life Sciences). HRP conjugates bound to antigen were detected and visualized by using an ECL detection kit (GE Life Sciences).

Immunoprecipitation was conducted in thymocytes, which were lysed at $4^{\circ} \mathrm{C}$ in immunoprecipitation buffer $(0.025 \mathrm{M}$ Tris, $0.15 \mathrm{M} \mathrm{NaCl}, 0.001 \mathrm{M}$ EDTA, $1 \% \mathrm{NP}-40,1 \%$ Triton X 100, 5\% glycerol) containing Complete ${ }^{\circledR}$ protease inhibitor and Phosphostop ${ }^{\circledR}$ phosphatase inhibitors (Roche). Immunoprecipitation was then conducted by first preclearing lysates with protein A/G-Sephrose (Thermo Fisher Scientific) for $1 \mathrm{~h}$ and then incubated with anti-TNFR1 (ab7365) cross-linked beads or anti-A20 (59A426) antibody (Abcam) for $2 \mathrm{~h}$ at $4^{\circ} \mathrm{C}$. Following incubation with only antibody $25 \mu \mathrm{l}$ of protein $\mathrm{A} / \mathrm{G}$ beads were added and incubated at $4^{\circ} \mathrm{C}$ on a roller overnight. Beads were washed $4 \mathrm{X}$ with lysis buffer and then eluted using low $\mathrm{pH}$ amide buffer for cross-linked beads or $30 \mu \mathrm{l}$ of Laemmli reducing gelloading sample buffer for non-cross linked beads. Samples were vortexed, heated to $100^{\circ} \mathrm{C}$ for $5 \mathrm{~min}$, cooled on ice for $10 \mathrm{~min}$, and then loaded onto a 8 or $10 \%$ agarose gel for immunoblotting for anti-A20 (56305/D13H3), anti-IאB $\alpha$ (9242), anti-IאK $\beta$ (2684), anti-JNK (9252), anti-TAK1 (52065), anti-phospho-IאB $\alpha$ (9256), anti-phospho-JNK (9255), antiphospho-TAK1 (4536/90C7), anti-TNFR1 (3736C25C1) (Cell Signaling Technology), antiRIP1 (H-207) (Santa Cruz), anti-RIP1 (610458) (BD bioscience), anti-TAK1 (491840) (R\&D systems), or anti-beta-actin (AC15) (Sigma-Aldrich). For B cell stimulation, splenic B cells purified by MACS with CD43 depletion were stimulated with anti-IgM F( $\left.a b^{\prime}\right) 2$ or LPS for 
the indicated times. Cells were lysed with TNE buffer (1\% Nonidet P-40, $20 \mathrm{mM}$ Tris-HCl, $\mathrm{pH} 8.0,150 \mathrm{mM} \mathrm{NaCl}, 0.1 \mathrm{mM}$ sodium orthovanadate, and complete protease inhibitor [Roche]). The following antibodies were used: anti-I $\mathrm{BB} \alpha(9242)$, anti-TNFAIP3 (5630/D13H3) (Cell Signaling Technology), anti-A20 (A-12), anti-ubiquitin (P4D1) (Santa Cruz) and anti-beta-actin (AC-15) (Sigma-Aldrich).

\section{In vitro reporter transfection studies}

Reporter assays were carried out as described previously ${ }^{63,64}$. NF- $\kappa B$ activity experiments were conducted using $\beta \mathrm{TC}_{3}$ cells transfected with $0.3 \mu \mathrm{g}$ of the NF- $\kappa \mathrm{B}$.Luc reporter (Promega) and $0.25 \mu \mathrm{g}$ CMV. $\beta$-galactosidase (a kind gift from Beth Israel Harvard Medical School, Boston, MA). pcDNA vectors encoding human WT or variant A20 constructs or the empty pcDNA3.1 reporter were then added $(0.3 \mu \mathrm{g})$, and each well topped with 0.15 pcDNA3.1 to make $1 \mu \mathrm{g}$ total DNA. Transfection was conducted using Lipofectamine 2000 (Invitrogen). Following transfection cells were stimulated with $200 \mathrm{U} / \mathrm{ml}$ of recombinant human (h) TNF $\alpha$ (R\&D Systems). Luciferase activity was assayed in cell lysates harvested $8 \mathrm{~h}$ post-stimulation, using a luciferase assay kit (Promega). Results were normalized to $\beta$-galactosidase activity (Galactostar) to give relative luciferase activity. Expression plasmids and reporters were obtained and maintained as described previously ${ }^{63,64}$.

\section{Ubiquitination assays}

Wildtype A20, A $20^{\mathrm{I} 25 \mathrm{~N}}$ or A20 ${ }^{\mathrm{C} 103 \mathrm{~A}}$ OTU domain protein $(1 \mu \mathrm{g})$ purified from E. coli was added to $2 \mu \mathrm{g}$ of K48-ubiquitin chains of mixed chain length $\left(\mathrm{Ub}_{2}-\mathrm{Ub}_{7}\right)$ or to purified tetra-ubiquitin $\left(\mathrm{Ub}_{4}\right)$ (\#UC-230, UC-210, Boston Biochem). A20 OTU domains added to mixed-length K48-ubiquitin chains were incubated in $100 \mu \mathrm{l}$ of deubiquitin buffer $(50 \mathrm{mM}$ HEPES pH 8.0, 0.01\% Brij-35, 3mM DTT) at $37^{\circ} \mathrm{C}$ with agitation at $400 \mathrm{rpm}$ for 60 or 150 min in a benchtop incubator shaker. A20 OTU domains added to K48-tetra-ubiquitin chains were incubated in $100 \mu 1$ of deubiquitin buffer (25 mM HEPES pH 8.0, $5 \mathrm{mM}$ DTT, $5 \mathrm{mM}$ $\mathrm{MgCl}_{2}$ ). At the indicated times, $20 \mu \mathrm{l}$ of reaction mixture was collected and the enzymatic reaction stopped by addition of SDS sample buffer. Recombinant Flag-tagged full length $\mathrm{A} 20^{+/+}$or $\mathrm{A} 20^{1325 \mathrm{~N}}$, was expressed in HEK-293T cells and purified as described previously ${ }^{14,17}$. Full-length A20 deubiquitination reactions were performed using $100 \mathrm{ng}$ recombinant A20, $500 \mathrm{ng}$ of the indicated ubiquitin chain and DUB reaction buffer with or without phosphatase inhibitor cocktail and were incubated for the indicated times at $37^{\circ} \mathrm{C}$ with agitation at 1,000 rpm. Following incubation samples were placed on ice and $20 \mu 1$ collected and added to SDS sample buffer to stop the reaction. Full-length ubiquitin ligase assay was performed as previously described ${ }^{14}$. Samples were subjected to 1D SDS-PAGE and immunoblotted for ubiquitin (clone P4D1; Santa Cruz or Cell Signaling Technology) or A20 (clone 59A426; Abcam or A-12; Santa Cruz), as described above.

\section{OTU protein preparation and crystallisation}

The N-terminal OTU domains of human and mouse A20 (human WT and I325N, residues 1-366; mouse WT and C103A, 1-360) were cloned into vector pGEX-6P-1 (GE Healthcare), facilitating bacterial expression as a GST-fusion. Sequences were confirmed by Sanger sequencing. Expression was performed in E. coli strain BL21 (DE3) Gold, where cells were induced at an OD600 of 0.5 with $0.2 \mathrm{mM}$ IPTG, followed by incubation at $20^{\circ} \mathrm{C}$ overnight in LB medium. Cells were harvested by centrifugation, lysed by three cycles of freeze-thaw and one cycle of pressure shock (human WT and I325N) or by sonication alone (mouse WT and C103A). The GST-fusions was captured from the cleared lysate by passage over GSH-Sepharose CL4B resin (GE). For purification of human WT and I325N, the resin was washed (50 mM Tris (pH 8.8) $200 \mathrm{mM} \mathrm{NaCl}, 5 \mathrm{mM}$ DTT, $1 \mathrm{mM}$ EDTA), then the A20 
component released by overnight incubation $\left(4^{\circ} \mathrm{C}\right)$ with PreScission protease. Eluted A20 was stabilized by incubation with iodoacetamide (Sigma; $30 \mathrm{mM}, 30 \mathrm{~min}$ at RT). The reaction was terminated by addition of an equivalent amount of $\beta$-mercaptoethanol. For purification of mouse WT and C103A protein, purified GST-OTU fusion protein was eluted (50 mM Tris- $\mathrm{HCl}$ [pH 8.0], $200 \mathrm{mM} \mathrm{NaCl}, 5 \mathrm{mM}$ DTT, $10 \mathrm{mM}$ glutathione) from the column and the A20 OTU component was released by overnight incubation $\left(4^{\circ} \mathrm{C}\right)$ with PreScission protease. The cleavage products were subject to anion-exchange chromatography (HiTrap Q FF; GE) where the OTU domain eluted as a single peak between 5 and $500 \mathrm{mM} \mathrm{NaCl}, 25$ $\mathrm{mM}$ Tris- $\mathrm{HCl} \mathrm{pH}$ 7.5. All proteins were then concentrated and subject to gel filtration chromatography (ÄKTA S200 26/60, buffers as described above).

Crystals of both the A20 ${ }^{1325 \mathrm{~N}}$ variant (long triangular rods) and wild-type A20 (long rods) OTU domains, grown under the same conditions; equal volumes of protein $(2.7 \mathrm{mg} / \mathrm{mL})$ and well solution (50 mM CaCl $2,100 \mathrm{mM}$ MES ( $\mathrm{pH} 6.0$ ), 5\% PEG1500) were combined in a hanging drop setup. Crystals grew over several weeks at RT. Partial cryoprotection was achieved by briefly (1-5 seconds) swimming crystals in a solution comprising equal volumes of mother liquor and well solution doped with glycerol $(25 \% \mathrm{v} / \mathrm{v}$ final) prior to being plunge vitrified in liquid $\mathrm{N}_{2}$. For the mouse wild-type A20, crystallization was achieved by vapordiffusion in hanging-drops at a protein concentration of $8 \mathrm{mg} / \mathrm{mL}$ in $1.8-2.4 \mathrm{M} \mathrm{NaCl}, 0.1 \mathrm{M}$ MES [pH 6-6.7]. Crystals were soaked in mother liquor containing 30\% ethylene glycol for one minute and immediately vitrified in a nitrogen cryo-stream.

\section{Crystallographic data reduction and model refinement}

Diffraction data using light of wavelength $0.9537 \AA$ was collected at $100 \mathrm{~K}$ at beamline MX2 at the Australian Synchrotron. Data were indexed and integrated with MOSFLM ${ }^{65}$. The spacegroups were scrutinized with POINTLESS, and the data scaled with AIMLESS ${ }^{66,67}$, or SCALA $^{68}$ accessed via the CCP4i software interface ${ }^{69}$. Although grown under essentially the same conditions, the human WT and I325N mutant A20 proteins crystallized in different space groups. These data were highly anisotropic, resulting in poor completeness, low multiplicity, and noisy electron density maps. In the case of the mouse OTU crystal, there was significant thermal diffuse scattering. See Table 5 for data reduction and refinement statistics.

Structures were solved by molecular replacement using PHASER ${ }^{70}$. The search model was the A-chain of PDB entry 3DKB, but stripped of surface loops that displayed conformational variability in other PDB entries (2VFJ and 3ZJD). In the case of the human $\mathrm{I} 325 \mathrm{~N}$ data the structure was originally solved in the space-group P $3{ }_{1} 2$ with 4 molecules in the asymmetric unit. However, crystal packing and residual unaccounted-for electron density suggested more molecules might be present. The structure was subsequently solved in the lower symmetry $\mathrm{P} 3_{1}$ space group, with 6 molecules in the asymmetric unit, sensible packing and no unaccounted-for density. The human wild-type A20 structure, solved as a control for the iodoactamide alkylation, also has 6 molecules (three dimers) in a different asymmetric unit and space group. The mouse OTU structure was indexed and refined in the $\mathrm{P} 3{ }_{2}$ space group, with a dimer in the asymmetric unit. Restrained B-factor refinement, using local noncrystallographic symmetry (NCS) restraints, was performed with REFMAC $5^{71}$. For the mouse A20 OTU structure TLS and restrained refinement was carried out using phenix.refine ${ }^{72}$. Between rounds of refinement, electron density maps and composite OMIT maps $^{73}$ and their fit to the model were examined using COOT $^{74}$. Amino acid side chains were added/subtracted if suggested by difference map electron density. The active-site cysteine (C103) was clearly identified through inspection of mFo-Dfc difference maps as the only cysteine residue alkylated by the iodoacetamide treatment in both human structures (PDB residue descriptor YCM). All 6 molecules refined in each structure are highly similar in fold, 
1001

1002

1003

1004

1005

1006

1007

1008

1009

1010

1011

1012

1013

1014

1015

1016

1017

1018

1019

1020

1021

1022

1023

1024

1025

1026 both to themselves, and compared with each other. All molecules form dimers with neighboring molecules, as observed in other crystal structures. Structure validation was performed using the MOLPROBITY web server ${ }^{75}$. The final human I325N, human WT, and mouse WT structures contain Ramachandran favored/outlier components of $88.64 / 0.00 \%$, $88.13 / 2.87 \%$, and $82.13 / 7.87 \%$, respectively.

Measurement of OTU domain thermal stability

Purified A20 OTU domains $\left(0.4 \mathrm{mg} \cdot \mathrm{mL}^{-1}\right)$ were exchanged into $100 \mathrm{mM} \mathrm{NaCl}, 5 \mathrm{mM}$ dl-dithiothreitol, $20 \mathrm{mM} \mathrm{Na}_{2} \mathrm{HPO}_{4}$ (pH 7.5). Circular dichroism data were collected with a Chirascan circular dichroism spectrometer (Applied Photophysics, UK) in a $1 \mathrm{~mm}$ cuvette. The protein was heated from $20^{\circ} \mathrm{C}$ to $90^{\circ} \mathrm{C}$ at a rate of $1^{\circ} \mathrm{C} \mathrm{min}^{-1}$ while ellipticity was monitored at $220 \mathrm{~nm}$. The thermally induced unfolding of A20 OTU domains was not reversible. The unfolding of the A20 OTU domains was described by a two-state model ${ }^{76}$ (Equation 1).

\section{Equation 1}

$$
y_{o b s}=\frac{y_{n}+m_{n} T+\left(y_{u}+m_{u} T\right) \exp \left(\frac{\Delta H_{\mathrm{vH}}}{\mathrm{R}}\left(\frac{1}{\mathrm{~T}}-\frac{1}{T_{\text {trs }}}\right)\right)}{1+\exp \left(\frac{\Delta H_{\mathrm{vH}}}{\mathrm{R}}\left(\frac{1}{\mathrm{~T}}-\frac{1}{T_{\text {trs }}}\right)\right)}
$$

Where $y_{o b s}$ is the observed elipticity, $y_{n}$ and $y_{u}$ are the elipticity values observed for the native and unfolded states, respectively. The $m_{n}$ and $m_{u}$ values are the linear temperature dependencies of $y_{n}$ and $y_{u} . \Delta H_{\mathrm{vH}}$ is the apparent van't Hoff enthalpy, $\mathrm{R}$ is the universal gas constant, and $T_{\text {trs }}$ is the temperature at which the population of unfolded protein is $50 \%$. Curves were fit by non-linear regression using GraphPad Prism v6 (GraphPad Software).

\section{Statistical methods}

Results are expressed as mean $+/$ - standard error mean (SEM). Statistical analysis was performed using the Student's $t$-test or ANOVA were indicated. 


\section{Supplementary Text}

1028

1029

1030

1031

1032

1033

1034

1035

1036

1037

1038

1039

1040

1041

1042

1043

1044

1045

1046

1047

1048

1049

1050

1051

\section{Extended Figure 3 legend:}

\section{Fig.3. Subclinical inflammatory and metabolic consequences of the $I 325 \mathrm{~N}$ variant. (A)} Body weights of 8 and 12 week old Tnfaip3 ${ }^{+/+}$, Tnfaip ${ }^{1325 \mathrm{~N} /+}$, Tnfaip ${ }^{1325 \mathrm{~N} / 1325 \mathrm{~N}}$ male or female mice. (B) Representative H\&E and insulin (INS) stained pancreas sections (note pancreatitis; scale $=100 \mu \mathrm{m})$ with $(\mathbf{C})$ cumulative insulitis scores $(0=$ no evidence of inflammation; 1 = mononuclear cells present, but not infiltrating islet; $2=0-25 \%$ mononuclear cell infiltration of islet [peri-insulitis]; $3=>25 \%$ insulitis; $4=>75 \%$ insulitis) and, (D) calculated beta cell mass for Tnfaip $3^{+/+}$and Tnfaip $3^{\mathrm{I} 325 \mathrm{~N} / 1325 \mathrm{~N}}$ mice. (E) Heat map depicting mRNA levels for islet early-immediate pro-inflammatory factors ${ }^{77}$ measured by RT-qPCR from islets isolated from individual mice and treated with TNF $\alpha$ for the indicated times. Values normalised against $0 \mathrm{~h} \mathrm{Tnfaip3^{+/+ }}$ islets. Data represents 3 independent islet preparations with 3-4 biological replicates. (F) Islets isolated of the indicated genotypes were transplanted under the kidney capsule of syngeneic diabetic Tnfaip $3^{+/+}$recipients. When euglycemia was established comparably by mutant or wild-type islets (see Extended Data Fig. 12A), a glucose tolerance test was conducted. Following an overnight fast, recipients received $2 \mathrm{~g} / \mathrm{kg}$ glucose (i.p.) and blood glucose monitored over time (min). Mean area under the curve was used for statistical comparison to wild-type. (G) At post-operative day 30, islet grafts were removed and analysed by H\&E staining (scale bar $=50 \mu \mathrm{m}$ ) with the fraction of islet grafts of each genotype exhibiting immune infiltrate shown below. (H) Islet grafts isolated on post-operative day 10 were analysed for indicated mRNAs by RT-qPCR. Gene expression was calculated using the average wild-type $\Delta \mathrm{Ct}$ value with each data point representing an individual graft. $\mathrm{P}$ values represent Student's $t$-test unless otherwise stated $* P$ $<0.05 ; * * P<0.01 ; * * * * P<0.0001$. 
bioRxiv preprint doi: https://doi.org/10.1101/589507; this version posted March 27, 2019. The copyright holder for this preprint (which was not

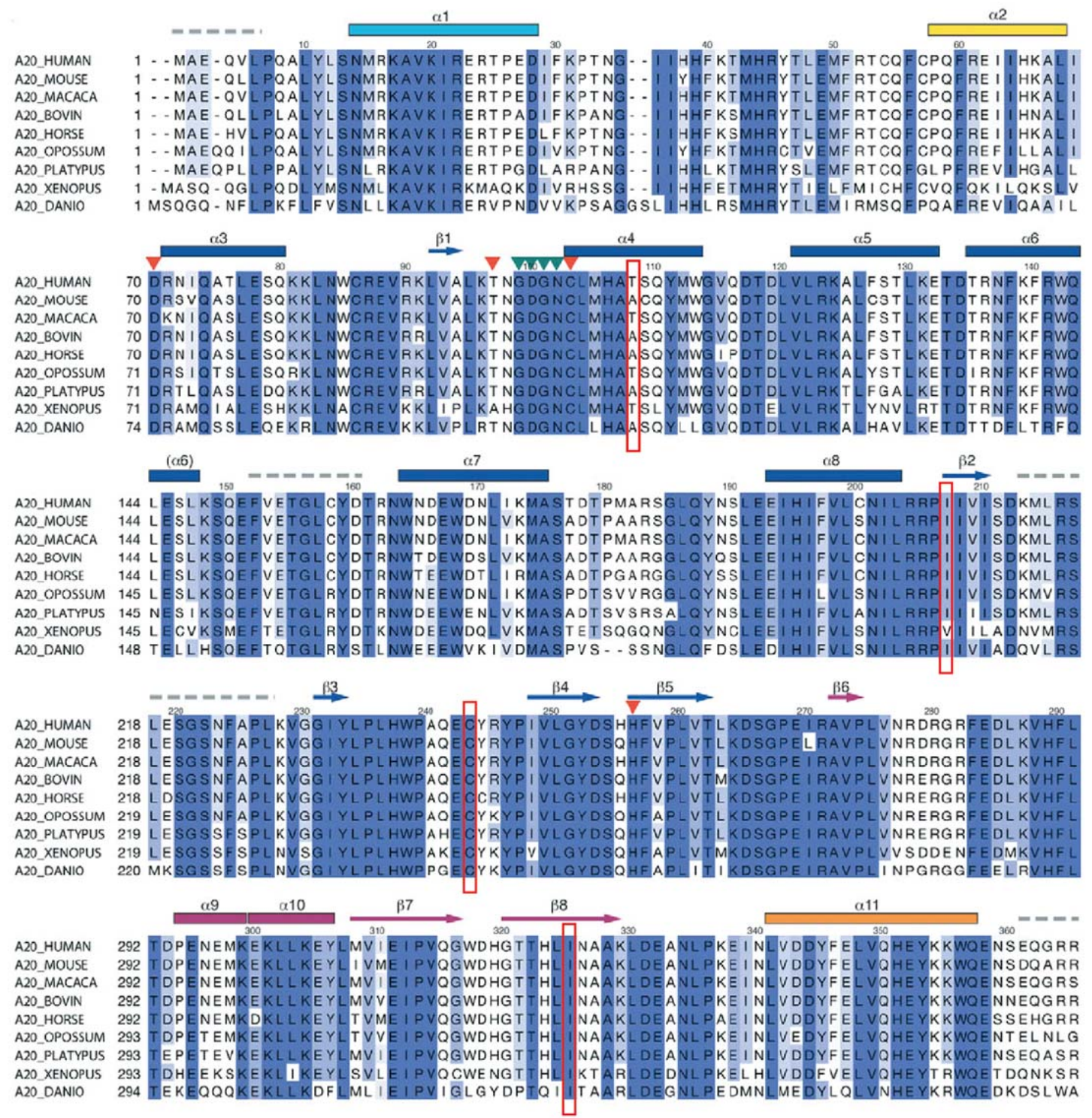

1055 Extended Data Fig. 1.

1056 Evolutionary conservation of I207, C243 and $\mathbf{I 3 2 5}$ positions in A20 protein amongst

1057 jawed vertebrates. Aligned amino acid sequence and secondary structure elements of the 1058 A20 OTU domain, from ${ }^{40}$. T108, I207, C243 and I325 residues are boxed in red. 
A

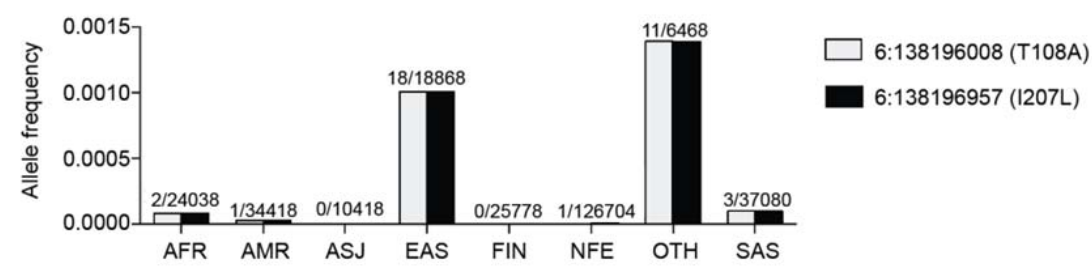

B

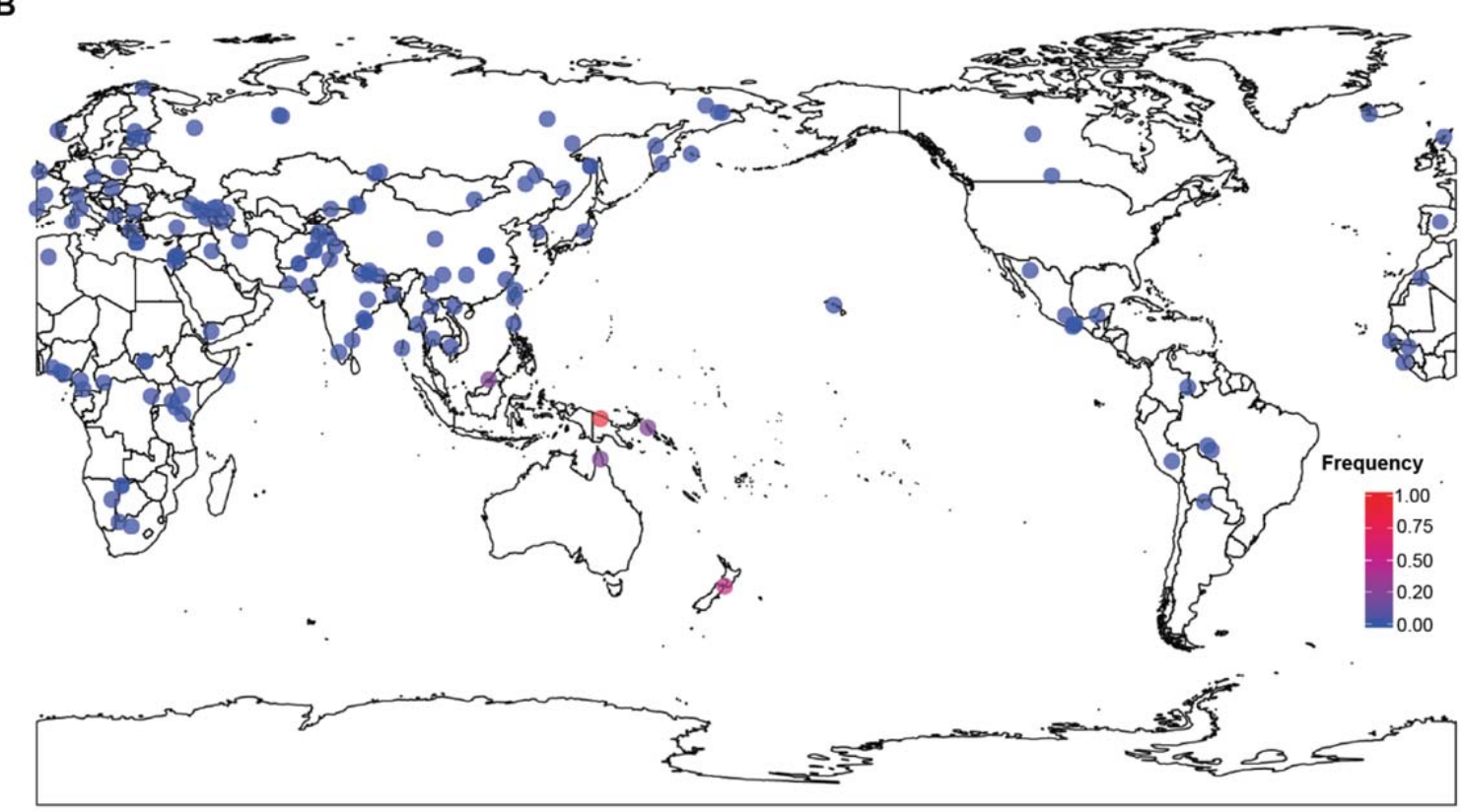

1059

\section{Extended Data Fig. 2.}

1061 Global distribution of the T108A;I207L TNFAIP3 haplotype. (A) gnomAD r2.0.2

1062 population allele frequencies for the T108A and I207L missense variants in TNFAIP3, with

1063 allele counts above each bar (total as denominator). Populations are defined by principal

1064 component clustering of samples with individuals of known ancestry: those which do not

1065 cluster fall into the OTH group. AFR, African; AMR, Latino; ASJ, Ashkenazi Jew; EAS,

1066 East Asian; FIN, Finnish European; NFE, non-Finnish European; OTH, other; SAS, South

1067 Asian. The OTH population includes one homozygote, while all other alleles are

1068 heterozygous. (B) Frequency of the T108A;I207L TNFAIP3 haplotype within 279 individual

1069 genomes from the Simons Genome Diversity Project ${ }^{22}$. 
A
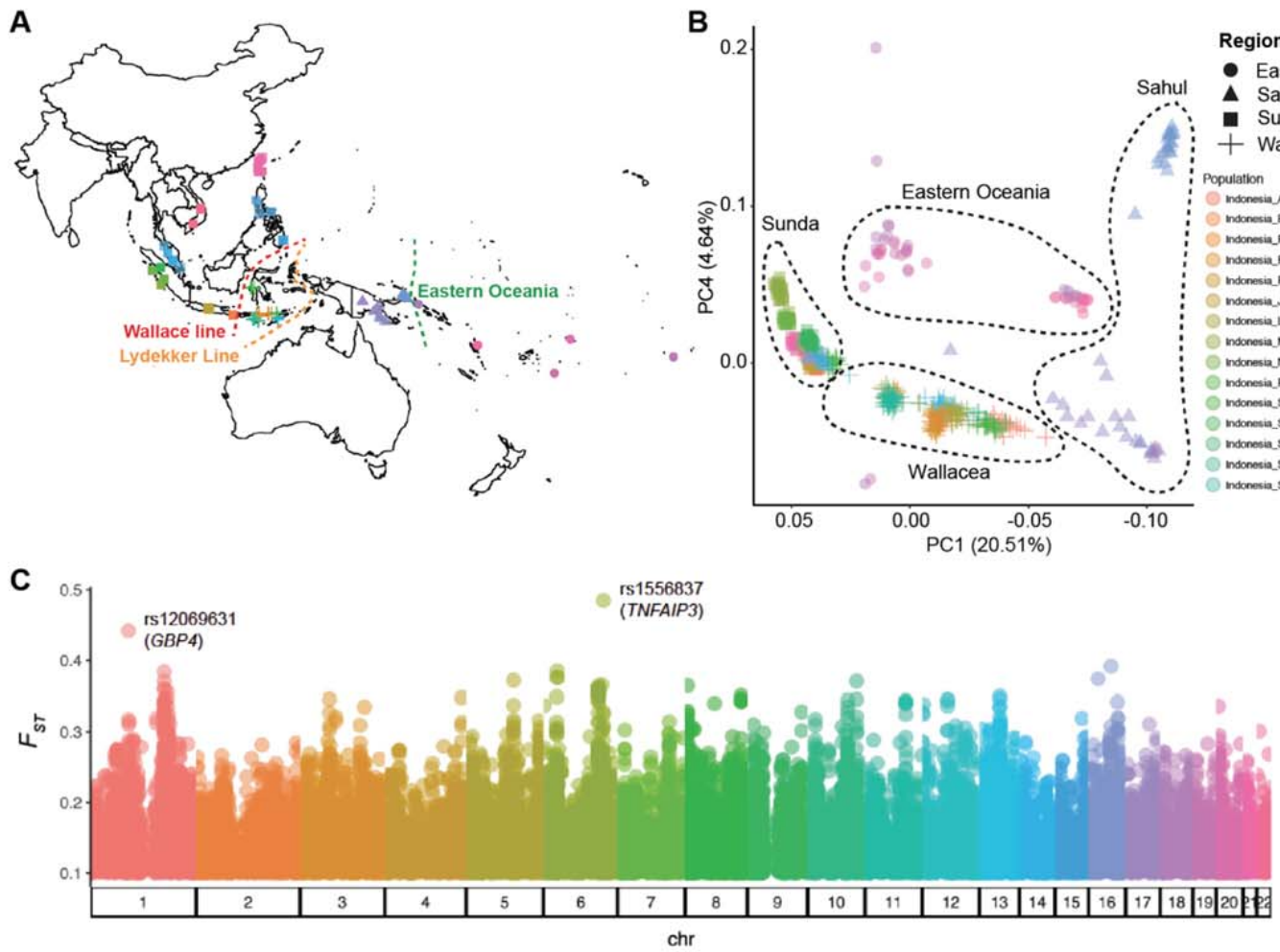

D

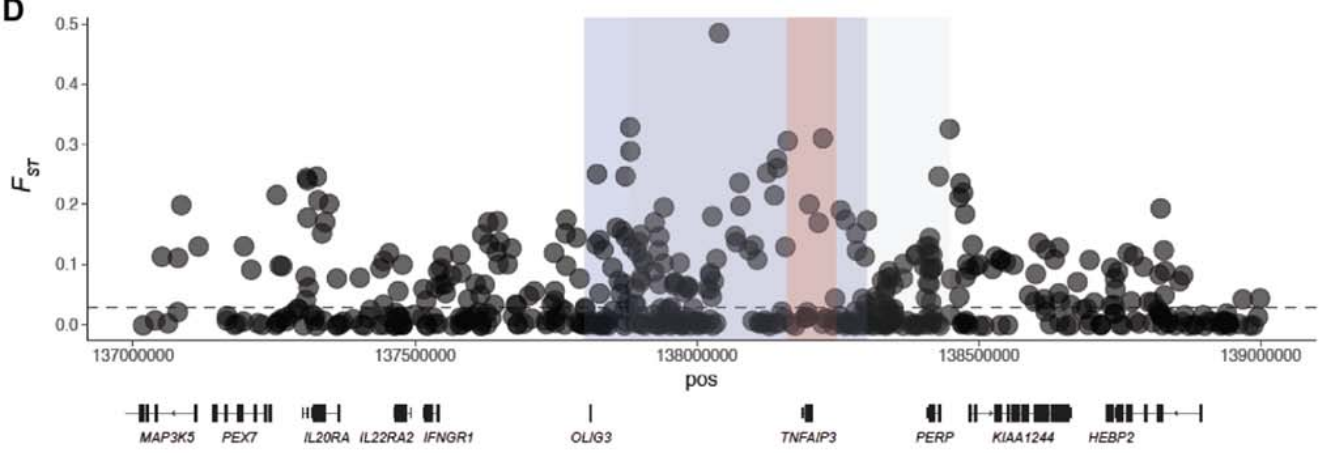

E

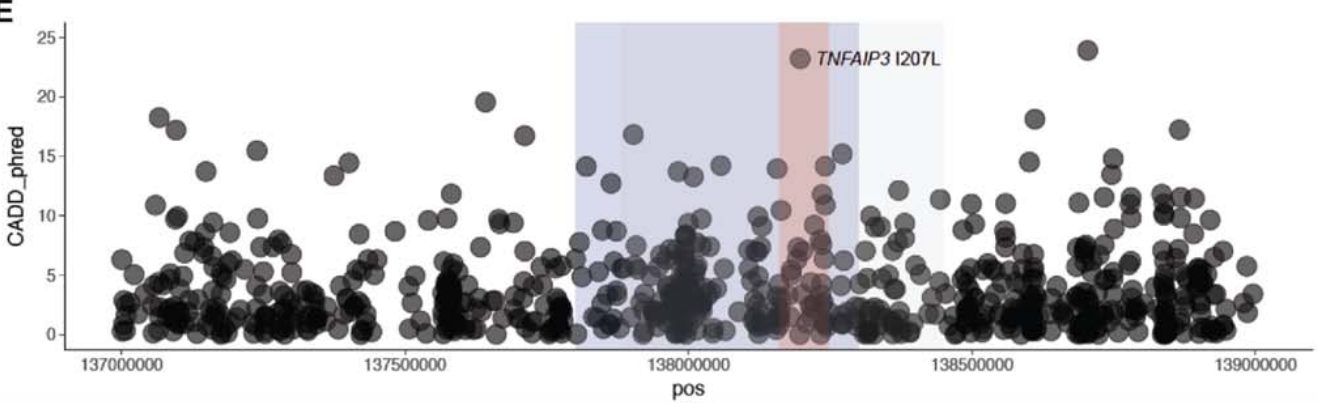

1070

\section{Extended Data Fig. 3.}

1072 Population genetics of the Denisovan TNFAIP3 haplotype. (A) Geographic distribution of samples used for population genetic analyses. Wallace Line (red) ${ }^{31}$, Lydekker Line (yellow). Eastern Oceania is defined here as islands east of the Bismarck Archipelago (green line). (B) Principal component analysis (PCA), with the proportion of variance explained by each PC indicated on each axis (C) Genome-wide $F_{S T}$ values between indigenous populations east and 
1078 TNFAIP3 locus. Shaded regions correspond to peak $\mathrm{F}_{\mathrm{ST}}$ values between populations east and 1079 west of the Wallace Line (grey, 6:137881500-138448062), a previously described haplotype 1080 of elevated Denisovan ancestry in Oceanians (blue, 6:137800000-138300000, ${ }^{25}$ ), and a 1081 putatively adaptively introgressed haplotype in Papuans (red, 6:138160925-138246514, ${ }^{29}$ ). 1082 (E) Phred-scaled CADD scores of all PASS variants with gnomAD allele frequency $<0.01$

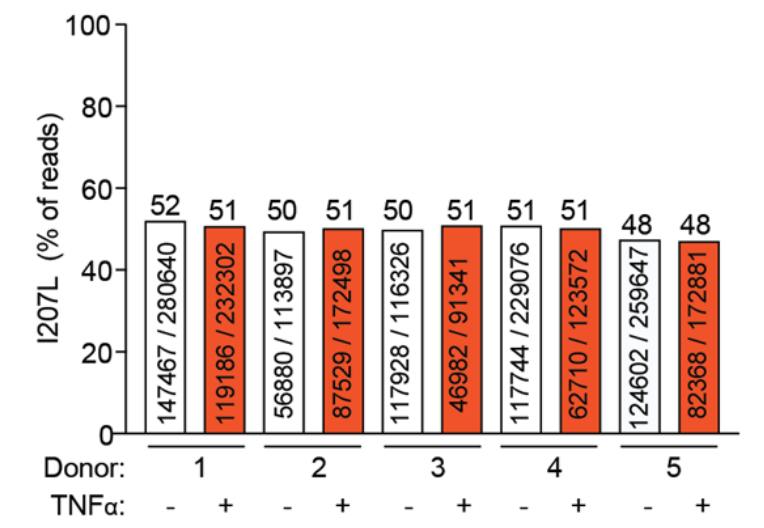

1090

1091 Extended Data Fig. 4.

1092 Relative abundance of Denisovan and modern human TNFAIP3 mRNA from 1093 heterozygous leukocytes. Peripheral blood mononuclear cells from five healthy 1094 T108A;I207L heterozygous donors were cultured with (+) or without (-) TNF $\alpha$ for 2 hours, 1095 mRNA isolated and converted to cDNA and amplified with primers in exon 3 and 4 on either 1096 side of the 1207 codon. The products were deep sequenced on an Illumina MiSeq. Shown are 1097 the fraction and percentage of reads derived from the T108A;I207L Denisovan allele. 
bioRxiv preprint doi: https://doi.org/10.1101/589507; this version posted March 27, 2019. The copyright holder for this preprint (which was not certified by peer review) is the author/funder, who has granted bioRxiv a license to display the preprint in perpetuity. It is made available under aCC-BY 4.0 International license.

A
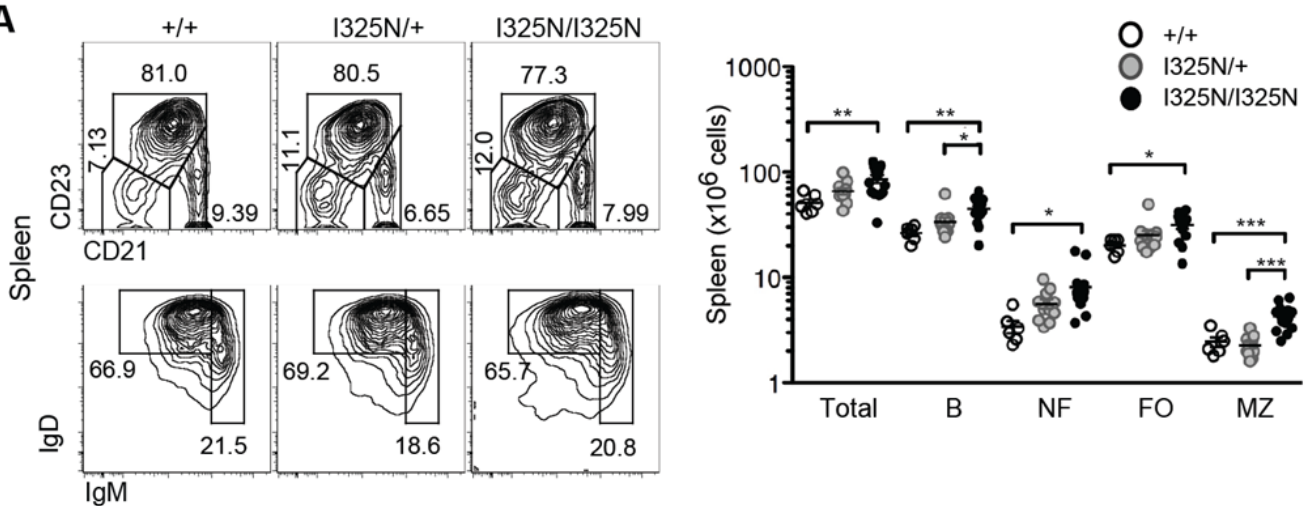

B

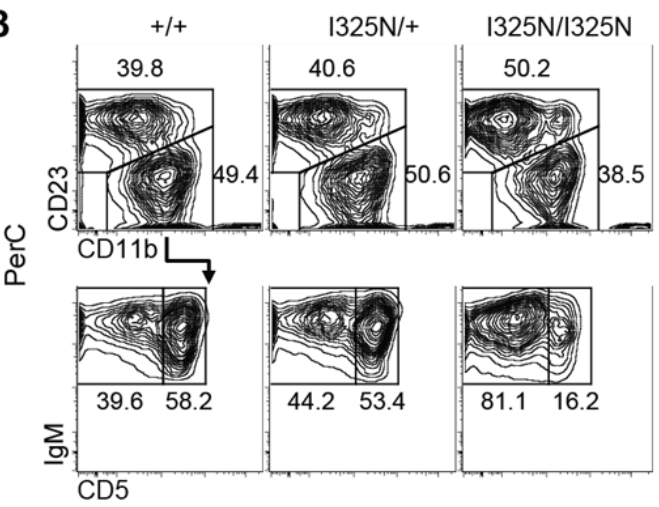

C

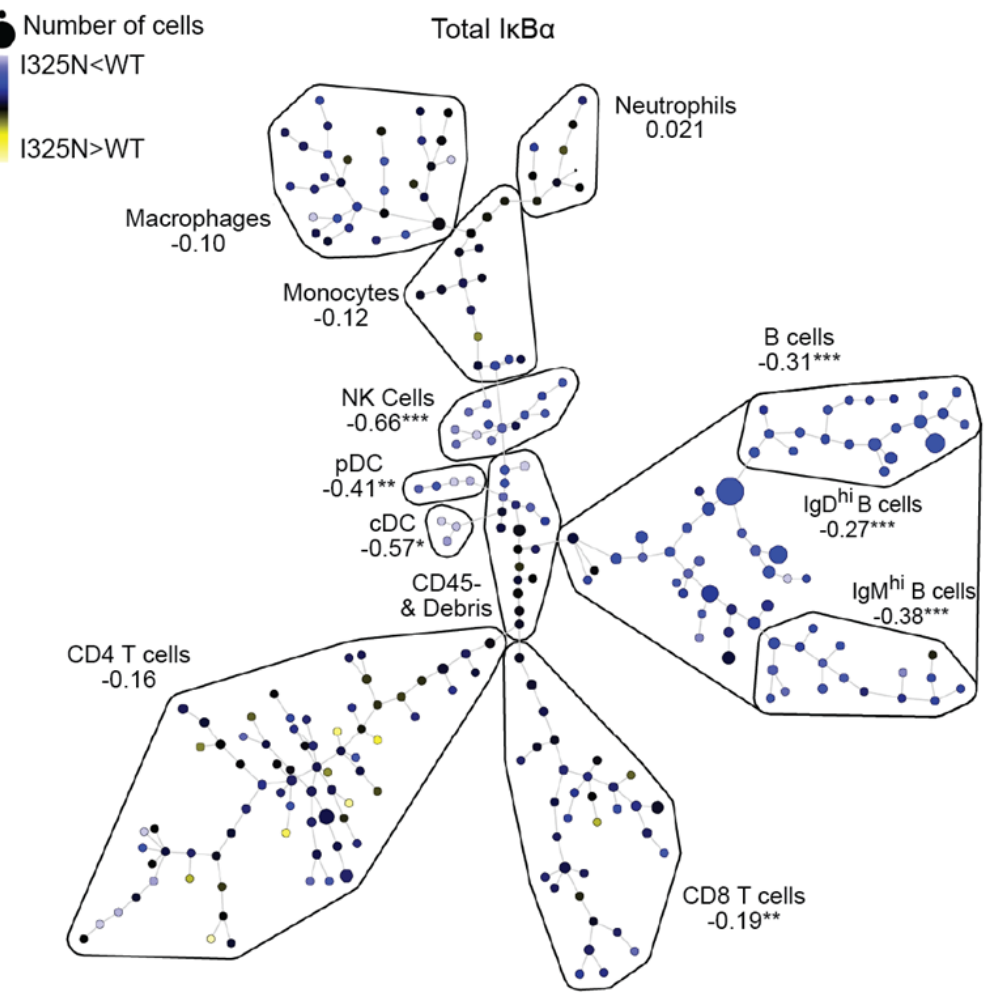

1098

1099

\section{Extended Data Fig. 5.}


1100 B cell lymphocytosis induced by the Tnfaip $3^{\text {I325N }}$ mutation. (A) Representative flow

1101 cytometry plots from mice of the indicated genotypes showing total frequency of splenic

$1102 \mathrm{CD}_{2} 3^{+}$and $\mathrm{CD} 21^{+}$positive cells (top panel). The bottom panel shows cells subsetted into

$1103 \mathrm{IgD}^{+}$and $\operatorname{IgM}^{+} \mathrm{B}$ cells. Note that the number of splenocyte $\mathrm{B}$ cell subsets is increased in

1104 Tnfaip3 ${ }^{1325 \mathrm{~N} / 1325 \mathrm{~N}}$ mice, shown to the right. (B) Representative flow cytometry plots from mice

1105 of the indicated genotypes showing the frequency of $\mathrm{CD} 23^{+}$and $\mathrm{CD} 21^{+}$positive cells in the

1106 peritoneal cavity (top panel). The bottom panel shows frequency of $\operatorname{IgM}^{+}$and $\mathrm{CD} 45^{+} \mathrm{B}$ cells.

1107 Number of peritoneal cavity B cell subsets in mice of indicated genotypes is shown in Fig.

1108 2B. (C) CYTOF analysis of intracellular I $\mathrm{CB} \alpha$ in immune cells. Unstimulated spleen cells

1109 from Tnfaip3 ${ }^{+/+}$or Tnfaip $3^{\mathrm{I} 325 \mathrm{~N} / 1325 \mathrm{~N}}$ mice $(n=4$ per genotype) were individually labeled with

1110 mass-barcodes, mixed, permeabilized and stained with mass-labeled antibodies to a panel of

1111 cell surface markers and intracellular proteins including $\mathrm{I} \kappa \mathrm{B} \alpha$, and analyzed by CYTOF mass

1112 spectrometry ${ }^{59,60}$. Spanning-tree Progression Analysis of Density-normalized Events

1113 (SPADE; ${ }^{61}$ ) analysis was used to resolve leukocyte lineages and subsets, and the relative

1114 intensity of I $\kappa \mathrm{B} \alpha$ in each subset was compared between Tnfaip $3^{\mathrm{I} 25 \mathrm{~N} / 1325 \mathrm{~N}}$ and wild-type cell

1115 counterparts. Shown by color and numbers is the mean hyperbolic arcsine (arcsinh) ratio in

1116 minor and major leukocyte subsets. Note that $\mathrm{I} \kappa \mathrm{B} \alpha$ levels are reduced in B cell subsets

1117 indicating increased NF- $\mathrm{BB}$ activation. Significant differences indicated by Student's $t$-test

1118 comparison of major subsets are marked: ${ }^{*} P<0.05 ; * * P<0.01 ; * * * P<0.001$. 

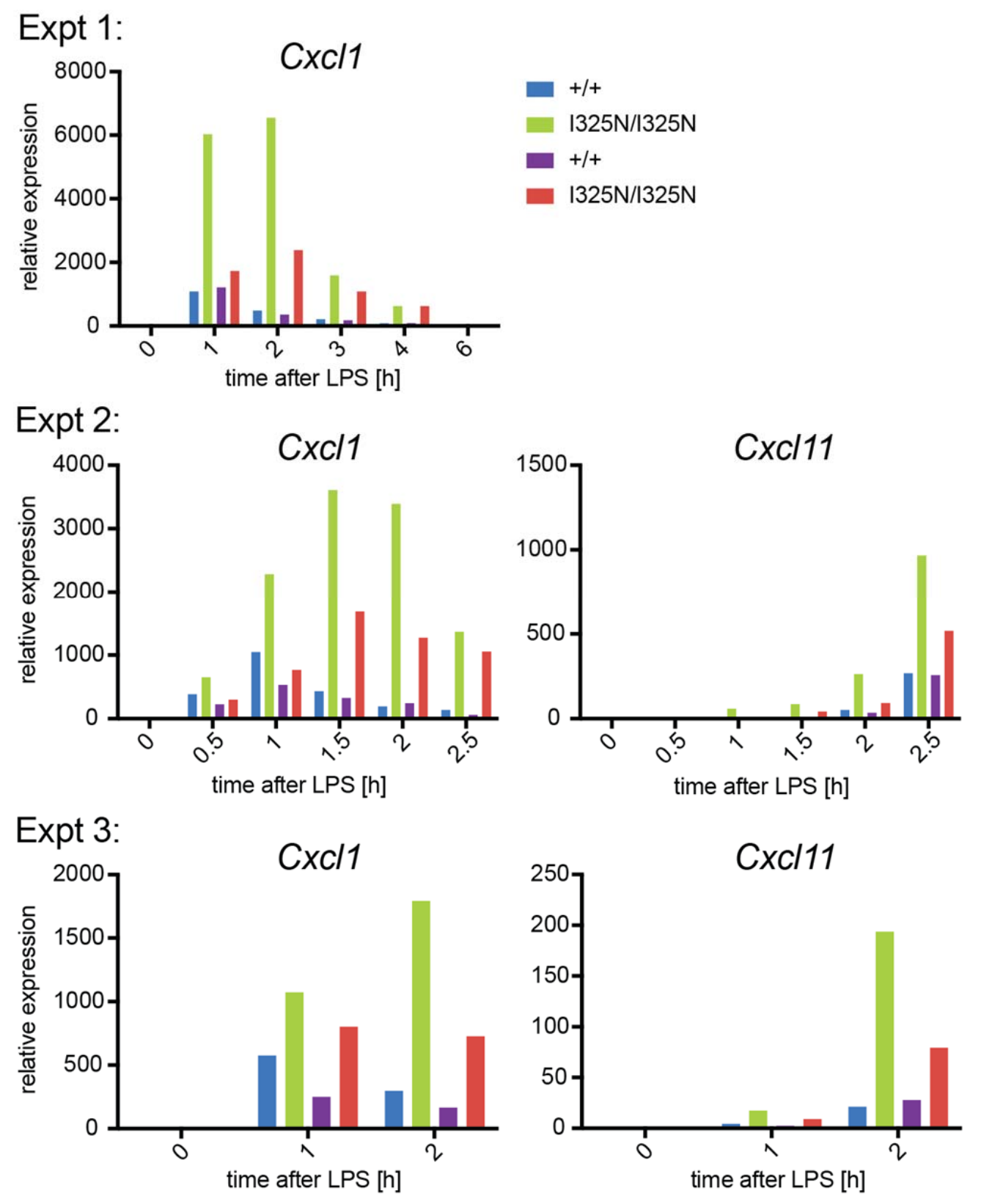

1119

\section{Extended Data Fig. 6.}

1121 Exaggerated cytokine production by bone marrow-derived macrophages with the

1122 Tnfaip3 ${ }^{\mathbf{I 3 2 5 N}}$ mutation. Bone marrow macrophages derived from conditionally Hoxb8-

1123 immortalized bone marrow progenitor cells were derived from two separate pairs of wild-

1124 type and I325N homozygous mice, stimulated with LPS (10ng/ml) for the indicated times,

1125 and Cxcl1 or Cxcl11 mRNA determined by qPCR relative to Ef1a expression. Data are

1126 shown from three independent experiments, each with two different mouse donors of each

1127 genotype. 
A

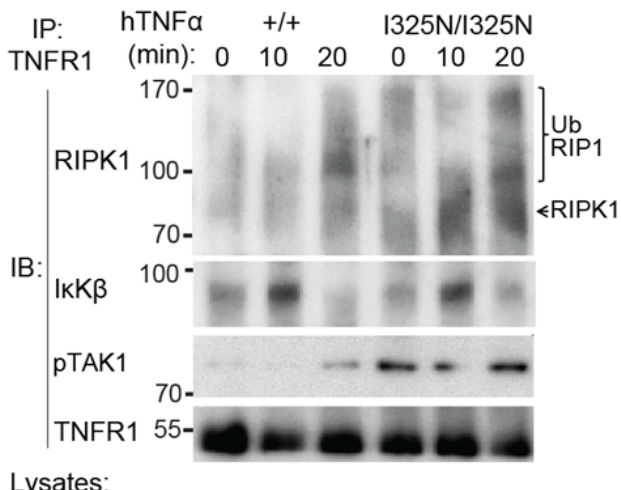

Lysates:

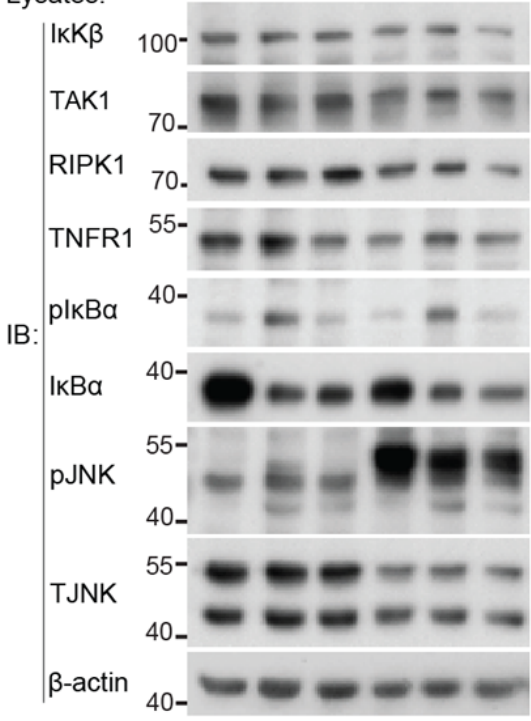

B

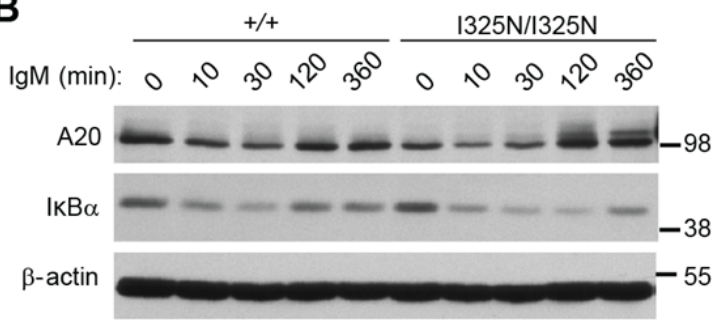

C

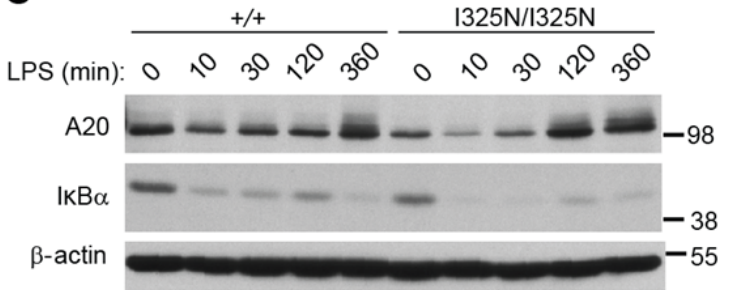

\section{Extended Data Fig. 7.}

1130 Prolonged NF- $\kappa$ B signaling in thymocytes and B cells extracted from $\mathbf{I 3 2 5 N}$ variant

1131 C57BL/6 mice. (A) Representative immunoblot analysis (IB; $n=3$ independent experiments)

1132 of canonical NF- $\kappa$ B components following immunoprecipitation (IP) of TNFR1 from lysates

1133 of Tnfaip3 $^{+/+}$or Tnfaip3 $3^{\mathrm{I325N/1325N}}$ thymocytes treated with $200 \mathrm{U} / \mathrm{ml}$ hTNFa for the indicated

1134

1135

1136

1137

1138

1139

1140

1141

1142 times. Following TNF $\alpha$ stimulation RIPK1 was recruited to the TNFR1 complex, with increased high molecular weight polyubiquitinated forms of RIPK1 (UbRIP1) and autophosphorylated transforming growth factor $\beta$ activated kinase- $1\left[\mathrm{TAK}^{78}\right]$ in $\mathrm{A} 20^{1325 \mathrm{~N} / 1325 \mathrm{~N}}$ thymocytes (A). Mutant thymocytes exhibited a modest increase in I $\mathrm{B} \alpha \alpha$ degradation relative to wild-type, and increased JNK phosphorylation (Lysate blots). A similar pattern of enhanced TAK1 activation and JNK phosphorylation was seen in murine embryonic fibroblasts and bone marrow derived macrophages expressing catalytically dead A20 OTU or ZnF4 mutants ${ }^{18}$. (B, C) Wild-type (+/+) and I325N homozygous (I325N/I325N) Tnfaip3 splenic B lymphocytes were stimulated for the indicated times with anti-IgM (B), or lipopolysaccharide (LPS) (C) and lysates analyzed by immunoblotting for A20, IкB $\alpha$ and $\beta$ actin (loading control). As observed for mutant thymocytes, B cells exhibited a modest

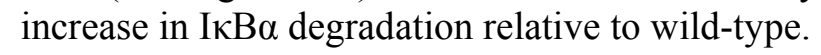


1146

\section{7}

1148

1149

1150

1151

1152

1153

1154

1155

1156

1157

1158

1159

1160

1161

1162

1163

1164

1165

1166

1167

1168

1169

1170

1171

1172
A

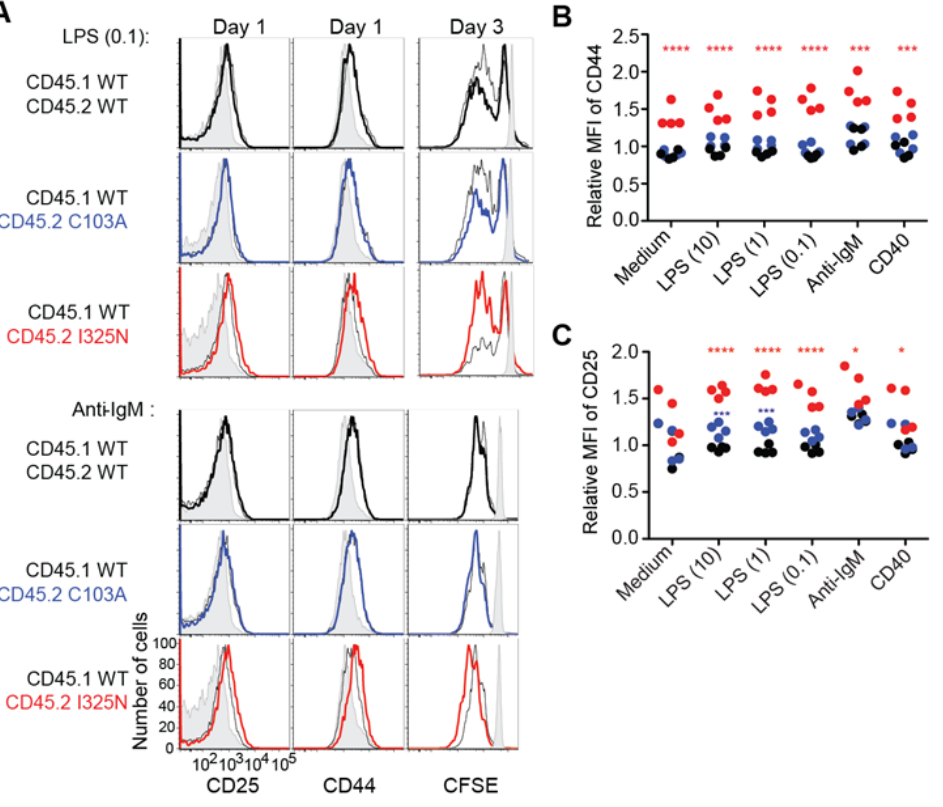

\section{Extended Data Fig. 8.}

D

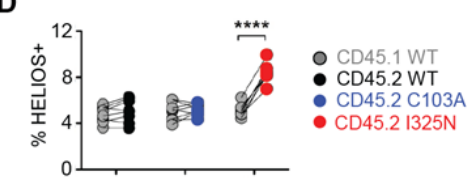

E

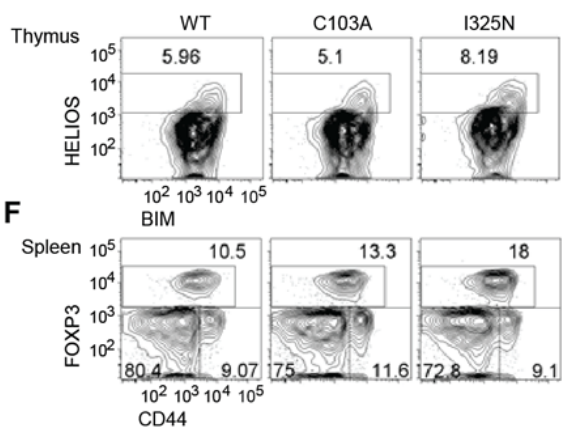

Cell autonomous exaggeration of $B$ cell activation and Treg formation by Tnfaip3 I325N more than C103A mutations. B6.CD45. $1^{+}$wild-type mice were transplanted with a congenic bone marrow mixture from Tnfaip ${ }^{+/+} \mathrm{CD} 45.1^{+}$donors, to provide wild-type lymphocytes as an internal control, and CD $45.2^{+}$donors of Tnfaip $3^{I 325 N / / 325 N}$, Tnfaip3 $^{\text {C103A/C103A }}$ or Tnfaip3 ${ }^{+/+}$genotypes. (A) Representative flow cytometric histograms of CD25 and CD44 expression on B cells from chimeric mice cultured for 1 day and CFSE dilution after 3 days with $0.1 \mathrm{ug} / \mathrm{ml}$ LPS or anti-IgM. Black or colored histograms, CD $45.2^{+}$ B cells of the indicated Tnfaip3 genotype; grey line unfilled histograms, CD $45.1^{+}$control B cells in the same stimulated culture; grey filled histograms, B cells in a parallel unstimulated culture. $(\mathbf{B}, \mathbf{C})$ Data from independent mixed chimeric animals showing relative mean fluorescence intensity (MFI) of CD25 or CD44 on CD45.2 ${ }^{+} \mathrm{B}$ cells of the indicated genotypes (red, I325N; blue, C103A; black, WT) compared to the co-cultured CD45. ${ }^{+}$wildtype B cells. Statistical analysis by ANOVA: ${ }^{*} P<0.05 ; * * P<0.01 ; * * * P<0.001 ; * * * * P<$ 0.0001 . Figure $2 \mathrm{C}$ shows the percentage of $\mathrm{CD} 45.2^{+}$cells of the indicated genotypes among viable $\mathrm{B}$ cells, relative to starting percentage, in cultures from individual mixed chimera donors stimulated with $0.1 \mathrm{ug} / \mathrm{ml}$ LPS. (D) Pairwise comparison of percent HELIOS ${ }^{+}$cells among the indicated $\mathrm{CD} 45.2^{+}$and $\mathrm{CD} 45.1^{+}$subsets of $\mathrm{CD} 4^{+} \mathrm{CD} 8^{-} \mathrm{CCR} 7^{+} \mathrm{CD} 24^{+} \mathrm{FOXP}^{-}$ thymocytes from the same chimera. Analysis by paired Student's $t$-test; $* * * * P<0.0001$. Compared to the $\mathrm{C} 103 \mathrm{~A}$ mutation, the $\mathrm{I} 325 \mathrm{~N}$ mutation exaggerated thymic formation of $\mathrm{FOXP}^{+} \mathrm{CD}^{+}$cells and their Helios ${ }^{+} \mathrm{FOXP}^{-}$precursors, which depend on TCR signaling through CARD11 to NF- $\kappa B$. (E, F) Representative profiles gated on CD45. $2^{+}$cells of the indicated Tnfaip3 genotypes. (E) Analysis of $\mathrm{CD} 4^{+} \mathrm{CD} 8^{-} \mathrm{CCR} 7^{+} \mathrm{CD} 24^{+} \mathrm{FOXP} 3^{-}$thymocytes, showing the percentage of immature medullary CD4 $\mathrm{T}$ cells induced by strong self-reactivity to express high levels of HELIOS and BIM. (F) Percentage of FOXP3 ${ }^{+} \mathrm{CD}_{4} 4^{+}$cells among $\mathrm{CD} 4^{+}$splenic T cells. 

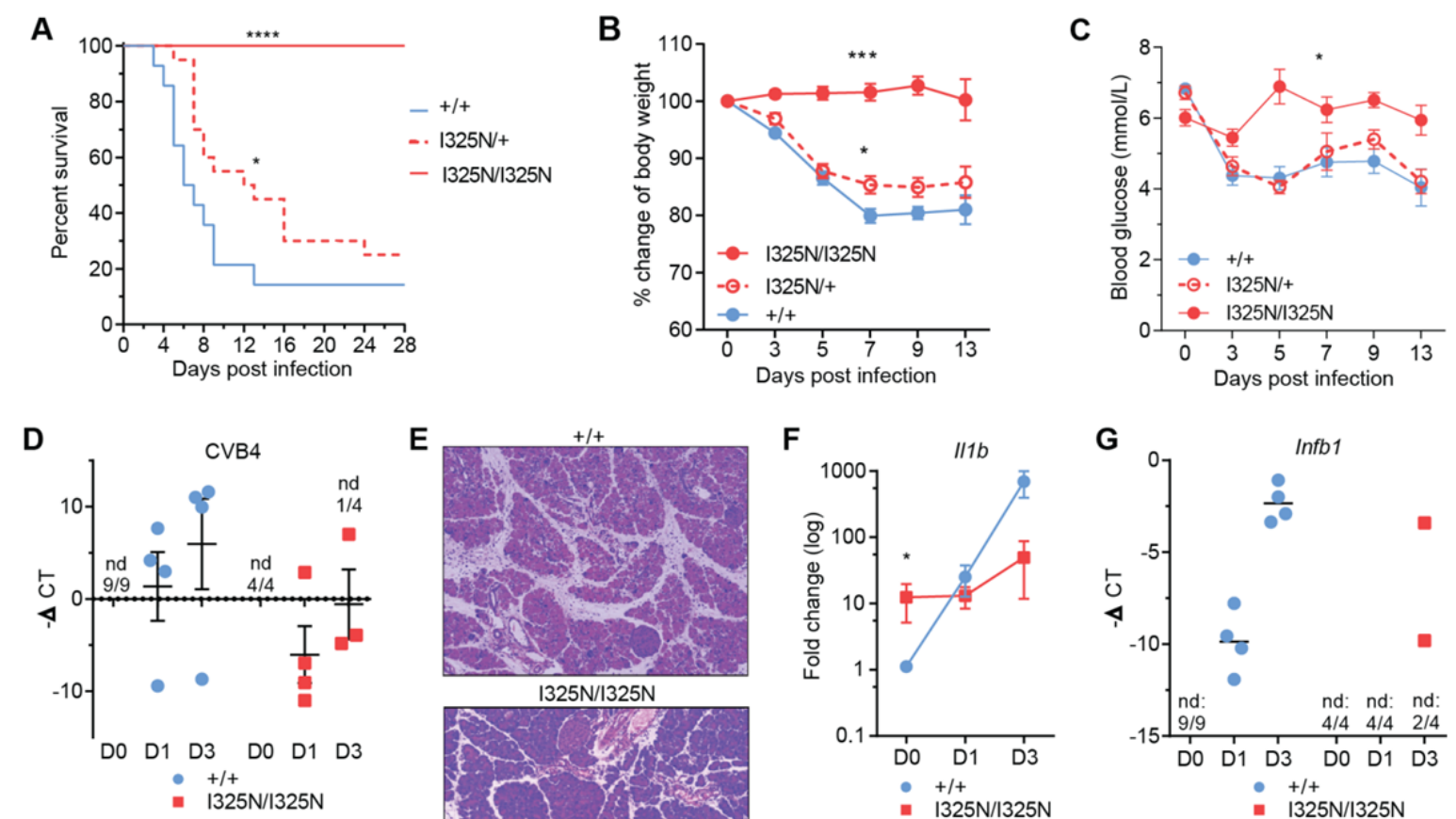

1173
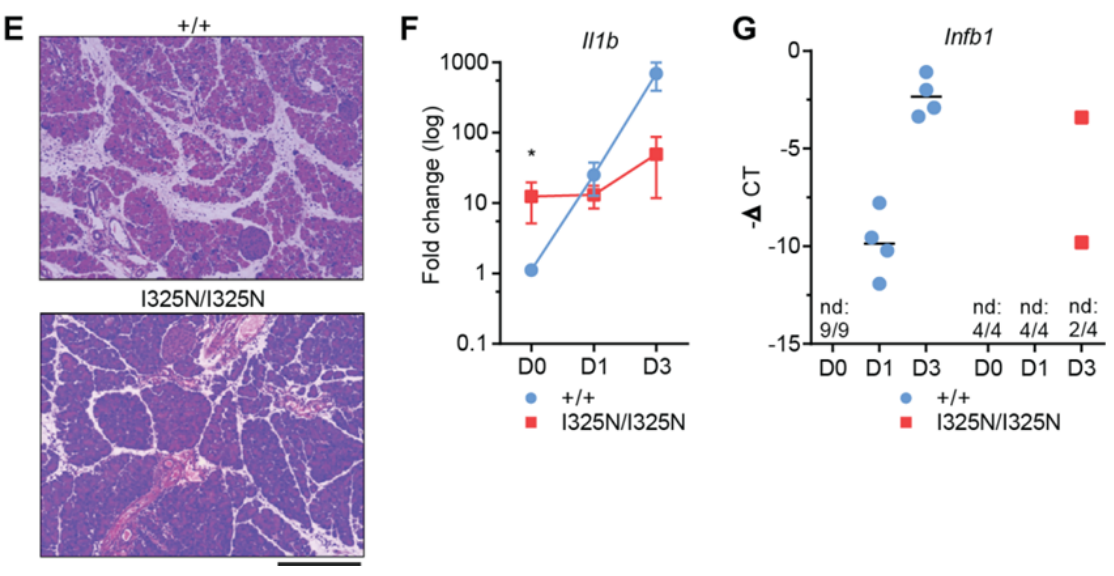

\section{Extended Data Fig. 9.}

1175 Increased resistance to Coxsackievirus B4 in A20 I325N mice. Infection of C57BL/6 male

1176 mice of the indicated Tnfaip3 genotypes with 20 plaque forming units (PFU) of

1177 Coxsackievirus B4 (CVB4) E2 strain by intraperitoneal injection. (A) Kaplan-Meier survival

1178 curve showing a mean survival time of 6.5 and 12.5 days for Tnfaip3 ${ }^{+/+}$and Tnfaip $3^{+/ 1325 \mathrm{~N}}$

1179 mice, respectively. No Tnfaip3 $3^{\mathrm{I} 25 \mathrm{~N} / 1325 \mathrm{~N}}$ mice succumbed to infection. Significance

1180 determined by Log-rank test. (B) Percent change in body weight after CVB4 infection and

1181 (C) Blood glucose levels of mice with indicated Tnfaip3 genotype, compared to wild-type by

1182 area under the curve analysis. (D) CVB4 mRNA abundance on indicated days (D0-3) post

1183 infection. (E) Hematoxylin \& eosin stained sections of pancreas from Tnfaip3 ${ }^{+/+}$and

1184 Tnfaip3 ${ }^{1325 \mathrm{~N} / 1325 \mathrm{~N}}$ mice at post-infection day 9 . Note better preserved pancreatic architecture in

1185 Tnfaip3 $3^{\mathrm{I} 325 \mathrm{~N} / 1325 \mathrm{~N}}$ mice. Scale bar $=200 \mu \mathrm{m}$. (F, G) RTPCR analysis for inflammatory genes

$1186 I I 1 b(\mathrm{~F})$ or $\operatorname{Infb1}(\mathrm{G})$ at post-infection day 0,1 and 3. Error bars represent SEM and Student $t-$

1187 test used for significance analysis unless otherwise stated, $* P<0.05 ; * * * P<0.001$. 
A

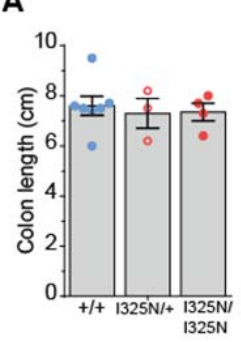

B

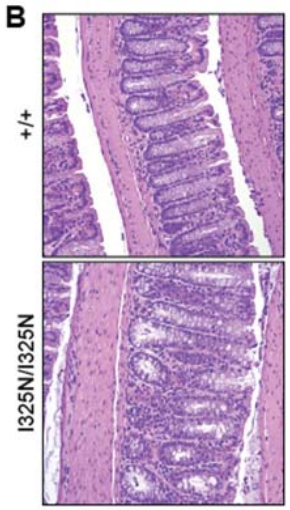

D

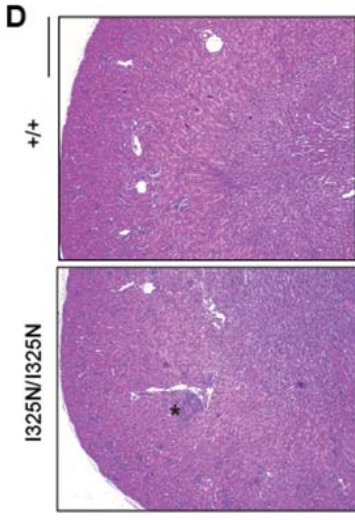

$\mathbf{F}$

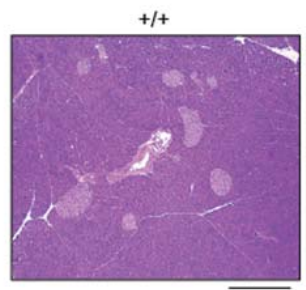

G

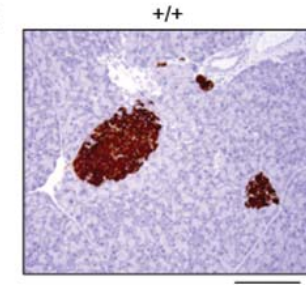

$1325 \mathrm{~N} / 325 \mathrm{~N}$

$1325 \mathrm{~N} / 325 \mathrm{~N}$
$C_{+/+}$
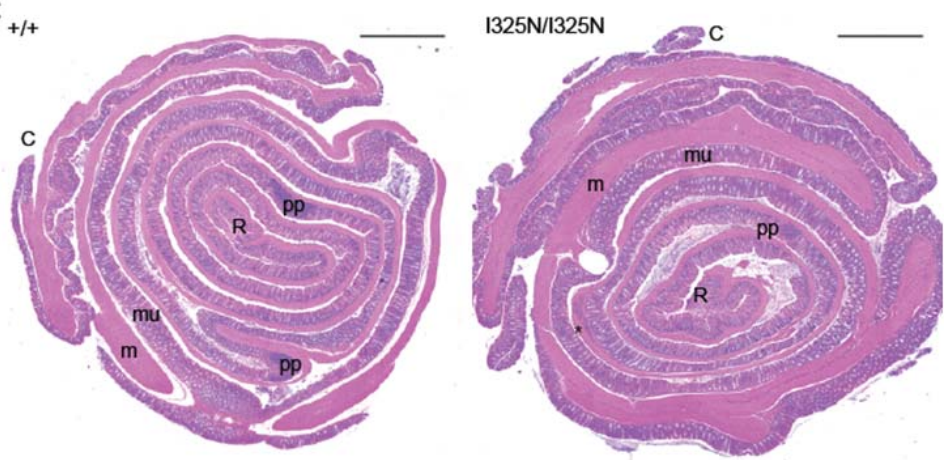

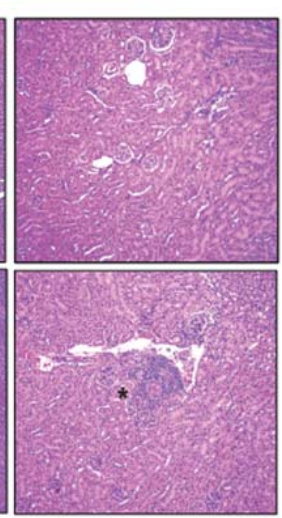

E
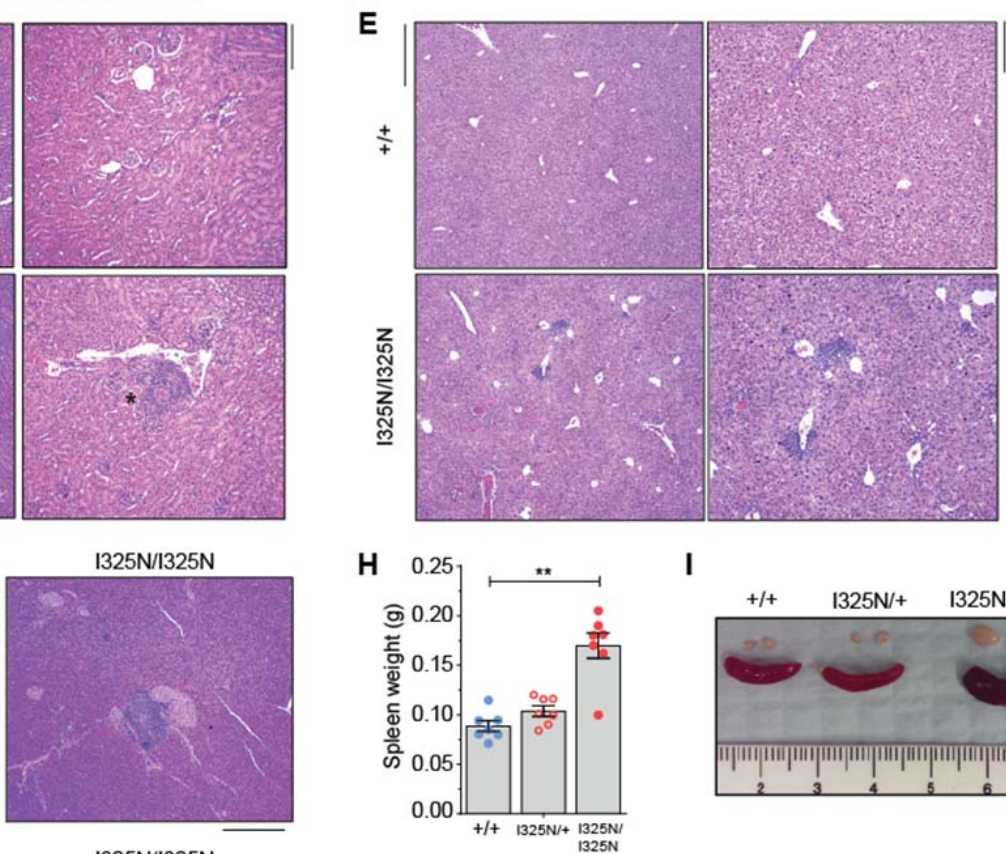

I

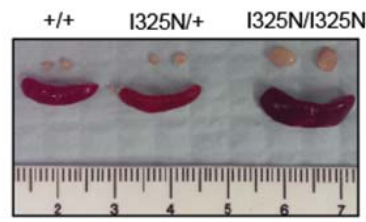

\section{Extended Data Fig. 10.}

1190 Histological analysis of tissues from $\mathbf{A 2 0}{ }^{\mathbf{I 3 2 5}}$ mice. (A) Colon length (cm) and (B)

1191 Hematoxylin and eosin (H\&E) stained sections from Tnfaip3 $3^{+/+}$and Tnfaip3 ${ }^{1325 \mathrm{~N} / 1325 \mathrm{~N}}$ mice colon $(20 \mathrm{X}$ magnification; scale bar $=200 \mu \mathrm{m})$ and $(\mathbf{C})$ power-mosaic image of whole colon cross section ( $\mathrm{R}=$ rectum; $\mathrm{C}=$ Caecum; $\mathrm{m}=$ muscularis; $\mathrm{mu}=$ mucosa; $\mathrm{p}=$ =Peyer's patches; scale $=1 \mathrm{~mm}$ ). (D) H\&E sections of kidney (4X left images, scale bar $=500 \mu \mathrm{m} ; 10 \mathrm{X}$ right images, scale bar $=200 \mu \mathrm{m})$ and $(\mathbf{E})$ liver $(4 \mathrm{X}$ left images, scale bar $=500 \mu \mathrm{m} ; 10 \mathrm{X}$ right images, scale bar $=200 \mu \mathrm{m})$. (F) H\&E stained sections of pancreas $(10 \mathrm{X}$ images, scale bar $=$ $200 \mu \mathrm{m})$ or, (G) insulin stained sections $(20 \mathrm{X}$ images, scale bar $=100 \mu \mathrm{m})$. (H) Weight of spleens in grams (g). (I) Gross appearance of spleen and salivary glands from Tnfaip $3^{+/+}$and Tnfaip $3^{\mathrm{I} 225 \mathrm{~N} / 1325 \mathrm{~N}}$ mice. Images are representative from $n=4$ Tnfaip $3^{+/+}$and $n=4$ Tnfaip ${ }^{1325 N / 325 \mathrm{~N}} 16$ week old mice. Error bars represent SEM, ${ }^{* * P}<0.01$. 

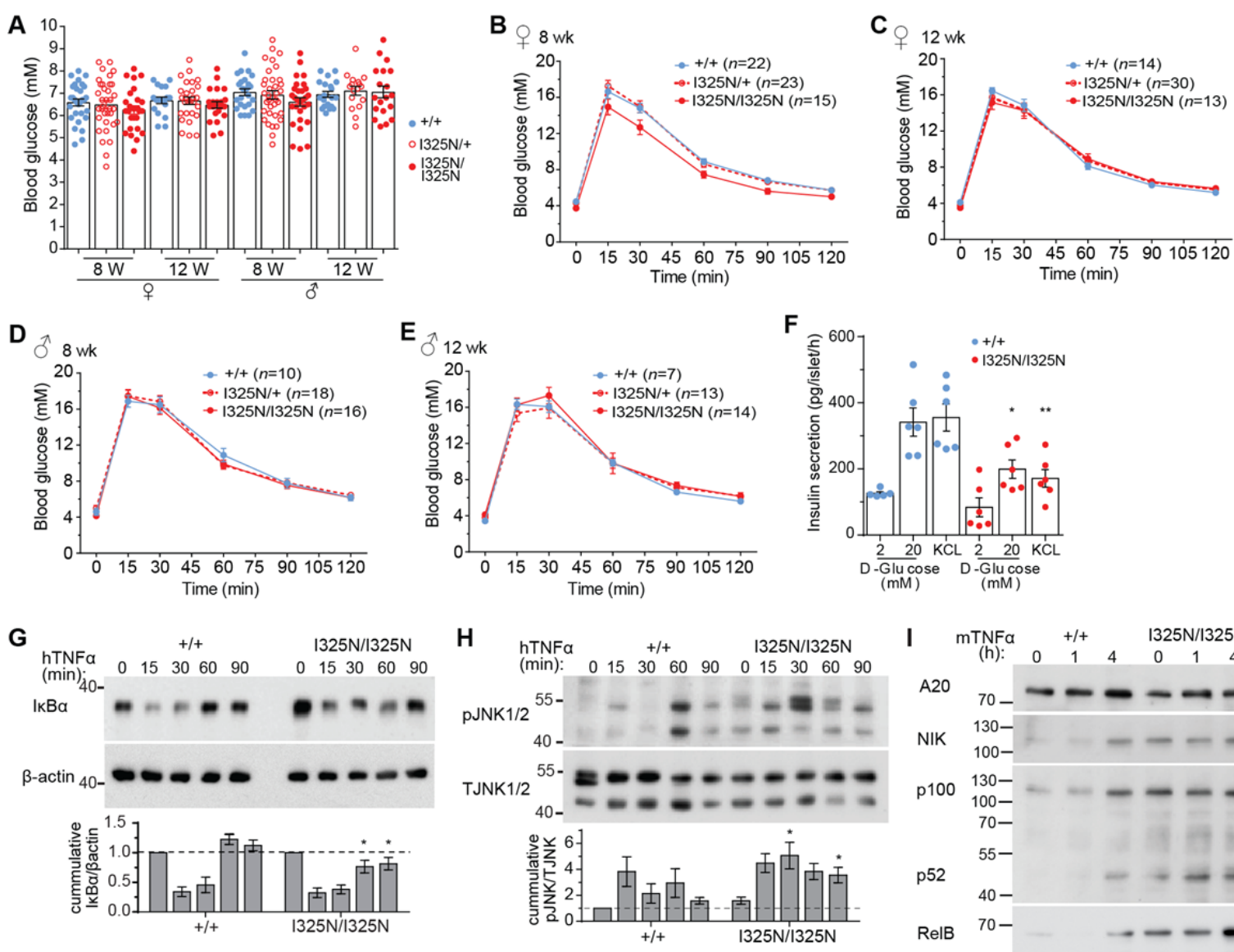

1201

\section{Extended Data Fig. 11.}

1203 Glucose homeostasis of $\mathbf{A 2 0}{ }^{\mathbf{I 3 2 5 N}}$ mice and isolated islets. (A) Random blood glucose levels

1204

1205

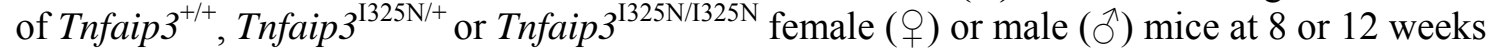

1206 of age. (B-E) Blood glucose levels $(\mathrm{mM})$ were monitored following an intraperitoneal

1207 injection of glucose $(2 \mathrm{~g} / \mathrm{kg})$ in 8 (B, D) or 12 week-old (C, E) mice. (F) Pancreatic islets

1208

1209

1210

1211

1212

1213

1214

1215

1216

1217

1218 were isolated from individual mice of the indicated A20 genotypes and incubated overnight. Following incubation an in vitro Glucose-Stimulated Insulin Secretion (GSIS) response in conditions of $2 \mathrm{mM}, 20 \mathrm{mM}$ D-glucose, or $25 \mathrm{mM} \mathrm{KCl}$ was conducted in separate groups of islets. Error bars represent SEM and Student's $t$-test used for significance between treatments, ${ }^{*} P<0.05 ;{ }^{* *} P<0.01$. (G-H) Pancreatic islets were isolated from individual mice of the indicated A20 genotypes, incubated overnight, and treated with $200 \mathrm{U} / \mathrm{ml} \mathrm{TNF} \alpha$ for the

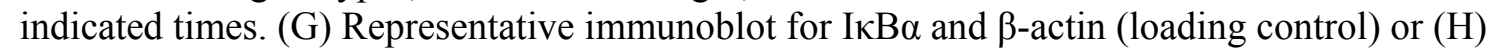
phosphorylated JNK (pJNK) and total JNK (TJNK, loading control). Cumulative densitometry from 5 independent experiments is shown below ( $n=5$ Tnfaip $^{+/+}$and $n=6$ Tnfaip ${ }^{1325 \mathrm{~N} / 1325 \mathrm{~N}}$ biological replicates). (I) Immunoblot for non-canonical NF- $\kappa \mathrm{B}$ components NIK, p100/p52 and RelB; representative of 2 independent experiments. Tnfaip $3^{1325 \mathrm{~N} / 1325 \mathrm{~N}}$ islets exhibited increased activation of the non-canonical NF- $\mathrm{BB}$ pathway that can alter beta

1219 cell transcriptional programs to favor reduced insulin output ${ }^{38}$. 
1220

1221

1222

1223

1224

1225

1226

1227

1228

1229

1230

1231

1232

1233

1234

1235

1236

1237

1238

1239

1240
A

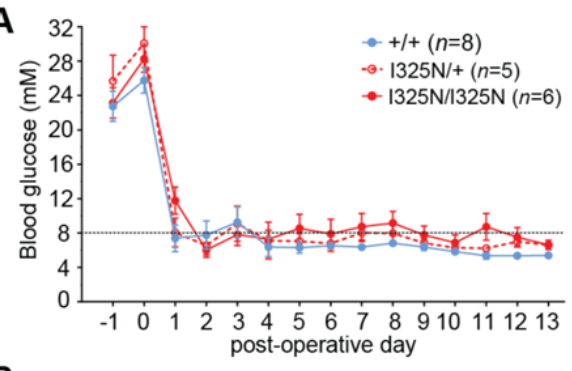

B
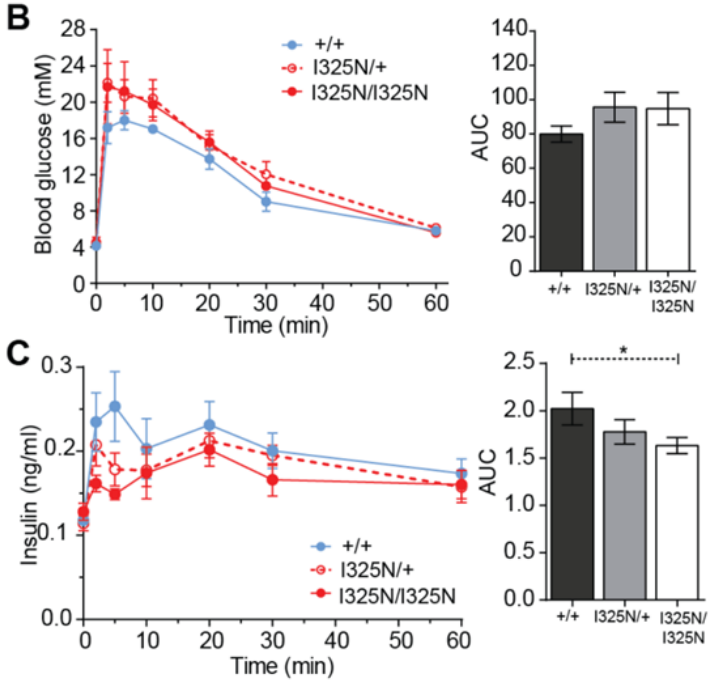

D
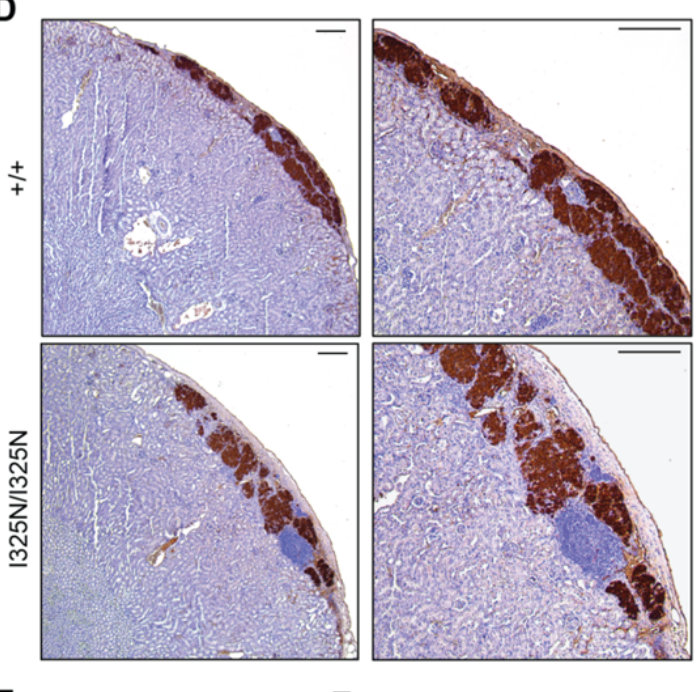

E

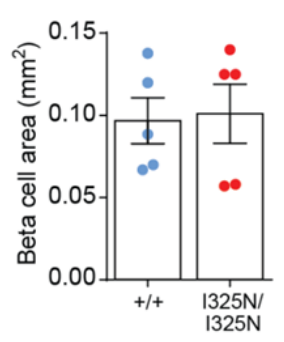

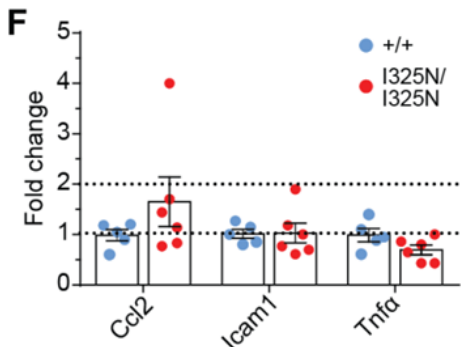

\section{Extended Data Fig. 12.}

$\mathrm{A20}^{\mathrm{I325N}}$ islet grafts exhibit a reduced first-phase insulin secretory response compared to wild-type A20 islet grafts independent to beta cell area. (A) Islets isolated from B6 mice of the indicated genotypes were transplanted under the kidney capsule of Tnfaip ${ }^{+/+}$B6 recipients that had been rendered diabetic with streptozotocin. Mean and SEM blood glucose on the indicated days relative to islet transplantation is shown. (B-C) At post-operative day 14 when euglycemia was established, mice were challenged with an (B) intravenous injection of glucose $(1 \mathrm{~g} / \mathrm{kg})$, and blood glucose monitored over time (min). (C) Blood insulin levels $(\mathrm{ng} / \mathrm{ml})$ were also measured at the same time points via an enzyme-linked immunosorbent assay from samples in (B). AUC $=$ area under the curve. Error bars represent SEM and ANOVA used for significance, ${ }^{*} P<0.05$. (D) Insulin immunostaining of wild-type $\left(\right.$ Tnfaip $\left.^{+/+}\right)$or A20 I325N homozygous mutant (Tnfaip $3^{\mathrm{I} 25 \mathrm{~N} / 1325 \mathrm{~N}}$ ) islet grafts transplanted under the kidney capsule of diabetic C57BL/6 mice for 30 days $\left(\right.$ Tnfaip $^{+/+}>\operatorname{Tnfaip}^{+/+} n=$ 5; Tnfaip3 $3^{1325 \mathrm{~N} / 1325 \mathrm{~N}}>$ Tnfaip $^{+/+} n=5$ ). (E) Islet graft beta cell area was determined by insulinpositive area quantification in continuous serial graft sections. Tnfaip3 $3^{1325 / 1325 \mathrm{~N}}$ grafts exhibited equivalent insulin-positive graft area, confirming that loss of glucose tolerance (B, C) was due to a defect in insulin secretion. (F) Tnfaip $3^{+/+}$or Tnfaip $3^{1325 \mathrm{~N} / 1325 \mathrm{~N}}$ islet grafts from an independent cohort of recipients were isolated on post-operative day 10 and analyzed for the indicated mRNAs by RT-qPCR ${ }^{77}$. The difference in gene expression of indicated islet grafts is shown. Fold change calculated using average wild-type $\Delta \mathrm{Ct}$ value. 
A

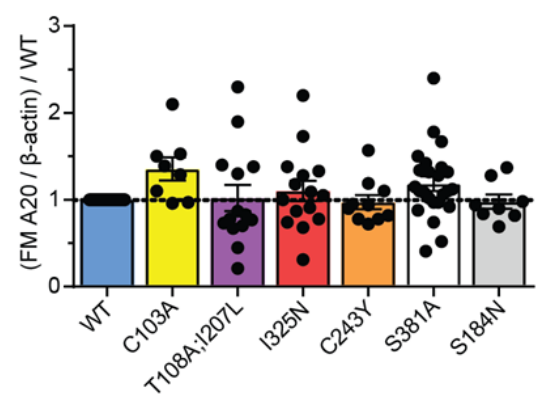

C
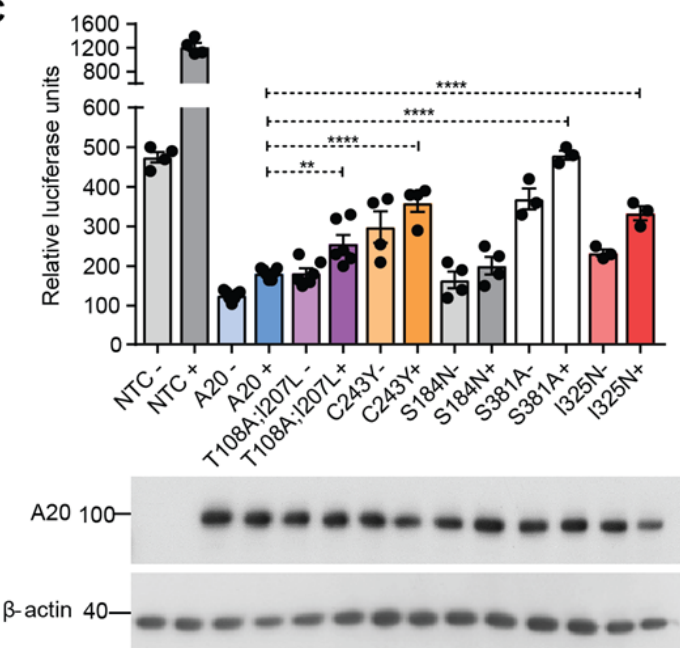

E

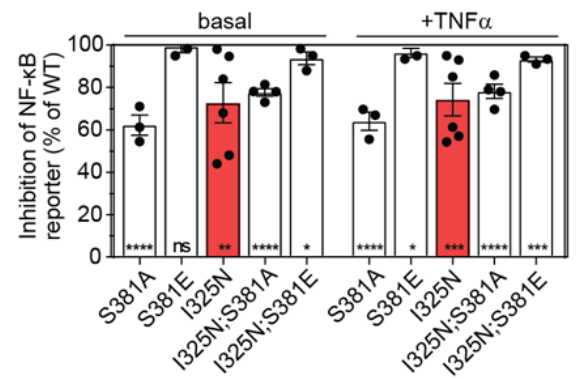

B

\begin{tabular}{lll} 
Vector & Total (unique) peptides & S381-P \\
\hline A20 WT & $178(66)$ & Yes $\sim 2 \%$ \\
A20 C103A & $229(74)$ & Yes $~ 2 \%$ \\
A20 I325N & $164(63)$ & No
\end{tabular}

D
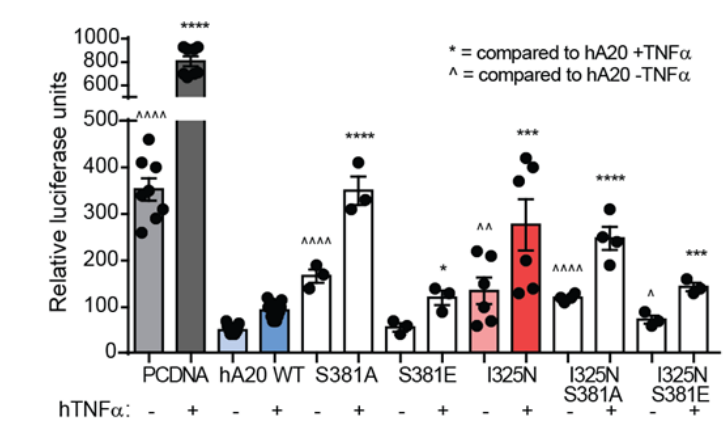

A20 70

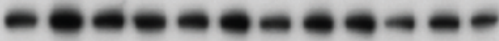

$\beta$-actin 40

$\mathbf{F}$

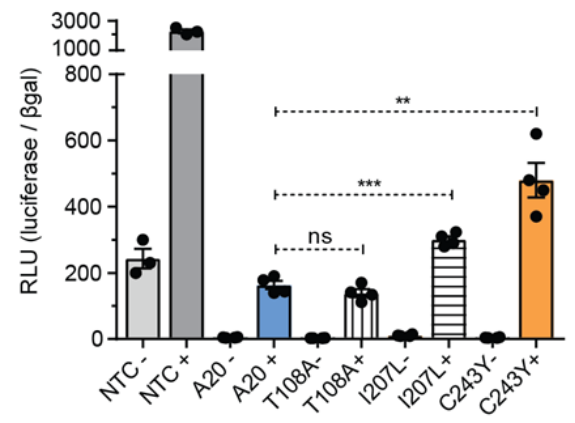

1241

1242

1243

1244

1245

1246

1247

1248

1249

1250

1251

1252

1253

1254

1255

1256

1257

Extended Data Fig. 13.

In vitro analysis of missense variant effects on A20 control of NF-кB. (A) A20

accumulation in $\beta$ TC3 mouse insulinoma cells transfected with wild-type (WT) A20, C103A A20, T108A;I207L A20, I325N A20, C243Y A20, S381A A20 or S184N A20 was determined by densitometry analysis of experimental immunoblots. Fast migratory (A20) 98 $\mathrm{kDa}$ A20 was corrected to loading control and compared to WT A20 of the same immunoblot [(FM A20/ $\beta$-actin)/A20]. (B) Results of mass spectrometry analysis of full length WT A20, C103A mutant A20, or I325N mutant A20 expressed in and purified from HEK293 cells and analysed by mass spectrometry for phosphorylation of the indicated residues as per references ${ }^{18,19}$. (C) $\beta$ TC3 cells co-transfected with an NF- $\kappa$ B.luciferase reporter and a CMV. $\beta$ gal expression construct alone or with PCDNA3.1 encoding human wild-type A20 (hA20 WT; blue), A20 T108A/I207L (purple), A20 C243Y (orange), A20 S184N (grey), A20 I325N (red) or A20 S381A (white). Cells were stimulated with (+) $200 \mathrm{U} / \mathrm{ml} \mathrm{hTNF} \alpha$ for $8 \mathrm{~h}$ or left untreated (-). Data presented as relative luciferase units. Each column represents 3-5 independently transfected aliquots of cells within one experiment marked by circle symbols (representative of 3 independent experiments) and columns are arithmetic means. Statistical 
1258 comparison by Student's $t$-test against WT hA20 (blue). (D-F) $\beta$ TC $_{3}$ cells co-transfected with

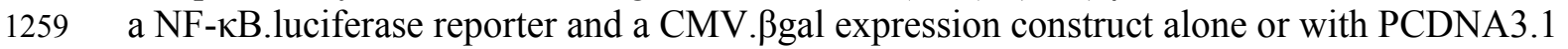
1260 encoding human wild-type A20 (hA20 WT; blue), or (D) A20 I325N variant (I325N; red), or 1261 A20 with serine 381 substituted to non-phosphorylatable alanine (S381A or I325N S381A), 1262 or to phosphomimetic glutamate (S381E or I325N;S381E), (F) or A20 with the point variants 1263 T108A (vertical stripes), I207L (horizontal stripes) or C243Y (orange). Cells were stimulated 1264 with (+) $200 \mathrm{U} / \mathrm{ml} \mathrm{hTNF} \alpha$ for $8 \mathrm{~h}$ or left untreated (-). In (E) the two missense variants in the 1265 Denisovan haplotype, T108A and I207L, are tested individually (cross-hatched columns).

1266 Data presented as relative luciferase units. Each column represents mean of 3-6

1267 independently transfected aliquots of cells within one experiment marked by circle symbols 1268 (representative of 3 independent experiments) and columns are arithmetic means. Statistical 1269 comparison by Student's t-test against WT hA20 (blue) with TNFa (+) indicated by * or without (-) indicated by ${ }^{\wedge}$. In (F), data from (D) are presented as inhibition of NF- $\kappa$ B reporter as a percent of WT A20. Error bars represent SEM, $* P<0.05 ; * * P<0.01 ; * * * P<0.001$; $* * * * P<0.0001$. 

aCC-BY 4.0 International license.

\section{A}

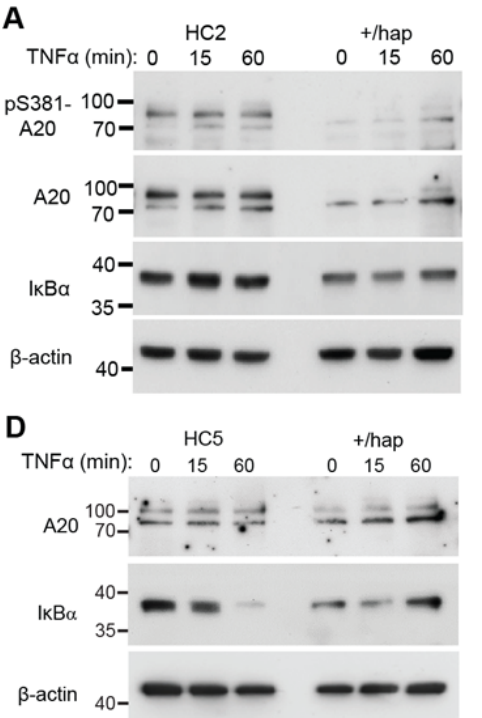

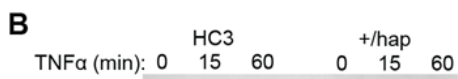

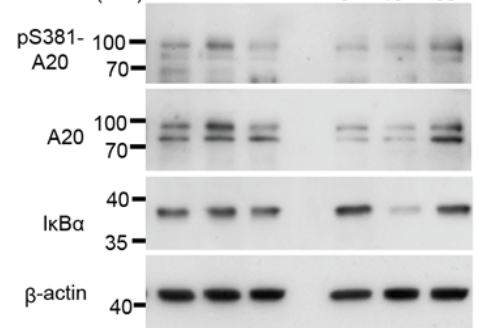

E
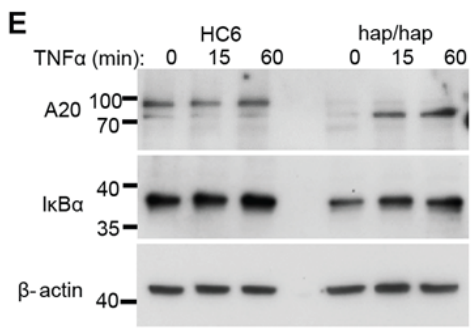

AFM
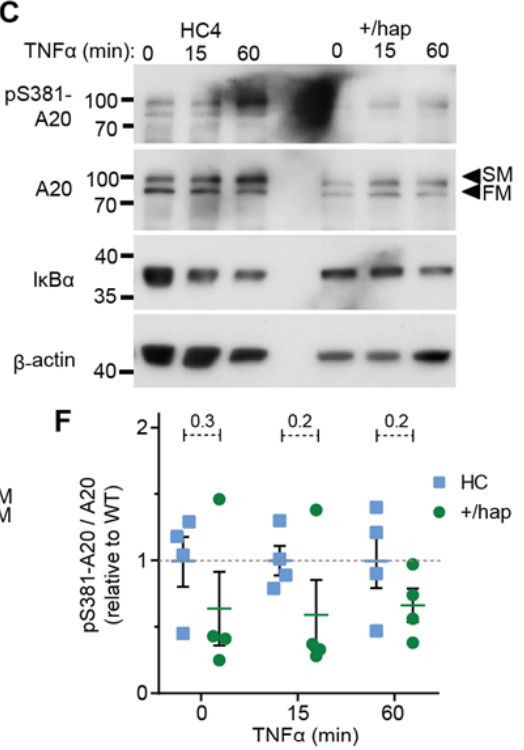

G
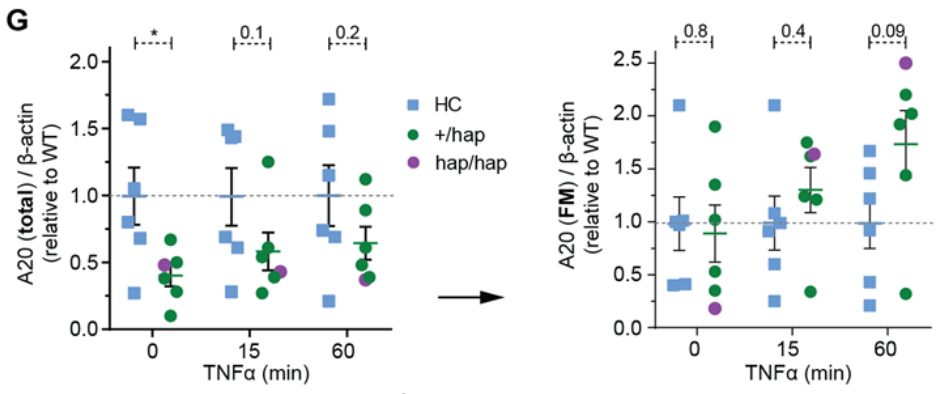

H

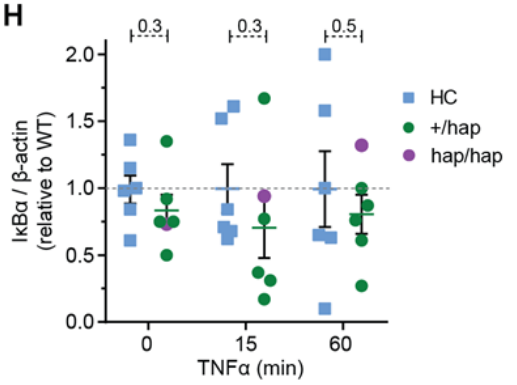

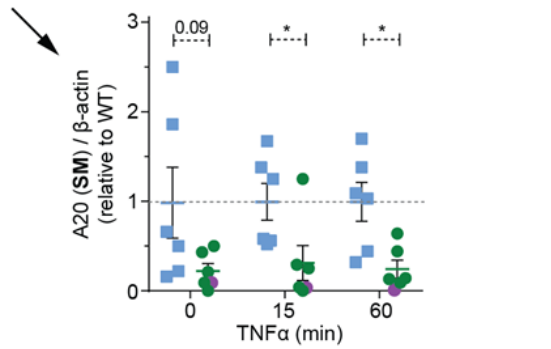

\section{Extended Data Fig. 14.}

Immunoblot analysis of peripheral blood mononuclear cells from healthy individuals with the T108A I207L haplotype. (A-E) Immunoblot analysis of peripheral blood mononuclear cells (PBMC) from individuals with the Denisovan TNFAIP3 haplotype (hap) or without (healthy control donor; HC). PBMCs were left untreated or stimulated with recombinant human TNF $\alpha$ (hTNF $\alpha$ ) for 15 or 60 min. Proteins assessed include A20,

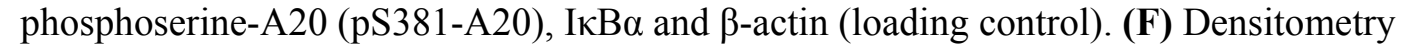
analysis of pS381-A20 levels in immunoblots A-C and Fig. 4D. Densitometry was calculated by correcting to total A20 present and using the average value from samples without the T108A;I207L haplotype (HC) to compare all samples. (G) Densitometry analysis of total A20 levels in immunoblots A-C and Fig. 4D. Densitometry was calculated by correcting to $\beta$ actin loading control and using the average WT value to compare all samples. $(\mathrm{G})$ is further divided into fast migrating (FM) or slow migrating (SM) A20. No significant difference is observed for FM A20 between hap or HC individuals. In contrast, a significant difference is observed between hap and HC individuals for SM A20, which correlates with phosphorylated A20 in in vitro studies (Fig. 4D, E) ${ }^{18,19}$; consistent with reduced phosphorylation for A20 
1290 T108A;I2107L. (H) Densitometry analysis of IкB $\alpha$ levels in immunoblots A-C and Fig. 4D. 1291 Densitometry was calculated by correcting to $\beta$-actin loading control and using the average 1292 value from samples without the T108A;I207L haplotype (HC) to compare all samples. Each 1293 symbol represents an individual lane in immunoblot. Error bars represent SEM and Student's $t$-test used for significance analysis unless otherwise stated, ${ }^{*} P<0.05$. 

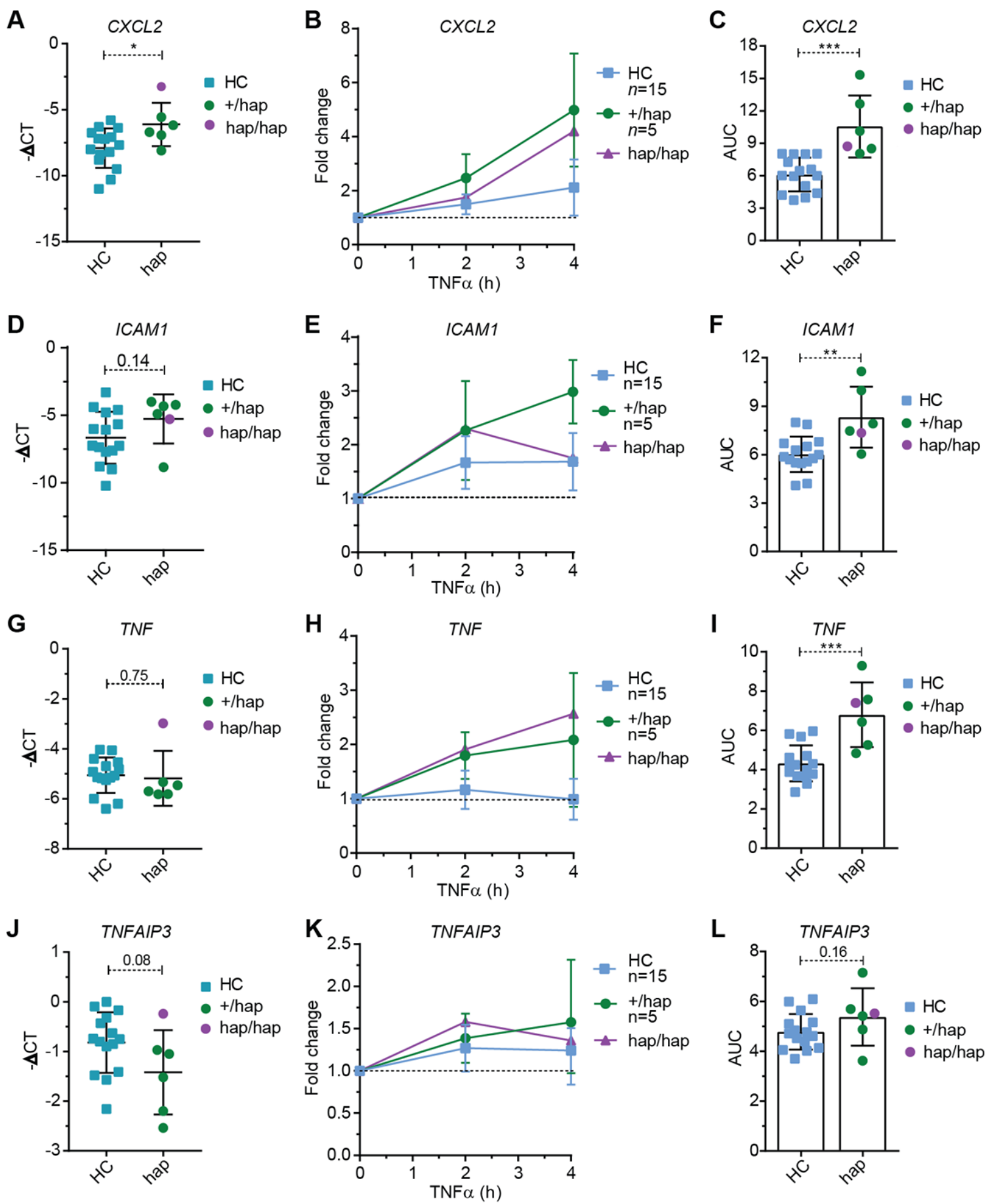

\section{Extended Data Fig. 15.}

\section{7 \\ Peripheral blood mononuclear cells from individuals with the Denisovan TNFAIP3} $T N F$, and TNFAIP3 genes expression from peripheral blood mononuclear cells (PBMCs) from individuals heterozygous (green circles) or homozygous (purple circle) for the Denisovan TNFAIP3 haplotype (hap) and 15 healthy control donors (HCs; blue squares), comparing negative $\Delta$ CT basal expression levels $(\mathbf{A}, \mathbf{D}, \mathbf{G}, \mathbf{J})$ or induction kinetics following stimulation with recombinant human TNF $\alpha$ for 02 or 4 h $(\mathbf{B}, \mathbf{E}, \mathbf{H}, \mathbf{K})$. Fold change was determined by comparing stimulated values against non-stimulated PBMC preparations 
bioRxiv preprint doi: https://doi org/10.1101/589507; this version posted March 27, 2019. The copyright holder for this preprint (which was not certified by peer review) is the author/funder, who has granted bioRxiv a license to display the preprint in perpetuity. It is made available under aCC-BY 4.0 International license.

1305 within the same group. Significance between groups was determined by area under the curve 1306 analysis $(\mathbf{C}, \mathbf{F}, \mathbf{I}, \mathbf{L})$. Error bars represent SD and Student's $t$-test used for significance

1307 analysis unless otherwise stated, $* P<0.05 ; * * * P<0.001$. 
A

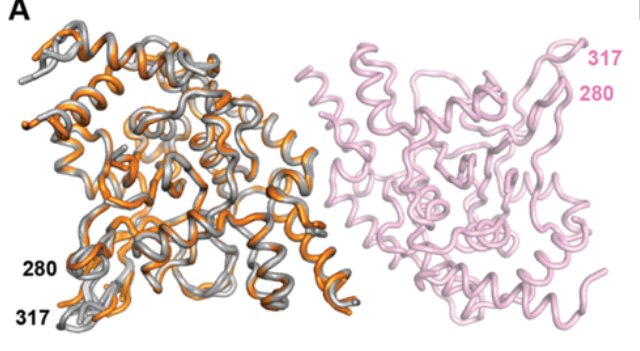

D

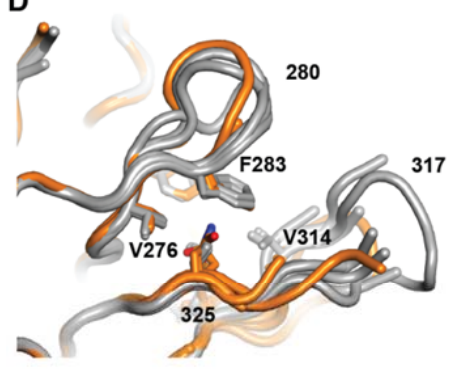

B

$\mathbf{E}_{\text {r }}$

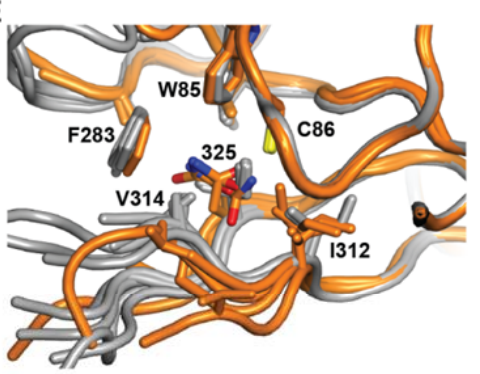

C

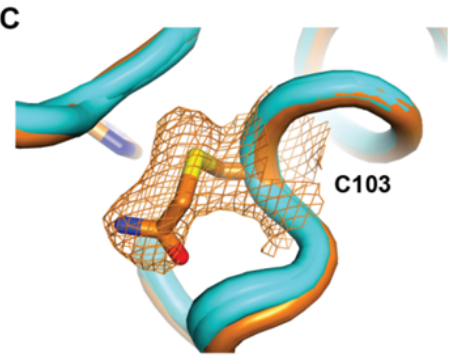

F

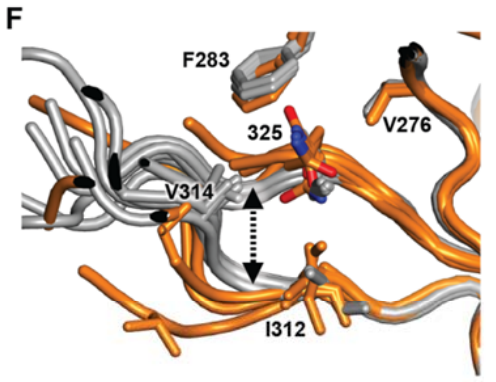

G

1308

1309

1310

1311

1312

1313

1314

1315

1316

1317

1318

1319

1320

1321

1322

1323

1324

1325
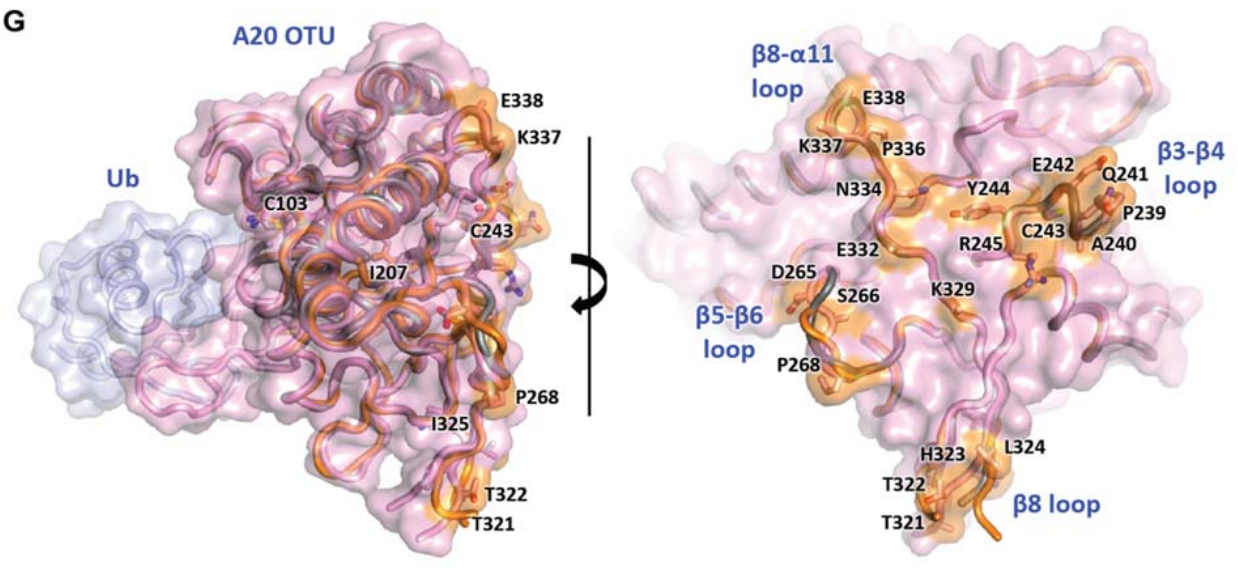

Extended Data Fig. 16.

A20 ${ }^{\text {I325N }}$ mutation subtly impacts the OTU structure. (A) Structures of human I325N variant (orange) and wild-type (WT; grey) A20 OTU domains superposed (each with 6 molecules per asymmetric unit). The dimer partner of one of these is shown in pink. Loop 317 and 280 are indicated on the periphery. (B) The I325N substitution does not alter the fold of the putative catalytic triad (orange cartoon and sticks) compared to previously published wild-type structures (cyan cartoon and sticks; PDB entries 3DKB, 2VFJ and 3ZJD). (C) The fold is additionally unperturbed by acetamidylation of $\mathrm{C} 103$ (orange mesh; $2 \mathrm{mFo}-\mathrm{DFc}$ composite omit map contoured at 1.2 sigma). (D-F) The $1325 \mathrm{~N}$ substituted side-chain sits at the base of the $\beta 7-\beta 8$ loop containing residue 317 , in a pocket also lined by the $\beta 6-\alpha 9$ loop containing residue 280 (D). Adjacent hydrophobic residues include W85, V276, F283, I312, V314 (E). The I325N substitution results in the base of the $\beta 7-\beta 8$ loop splaying apart (F, arrow), increasing $\beta 7-\beta 8$ loop disorder. (G) Structures of human $1325 \mathrm{~N}$ variant (orange) and wild-type (WT; grey) A20 OTU domains superposed on the wild-type OTU-ubiquitin structure $5 \mathrm{LRX}{ }^{42}$. Conserved residues on the posterior surface are coloured orange. The $\beta 3$ $\beta 4$ loop containing the $\mathrm{C} 243 \mathrm{Y}$ mutation and the structured base of the $\beta 7-\beta 8$ loop containing the $\mathrm{I} 325 \mathrm{~N}$ mutation are marked. 
A

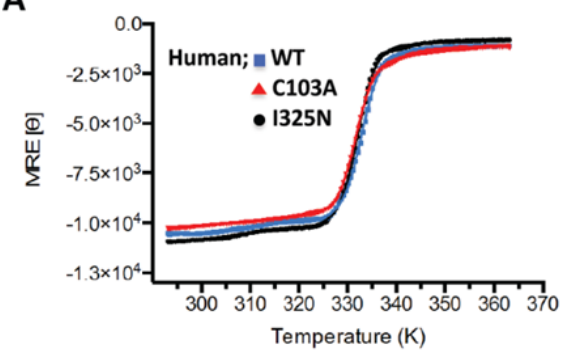

C

\begin{tabular}{|c|c|}
\hline Variant & $T_{\text {trs }}\left({ }^{\circ} \mathrm{C}\right)$ \\
\hline Human & \\
\hline WT & $59.8 \pm 0.3$ \\
\hline C103A & $59.0 \pm 0.3$ \\
\hline $\mathrm{I} 325 \mathrm{~N}$ & $58.5 \pm 0.3$ \\
\hline Mouse & \\
\hline WT & $61.0 \pm 0.4$ \\
\hline C103A & $60.2 \pm 0.5$ \\
\hline $\mathrm{I} 325 \mathrm{~N}$ & $61.4 \pm 0.5$ \\
\hline
\end{tabular}

E

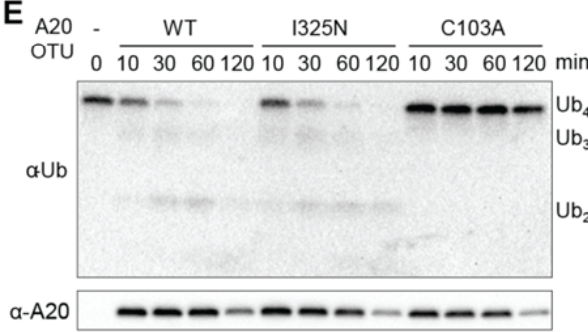

$\mathbf{F}$
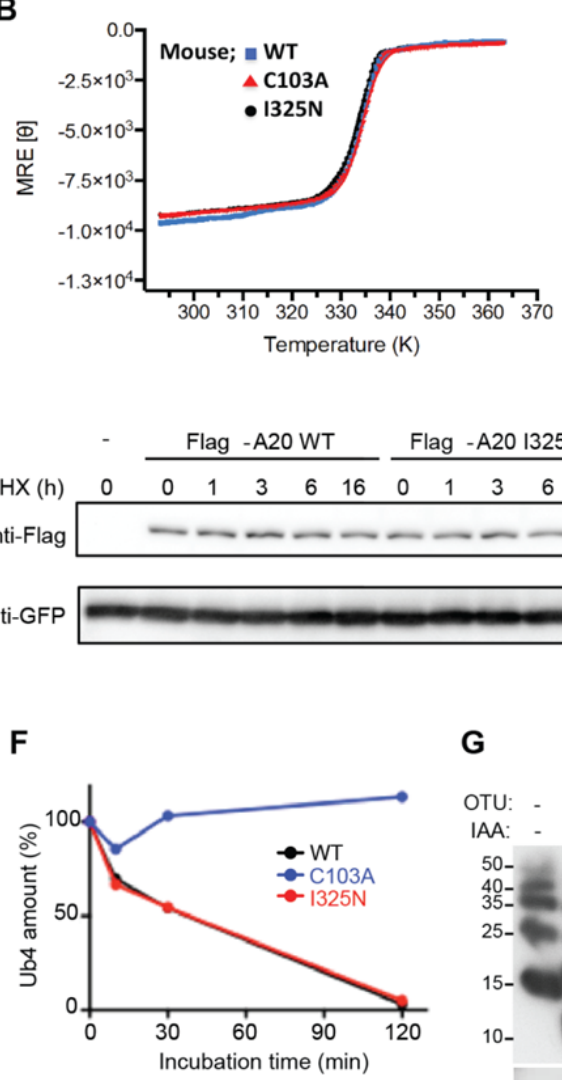

D

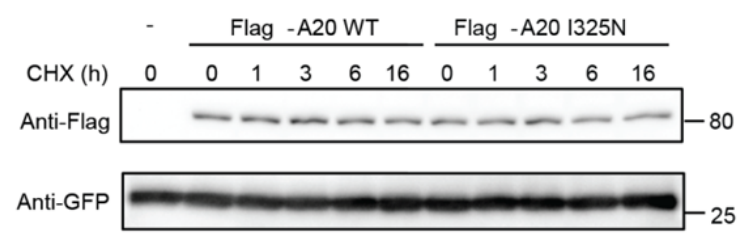

1

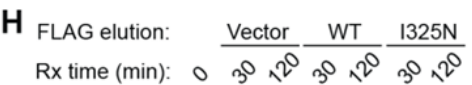
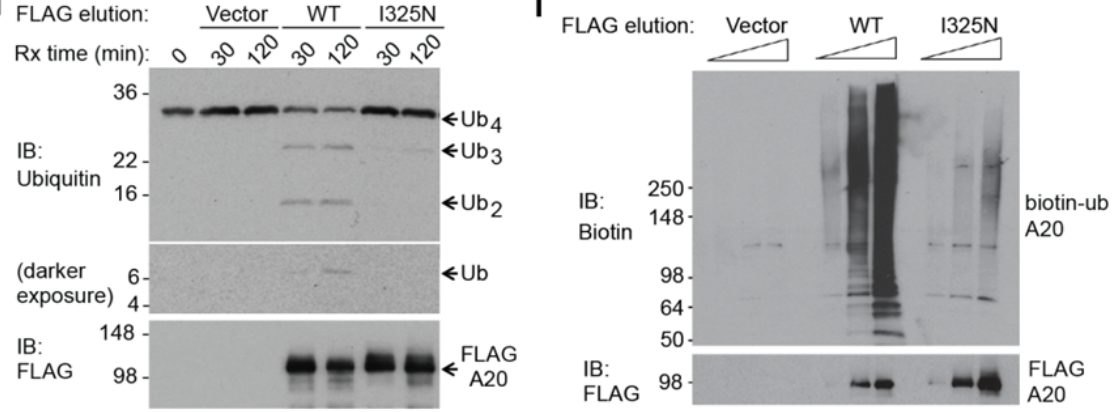

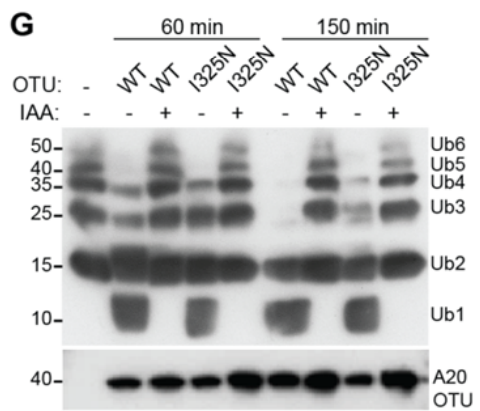

Extended Data Fig. 17.

Molecular characterization of A20 I325N and A20 C103A. (A-B) Thermal stability of mouse and human WT, C103A, and I325N variants were examined using circular dichroism, where mean residue ellipticity (MRE) was measured at $220 \mathrm{~nm}$ as a function of temperature as solutions were heated at a rate of $1^{\circ} \mathrm{C} / \mathrm{min}$. Human (A) or mouse (B) A20 OTU residues 1370; WT (blue squares), C103A (red triangles), I325N (black circles). Curves were fit by linear regression. (C) Unfolding transitions temperature $\left(\mathrm{T}_{\mathrm{trs}}\right)$ of human A20 OTU variants (residues 1-370) and mouse variants (residues 1-360), derived from the fit of the curves in (A) and (B). (D) HEK293T cells were transfected with bicistronic retrovirus vector pMXsIRES-GFP, expressing FLAG-tagged mouse full-length TNFAIP3 wild-type or I325N. Each group of transfected cells was replated $24 \mathrm{~h}$ after transfection and incubated with $10 \mu \mathrm{M}$ of cycloheximide $(\mathrm{CHX})$ for the indicated times before harvesting. Lysates were probed with anti-FLAG and anti-GFP antibodies. (E, F) Reactions containing K48-linked tetra-ubiquitin $\left(\mathrm{Ub}_{4}\right)$ and E. coli-expressed and purified WT or I325N A20 OTU domain, or the catalytically 
1341 deactivated A20 OTU domain, C103A, were incubated for the indicated times.

1342 Depolymerization of polyubiquitin was detected by immunoblotting for ubiquitin and A20;

1343 representative of two independent experiments. (G) Reactions containing mixed $\mathrm{Ub}_{2}-\mathrm{Ub}_{6}$

1344 K48-linked polyubiquitin chains and E. coli-expressed and purified WT or I325N A20 OTU

1345 domain \pm iodoacetamide (IA) treatment were incubated at $37^{\circ} \mathrm{C}$ for 60 or 150 minutes.

1346 Depolymerization of polyubiquitin was detected by immunoblotting for ubiquitin and the N-

1347 terminus of A20; representative of 4 independent experiments. (H, I) Flag-tagged full length

1348 human A20 proteins (WT or I325N mutant) were expressed in HEK-293T cells and purified

1349 as previously described ${ }^{14}$. Purified A20 proteins were tested for K63-linked tetra-ubiquitin

1350 depolymerization $(\mathrm{H})$ and in vitro ubiquitination assay (I). 
A

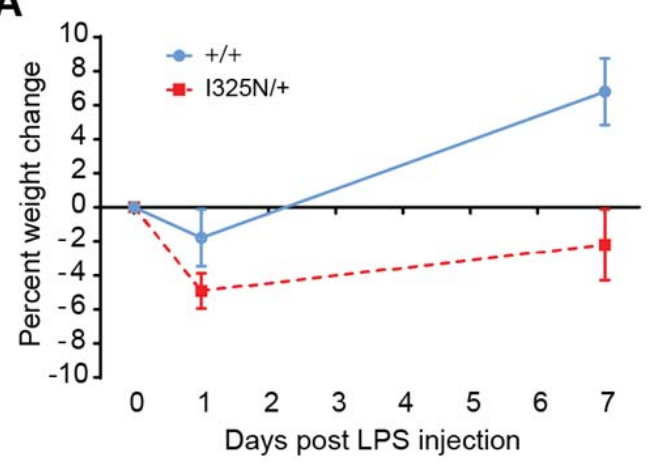

C

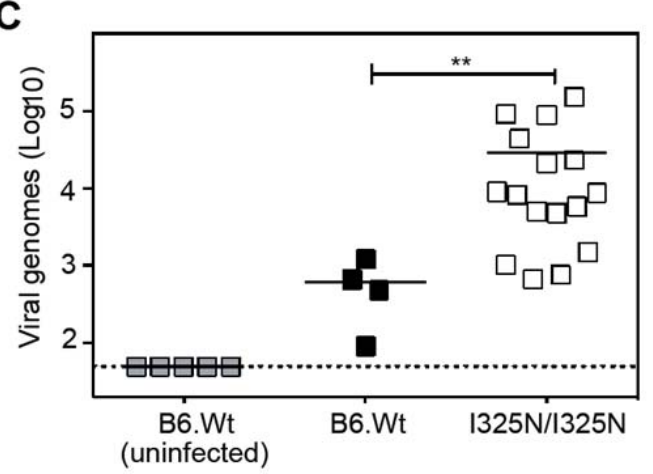

B

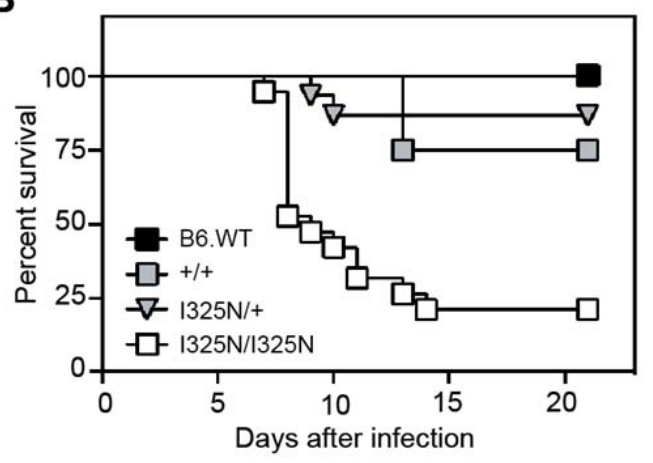

D

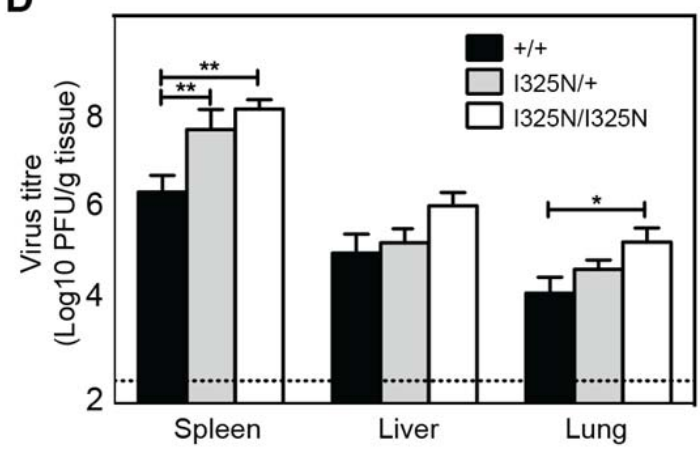

$1352 \quad$ Extended Data Fig. 18.

1353 A20 I325N are susceptible to LPS injection and poxvirus infection. (A) Daily body weights for Tnfaip ${ }^{+/+}$or Tnfaip $3^{\mathrm{I} 25 \mathrm{~N} /+}$ mice administered $50 \mu \mathrm{g}$ bacterial LPS by intraperitoneal injection. (B-D) Ectromelia virus infection of B6 male siblings of the indicated Tnfaip3 genotypes and wild-type B6 control mice, showing (B) Kaplan-Meyer survival plots and (C) viral load in blood on day 8 ; ${ }^{* *} P<0.005$ by unpaired $t$ test. (D) Virus load in spleen, liver and lung, respectively. Data expressed as mean $\pm \mathrm{SEM}$; data was logtransformed and statistical significance determined by 2 -way ANOVA; ${ }^{*} P<0.05,{ }^{*} P<$ 0.01 . Dotted lines in $(C, D)$ denote limit of detection. 
A

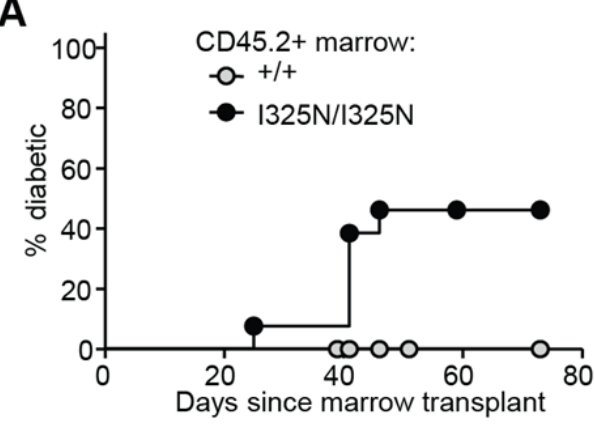

B

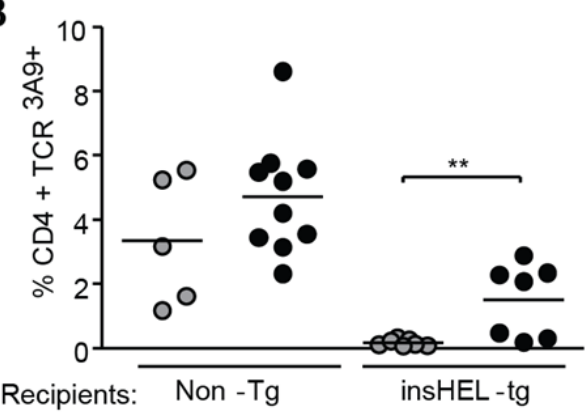

1361

1362 Extended Data Fig. 19.

1363

1364

1365

1366

1367

1368

1369

1370

1371

1372

1373

1374

1375

1376

1377

1378

1379

1380

1381
D

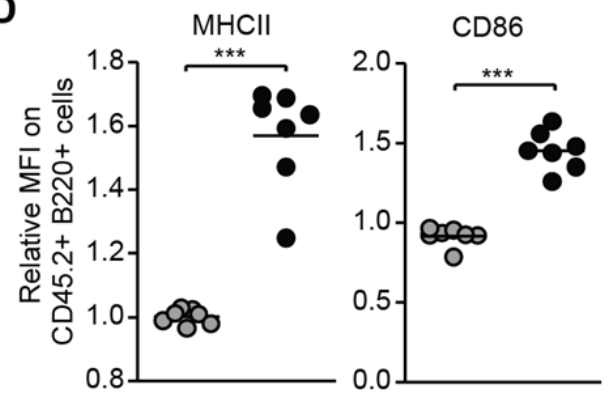

E

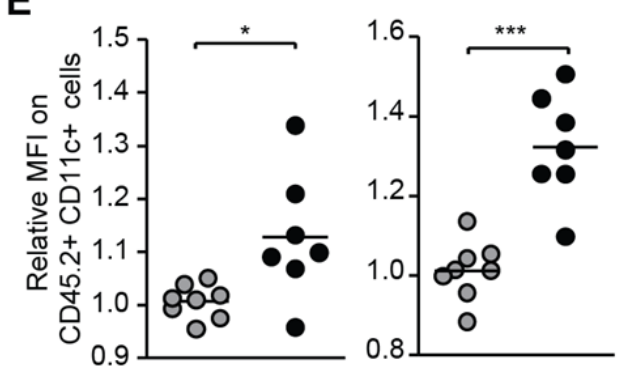

$\mathbf{F}$

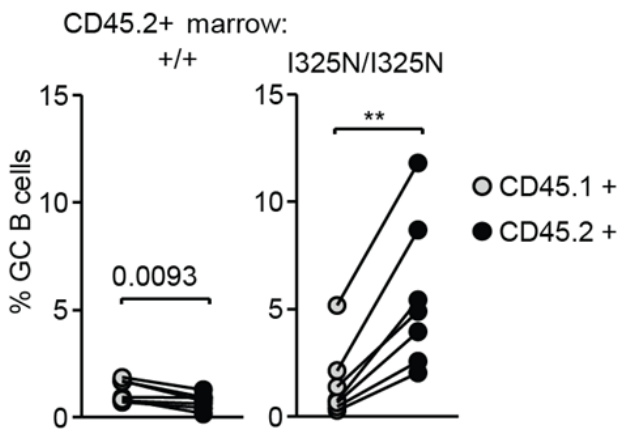

\section{Diminished tolerance to self-antigen caused by mutant A20. InsHEL-transgenic mice or} non-transgenic controls, both with wild-type A20 in pancreatic islets, were transplanted with a congenic bone marrow mixture from Tnfaip3 ${ }^{+/+} \mathrm{CD} 45.1^{+} \mathrm{TCR}^{3 \mathrm{~A} 9}$-transgenic donors, to serve as an internal control, and CD45.2 $\mathrm{TCR}^{3 \mathrm{~A} 9}$-transgenic donors with either Tnfaip3 ${ }^{1325 \mathrm{~N} / 1325 \mathrm{~N}}$ (black circles) or Tnfaip3 ${ }^{+/+}$(grey circles) genotype. (A) Incidence of diabetes in insHEL-transgenic recipients as a function of time after transplantation $(n=12$ chimeras for $+/+$ and 14 chimeras for $\mathrm{I} 325 \mathrm{~N} / \mathrm{I} 325 \mathrm{~N}$ pooled from 2 separate experiments). (B) Frequency of $\mathrm{TCR}^{3 \mathrm{~A} 9}$ positive $\mathrm{CD} 4^{+} \mathrm{T}$ cells among CD45.2 $2^{+}$Tnfaip3 $^{+/+}$(grey circles) or Tnfaip3 ${ }^{\mathrm{I} 25 \mathrm{~N} / 1325 \mathrm{~N}}$ (black circles) lymphocytes in pancreatic lymph nodes. Test recipients expressed the insHEL antigen in pancreatic islets (insHEL-transgenic), while parallel nontransgenic recipients lacked the autoantigen. (C) Percentage of CD45.2 ${ }^{+}$Tnfaip3 $^{+/+}$(grey circles) or Tnfaip ${ }^{1325 \mathrm{~N} / 1325 \mathrm{~N}}$ (black circles) cells among $\mathrm{TCR}^{3 \mathrm{~A} 9+} \mathrm{CD}^{+} \mathrm{T}$ cells in spleen. (DF) Analysis of insHEL transgenic recipients. Relative mean fluorescence intensity (MFI) of staining for cell surface MHC class II or CD86 on CD45.2 $2^{+}$Tnfaip3 $^{+/+}$(grey circles) or Tnfaip3 ${ }^{1325 \mathrm{~N} / 1325 \mathrm{~N}}$ (black circles) B cells (D) or CD11 ${ }^{+}$dendritic cells (E), compared to CD $45.1^{+}$Tnfaip $^{+/+} \mathrm{B}$ cells or dendritic cells in the same sample. (F) Frequency of germinal center (GC) B cells among CD45.2+ B cells (black circles) compared to the frequency among CD45. $1^{+}$Tnfaip3 $^{+/+}$B cells in the same animal (linked by lines). Left panel, CD45.2 Tnfaip3 $^{+/+}$marrow donor; right panel, CD45.2 Tnfaip $^{\text {I325N/1325N }}$ marrow donor. In (B-F), 
bioRxiv preprint doi: https://doi org/10.1101/589507; this version posted March 27, 2019. The copyright holder for this preprint (which was not certified by peer review) is the author/funder, who has granted bioRxiv a license to display the preprint in perpetuity. It is made available under aCC-BY 4.0 International license.

1382 each symbol, or pair of symbols joined by a line, represents one chimeric mouse, all analyzed

1383 in a single experiment. Statistical analysis by 2 -tailed Student's $t$-tests: ${ }^{*} P<0.05 ;{ }^{*} P<$

1384 $0.01 ; * * * P<0.001$.

1385 

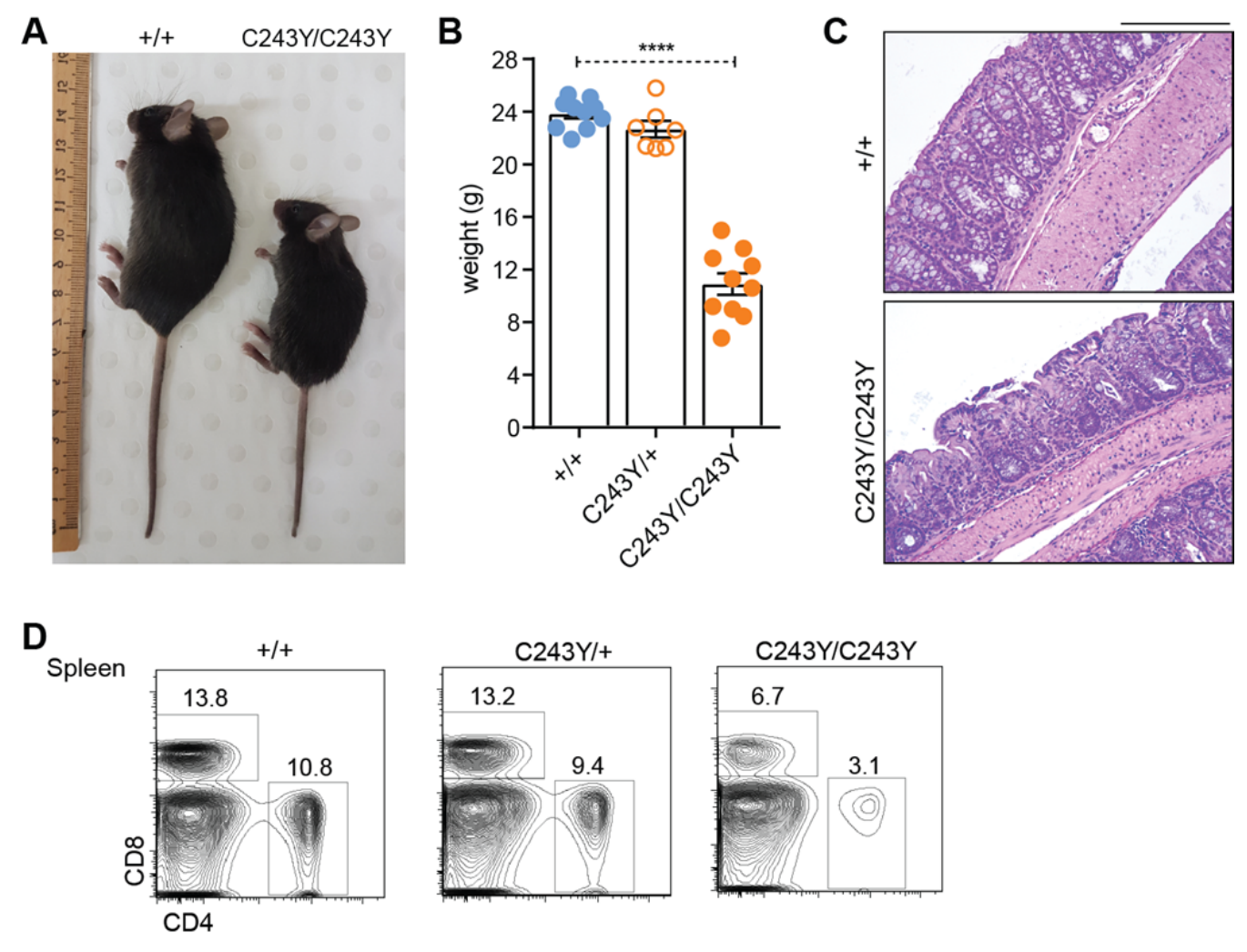

1386
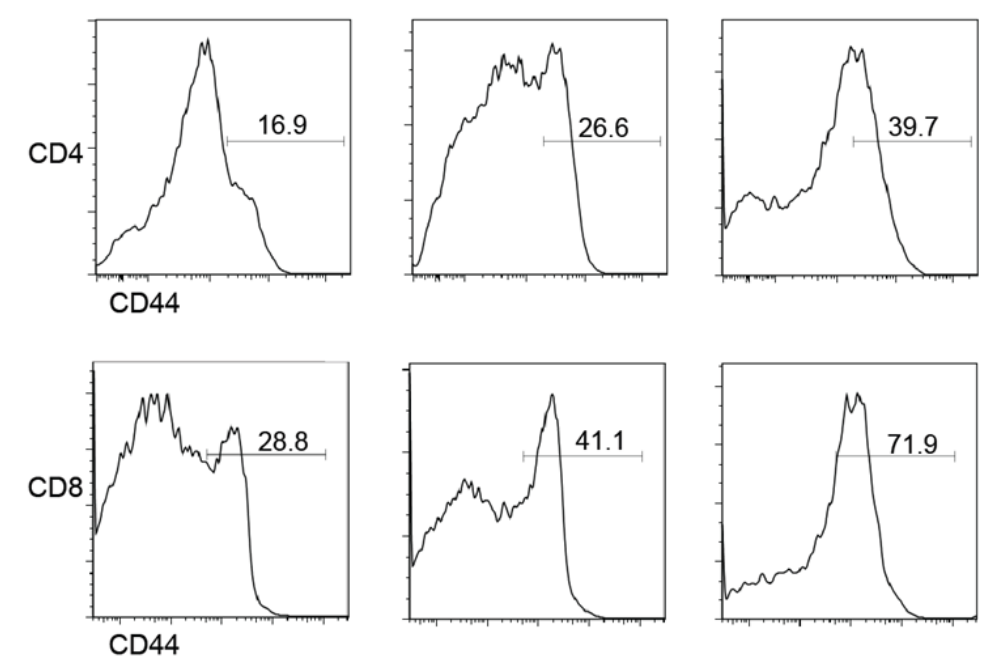

\section{Extended Data Fig. 20.}

1388 Histological analysis and immune phenotyping of $\mathbf{A 2 0}^{\mathbf{C 2 4 3 Y}}$ mice. (A) Representative 1389 photo of 8 week-old female Tnfaip3 ${ }^{+/+}$and Tnfaip3 ${ }^{\mathrm{C} 243 \mathrm{Y} / \mathrm{C} 243 \mathrm{Y}}$ mice. Statistical analysis by one-way ANOVA: $* * * * P<0.0001$. (B) Weights (g) 8 week-old male Tnfaip3 ${ }^{+/+}$, Tnfaip3 ${ }^{\mathrm{C} 243 \mathrm{Y} / \mathrm{C} 243 \mathrm{Y}}$ and Tnfaip3 ${ }^{\mathrm{C} 243 \mathrm{Y} / \mathrm{C} 243 \mathrm{Y}}$ mice. (C) Hematoxylin and eosin stained sections of colon from representative female mice in $(A)($ scale $=200 \mu \mathrm{m})$. (D) Flow cytometry of the percent $\mathrm{CD}^{+}$and $\mathrm{CD} 8^{+}$splenocytes (top panel) and the percentage of each subset that are 1395 CD $44^{\mathrm{hi}}$ activated/memory cells (histograms). 


\section{Extended Data Table 1.}

1397 Allele frequencies of the Denisovan T108A;I207L haplotype in the Simons Genome 1398 Diversity Project ${ }^{22}$, as presented in (Extended Data Fig. 2B).

\begin{tabular}{|l|l|l|l|}
\hline Region & $\begin{array}{l}\text { Denisovan } \\
\text { TNFAIP3 } \\
\text { alleles }\end{array}$ & $\begin{array}{l}\text { Total } \\
\text { TNFAIP3 } \\
\text { alleles }\end{array}$ & $\begin{array}{l}\text { Denisovan } \\
\text { allele } \\
\text { frequency }\end{array}$ \\
\hline Africa & 0 & 88 & 0.00 \\
\hline West Eurasia & 0 & 150 & 0.00 \\
\hline Central Asia & 0 & 54 & 0.00 \\
\hline South Asia & 0 & 78 & 0.00 \\
\hline East Asia & 0 & 94 & 0.00 \\
\hline Americas & 0 & 44 & 0.00 \\
\hline Oceania \& Island SE Asia: & 23 & 50 & 0.46 \\
\hline (Brunei) & 1 & 4 & 0.25 \\
\hline (Australia) & 1 & 4 & 0.25 \\
\hline (Papua New Guinea) & 19 & 30 & 0.63 \\
\hline (Bougainville) & 1 & 4 & 0.25 \\
\hline (New Zealand) & 1 & 2 & 0.50 \\
\hline
\end{tabular}




\section{$1400 \quad$ Extended Data Table 2.}

1401 Polymorphic observed (black) and imputed (red) variants within a putatively adaptively 1402 introgressed haplotype in Melanesians (6:138160925-138246514, $\left.{ }^{29}\right)$. Ancestral, modern 1403 human (b37), Denisovan, and Altai Neanderthal genotypes are shown at each position for 1404 comparison. Genomic coordinates are based upon the hg19 reference.

\begin{tabular}{|l|l|l|l|l|l|l|l|}
\hline Chr & Position & rsID & Missense & Ancestral & b37 & Denisovan & $\begin{array}{l}\text { Altai } \\
\text { Neanderthal }\end{array}$ \\
\hline 6 & 138161013 & rs6918329 & & G & A & G & G \\
\hline 6 & 138174328 & rs2027276 & & C & A & A & C \\
\hline 6 & 138190154 & rs3757173 & & G & A & A & G \\
\hline 6 & 138195402 & rs596493 & & C & T & C & C \\
\hline 6 & 138196008 & rs376205580 & T108A & A & A & G & A \\
\hline 6 & 138196957 & rs141807543 & I207L & A & A & C & A \\
\hline 6 & 138223082 & rs17066926 & & C & T & C & C \\
\hline 6 & 138241185 & rs4895499 & & G & A & G & G \\
\hline
\end{tabular}


1406

1407

1408

1409

\section{Extended Data Table 3.}

Mouse primers used for qRT-PCR analysis of genes. Designed using Primer3 with sequences obtained from GenBank and synthesised by Sigma Aldrich (Australia). Primers from Roche Universal ProbeLibrary (UPL) System Assay are indicated.

\begin{tabular}{|c|c|}
\hline Gene & Primer sequence \\
\hline Tnfaip3 & $\begin{array}{l}\text { F-5'-CCTGTCACCAACGCTCCAAG-3' } \\
\text { R-5'-ATTTCCAGTCCGGTGGCAAG-3' }\end{array}$ \\
\hline Ccl2 & $\begin{array}{l}\text { F- 5'-GGTCCCTGTCATGCTTCTGG-3' } \\
\text { R- 5'-CCTGCTGCTGGTGATCCTCT-3' }\end{array}$ \\
\hline Cph2 & $\begin{array}{l}\text { F- 5'-TGGACCAAACACAAACGGTTCC-3' } \\
\text { R- 5'-ACATTGCGAGCAGATGGGGT-3' }\end{array}$ \\
\hline Cxcl1 & $\begin{array}{l}\text { F- 5'-TGGCTGGGATTCACCTCAAG-3' } \\
\text { R- 5'-TATGACTTCGGTTTGGGTGCAG-3' }\end{array}$ \\
\hline Cxcl10 & $\begin{array}{l}\text { F- 5'-GACGGGCCAGTGAGAATGAG-3' } \\
\text { R- 5'-GTGTGTGCGTGGCTTCACTC-3' }\end{array}$ \\
\hline Icam1 & $\begin{array}{l}\text { F- 5'-CCATGGGAATGTCACCAGGA-3' } \\
\text { R- 5'-ATCACGAGGCCCACAATGAC-3' }\end{array}$ \\
\hline Il6 & $\begin{array}{l}\text { F- 5'-TCCTTCCTACCCCAATTTCCAA-3' } \\
\text { R- 5'-TGGATGGTCTTGGTCCTTAGCC-3' }\end{array}$ \\
\hline $\begin{array}{l}\text { Il1b } \\
\text { UPL probe } \# 38\end{array}$ & $\begin{array}{l}\text { F- 5'-AGTTGACGGACCCCAAAAG-3' } \\
\text { R- 5'-AGCTGGATGCTCTCATCAGG-3' }\end{array}$ \\
\hline $\begin{array}{l}\text { Rpl19 } \\
\text { UPL probe \#46 }\end{array}$ & $\begin{array}{l}\text { F- 5'-CCACAAGCTCTTTCCTTTCG-3' } \\
\text { R- 5'-GGATCCAACCAGACCTTCTTT-3' }\end{array}$ \\
\hline $\begin{array}{l}\text { Il6 } \\
\text { UPL probe } \# 28\end{array}$ & $\begin{array}{l}\text { F- 5'-GCTACCAAACTGGATATAATCAGGA-3' } \\
\text { R- 5'-CCAGGTAGCTATGGTACTCCAGAA-3' }\end{array}$ \\
\hline $\begin{array}{l}\text { CVB4 } \\
\text { UPL probe \#41 }\end{array}$ & $\begin{array}{l}\text { F- 5'-CCCGGACCGAGTATCAATAA-3' } \\
\text { R- 5'-CCGGGTAACGAACGGTTT-3' }\end{array}$ \\
\hline $\begin{array}{l}\text { Ifnb } \\
\text { UPL probe \#78 }\end{array}$ & $\begin{array}{l}\text { F- 5'-CACAGCCCTCTCCATCAACTA-3' } \\
\text { R- 5'-CATTTCCGAATGTTCGTCCT-3' }\end{array}$ \\
\hline
\end{tabular}


bioRxiv preprint doi: https://doi.org/10.1101/589507; this version posted March 27, 2019. The copyright holder for this preprint (which was not certified by peer review) is the author/funder, who has granted bioRxiv a license to display the preprint in perpetuity. It is made available under aCC-BY 4.0 International license.

\section{Extended Data Table 4.}

1412 Human primers used for qRT-PCR analysis of genes. Designed using Primer3with sequences 1413 obtained from GenBank and synthesised by Sigma Aldrich (Australia).

\begin{tabular}{|l|l|}
\hline TNFAIP3 & $\begin{array}{l}\text { F- 5'-AACGAACGGTGACGGCAAT-3' } \\
\text { R- 5'-GAAGTCCACTTCGGGCCAT-3' }\end{array}$ \\
\hline TNF & $\begin{array}{l}\text { F- 5'-TCCCCTGGAAAGGACACCAT-3' } \\
\text { R- 5'GGGTTTGCTACAACATGGGCT-3' }\end{array}$ \\
\hline CXCL2 & $\begin{array}{l}\text { F- 5'-AGGGAATTCACCTCAAGAACATCC-3' } \\
\text { R-5'-TGTGGCTATGACTTCGGTTTGG-3' }\end{array}$ \\
\hline RPL13A & $\begin{array}{l}\text { F- 5'-CAAGCGGATGAACACCAAC-3' } \\
\text { R- 5'-TGTGGGGCAGCATACCTC-3' }\end{array}$ \\
\hline ACTB & $\begin{array}{l}\text { F- 5'-CATCGAGCACGGCATCGTCA-3' } \\
\text { R- 5'-TAGCACAGCCTGGATAGCAAC-3'. }\end{array}$ \\
\hline
\end{tabular}

1414 


\section{Extended Data Table 5.}

1416 Data collection and refinement statistics (molecular replacement).

\begin{tabular}{|c|c|c|c|}
\hline & $\begin{array}{c}\text { I325N human } \\
\text { (PDB code } 5 \mathrm{~V} 3 \mathrm{P})\end{array}$ & $\begin{array}{l}\text { WT human } \\
\text { (PDB code } \\
\text { 5V3B) }\end{array}$ & $\begin{array}{l}\text { WT mouse } \\
\text { (PDB code } \\
\text { 5DQ6) }\end{array}$ \\
\hline \multicolumn{4}{|l|}{ Data collection } \\
\hline Space group & $\mathrm{P} 3_{1}$ & $\mathrm{P} 2_{1}$ & $\mathrm{P} 3_{2}$ \\
\hline \multicolumn{4}{|l|}{ Cell dimensions } \\
\hline$a, b, c(\AA)$ & $81.9,81.9,297.3$ & $98.7,80.9,153.4$ & $71.3,71.3,143.2$ \\
\hline$a, b, g\left(^{\circ}\right)$ & $90.0,90.0,120.0$ & $90.0,102.5,90.0$ & $90.0,90.0,120.0$ \\
\hline Resolution $(\AA ̊)$ & $\begin{array}{l}2.5-40.6(2.50- \\
2.55)^{\mathrm{a}}\end{array}$ & $\begin{array}{l}3.0-34.56(3.0- \\
3.10)^{\mathrm{a}}\end{array}$ & $\begin{array}{c}2.80-37.77(2.80- \\
2.93)^{\mathrm{a}}\end{array}$ \\
\hline$R_{\text {pim }}(\text { all I }+\& \mathrm{I}-)^{\mathrm{b}}$ & $0.076(0.471)$ & $0.056(0.687)$ & $0.033(0.398)$ \\
\hline$I / \mathrm{s}(I)$ & $7.8(2.2)$ & $9.9(1.5)$ & $12.0(1.42)$ \\
\hline$C C_{1 / 2}$ & $0.929(0.713)$ & $0.994(0.703)$ & $0.996(0.782)$ \\
\hline Completeness (\%) & $99.7(100.0)$ & $97.7(99.1)$ & $96.07(98.30)$ \\
\hline Redundancy & $4.5(4.6)$ & $5.3(5.6)$ & $4.3(4.3)$ \\
\hline Wilson B $\left(\AA^{2}\right)$ & 47.7 & 79.0 & 90.8 \\
\hline \multicolumn{4}{|l|}{ Refinement } \\
\hline Resolution $(\AA ̊)$ & $2.50-39.47$ & $3.0-34.56$ & $2.8-37.77$ \\
\hline No. reflections & 73040 & 44077 & 19279 \\
\hline$R_{\text {work }} / R_{\text {free }}$ & $0.161 / 0.200$ & $0.238 / 0.282$ & $0.253 / 0.291$ \\
\hline \multicolumn{4}{|l|}{ No. atoms } \\
\hline Protein & 17465 & 14207 & 5511 \\
\hline Water & 21 & - & 26 \\
\hline \multicolumn{4}{|l|}{$B$ factors average } \\
\hline Protein & 55.4 & 77.3 & 122 \\
\hline Water & 23.4 & - & 109 \\
\hline \multicolumn{4}{|l|}{ R.m.s. deviations } \\
\hline Bond lengths $(\AA)$ & 0.0115 & 0.0117 & 0.011 \\
\hline Bond angles $\left({ }^{\circ}\right)$ & 1.54 & 1.53 & 1.43 \\
\hline
\end{tabular}

